\author{
UNIVERstDADE DE SÃO PAULO \\ FFCLRP- DEPARTAMENTO DE BIOLOGIA \\ Programa de Pós-Graduação em Biologia Comparada
}

\title{
Caracterização bioquímica das $\beta$-glucosidases do Scytalidium thermophilum
}

\author{
Fabiana Fonseca Zanoelo
}

Tese de Doutorado apresentada a Faculdade de Filosofia, Ciências e Letras de Ribeirão Preto- USP, como parte das exigências para obtenção do Título de Doutor em Ciências - Área de Concentração: Biologia Comparada.

Ribeirão Preto 2005 


\section{FI CHA CATALOGRÁFI CA}

Preparada pela Biblioteca Central do Campus Administrativo de Ribeirão Preto / USP

\section{Zanoelo, Fabiana Fonseca}

Caracterização Bioquímica das $\beta$-glucosidases do Scytalidium thermophilum. Ribeirão Preto, 2005.

110 p. il.; $30 \mathrm{~cm}$

Tese de Doutorado, apresentada à Faculdade de Filosofia, Ciências e Letras de Ribeirão Preto/USP - Área de concentração: Biologia Comparada.

Orientador: J orge, J oão Atílio.

1. Scytalidium thermophilum glicosidase 4 . termofilia

2. $\beta$-glucosidase 3. $\beta$ - 


\section{UNIVERSIDADE DE SÃO PAULO \\ FFCLRP- DEPARTAMENTO DE BIOLOGIA \\ Programa de Pós-GRaduação EM Biologia Comparada}

\section{Caracterização bioquímica das $\beta$-glucosidases do Scytalidium thermophilum}

\section{Fabiana Fonseca Zanoelo}

Orientador: Prof. Dr. João Atílio Jorge

Tese de Doutorado apresentada a
Faculdade de Filosofia, Ciências e Letras de
Ribeirão Preto- USP, como parte das
exigências para obtenção do Título de
Doutor em Ciências - Área de
Concentração: Biologia Comparada.

Ribeirão Preto 2005 


\section{Agradecimentos}

Ao Prof. João Atílio, meus sinceros agradecimentos pela oportunidade de realização deste trabalho, orientação, tempo dedicado, confiança e especialmente pela amizade.

À prof. Maria de Lourde e ao Prof. Hector Francisco Terenzi, pela ajuda, colaboração e valiosas sugestões.

Aos amigos do laboratório: Karina, Giovana, Flaviana, Vanessa, Fabrício, Alexandre, Carol, Ana Carla, Altino, Luís, Simone, Michele pela amizade e ajuda nos momentos difíceis.

À Renata Secretária da Pós-graduação, por estar sempre disposta a me ajudar.

À Sandra por tornar nossos dias mais "saborosos"

Ao pessoal da Secretaria: Miriam, I sabel e Carlos, pela atenção e

Ao Maurício de Oliveira e Ricardo além do apoio técnico, pela amizade.

A Faculdade de Filosofia, Ciências e Letras de Ribeirão Preto.

À Fundação de Amparo à Pesquisa do Estado de São Paulo (FAPESP), e Capes pelo apoio financeiro.

À todos que de alguma forma contribuíram para que fosse possível a realização desse trabalho. 


\title{
ÍNDICE
}

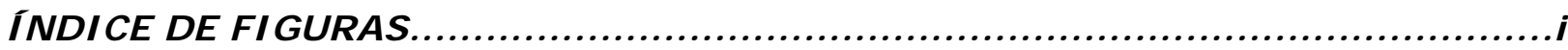

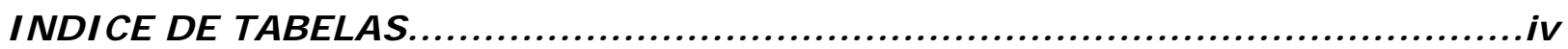

LI STA DE ABREVI ATURAS.......................................................................vi

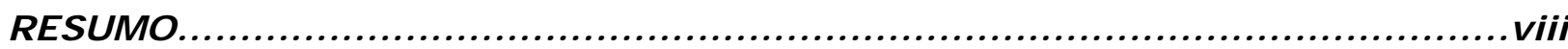

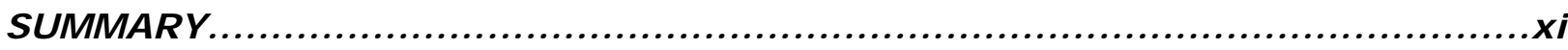

1.I NTRODUÇÃO.........................................................................................

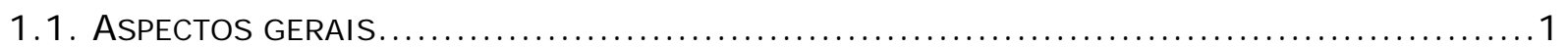

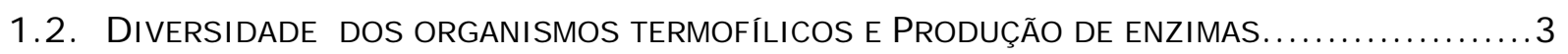

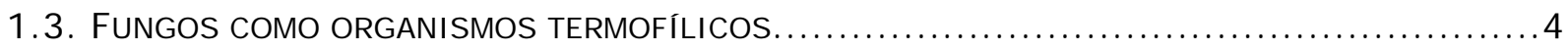

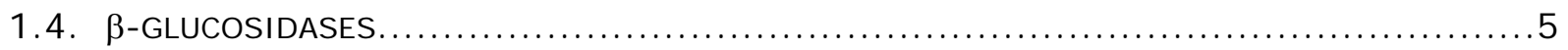

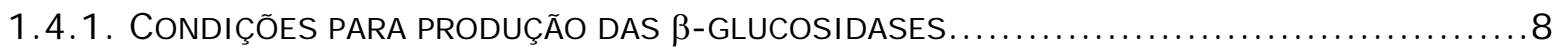

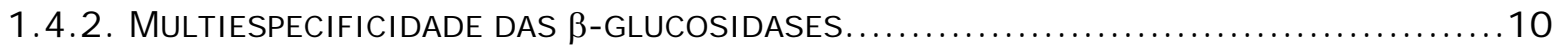

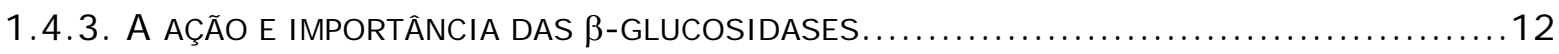

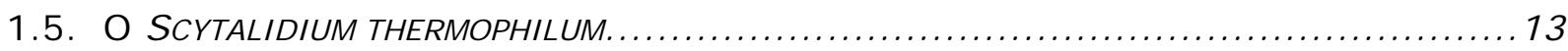

2- OBJ ETI VOS....................................................................................

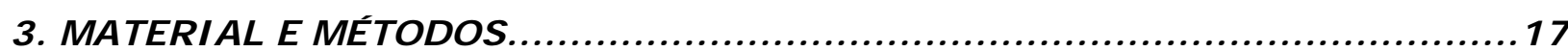

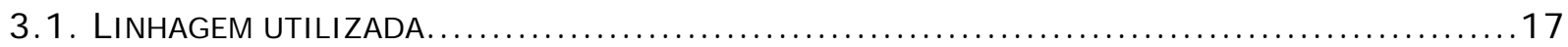

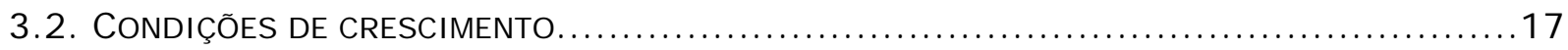

3.2.1. MANUTENÇÃO DA LINHAGEM EM MEIO SÓLIDO.......................................

3.2.2. COMPOSIÇÃO DO MEIO LÍQUIDO......................................... 17

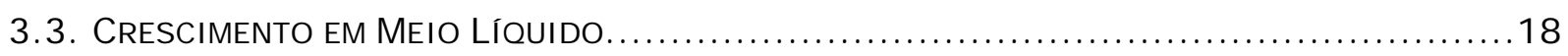

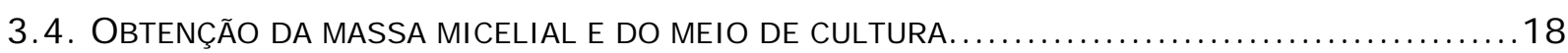

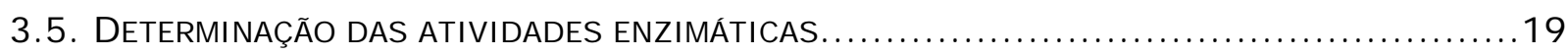

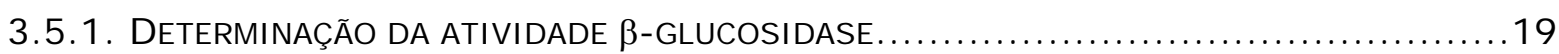

3.5.2. DETERMINAÇÃO DA ATIVIDADE $\beta$-GALACTOSIDASE E $\beta$-XILOSIDASE $\ldots \ldots \ldots \ldots \ldots \ldots \ldots . \ldots \ldots$ 


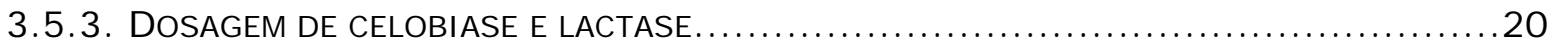

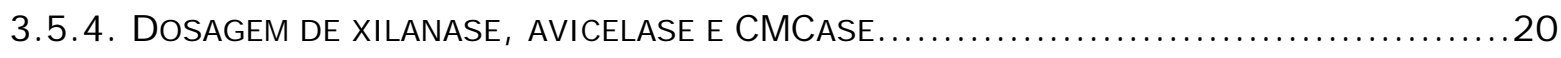

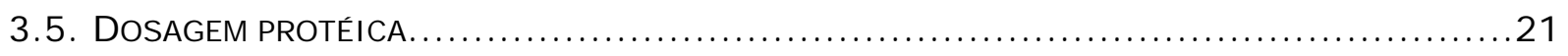

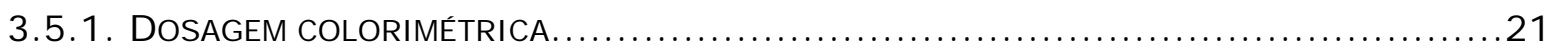

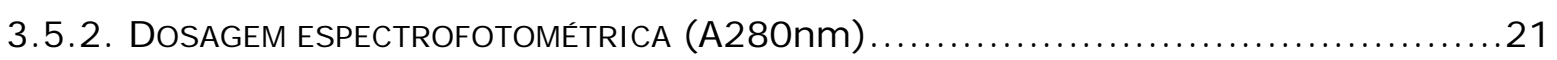

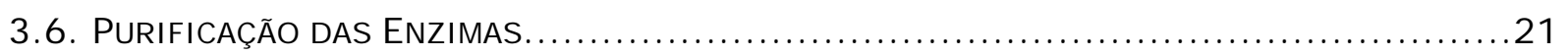

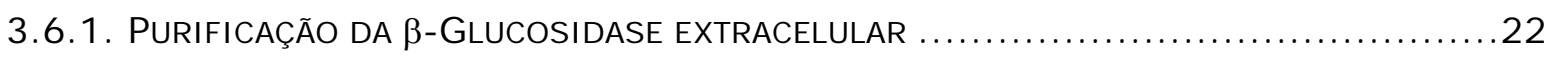

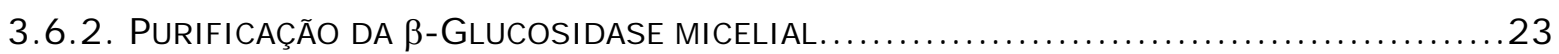

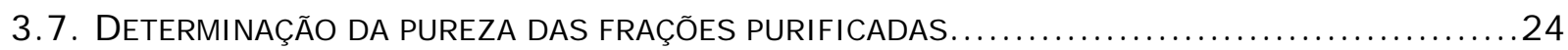

3.7.1. ElETROFORESE EM GEL DE POLIACRILAMIDA EM CONDIÇÕES NÃO-DESNATURANTES

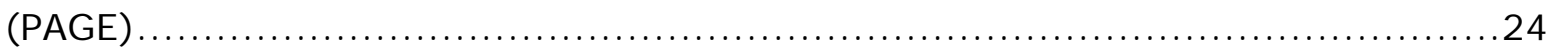

3.7.2. ElETROFORESE EM GEL DE POLIACRILAMIDA EM CONDIÇÕES DESNATURANTES (SDS-

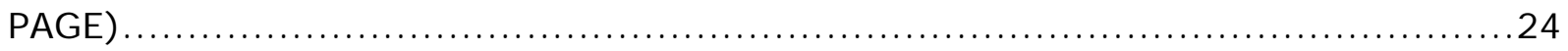

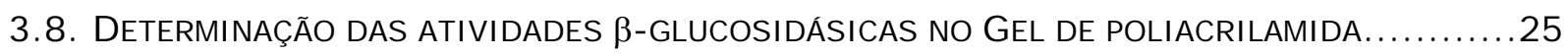

3.8.1. HIDRÓLISE DE SUBSTRATOS PRODUZINDO COMPOSTOS INSOLÚVEIS...................26

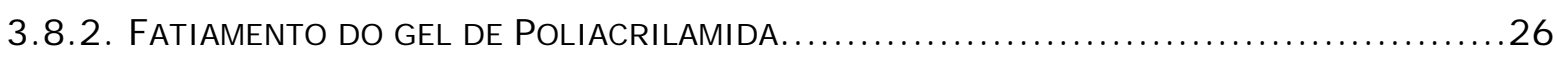

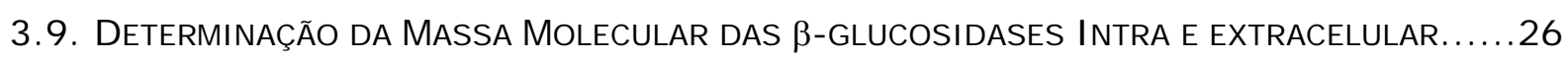

3.10. INFLUÊNCIA DE DIFERENTES COMPOSTOS IÔNICOS SOBRE AS ATIVIDADES $\beta$ -

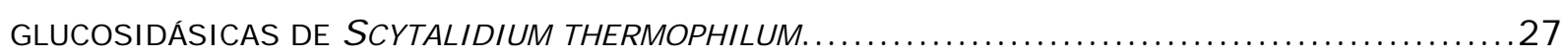

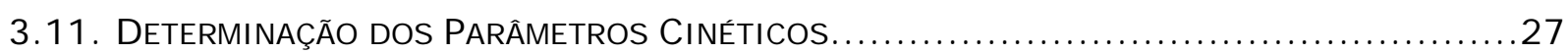

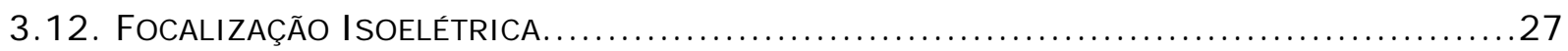

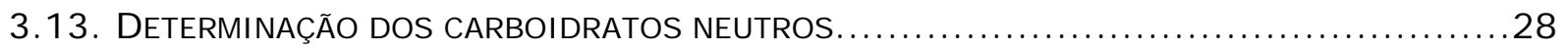

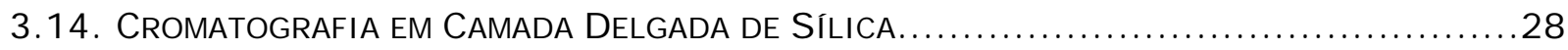

3.15. I MUNOENSAIO CONTRA A $\beta$-GLUCOSIDASE EXTRACELULAR PURIFICADA $\ldots \ldots \ldots \ldots \ldots \ldots \ldots .28$

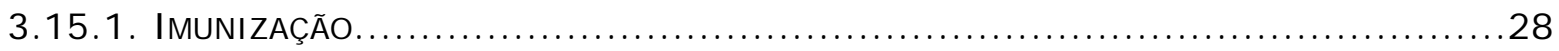

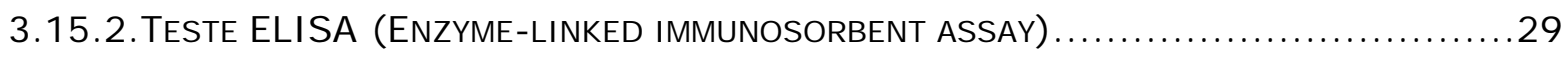

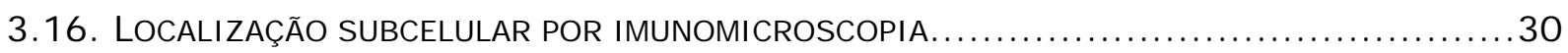

\section{4.-RESULTADOS}

4.1. ESTUdO DAS CONDIÇÕES MAIS FAVORÁVEIS E DETERMINAÇÃO DAS ATIVIDADES $\beta$ -

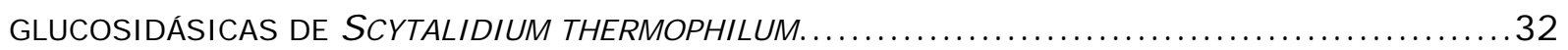

4.1.1. CURVA DE CRESCIMENTO DO SCYTALIDIUM VERSUS PRODUÇÃO DAS $\beta$-GLUCOSIDASES...32 4.1.2. I NFLUÊNCIA DE DIFERENTES FONTES DE CARBONO NA PRODUÇÃO E EXPORTAÇÃO DAS $\beta$ -

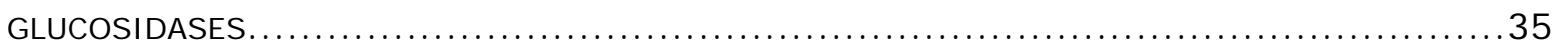

4.1.3. EFEITO REPRESSOR DA GLICOSE NA PRODUÇÃO DAS $\beta$-GLUCOSIDASES DO SCYTALIDIUM THERMOPHILUM. 
4.1.4. EFEITO DA CICLO-HEXIMIDA NA PRODUÇÃO DAS $\beta$-GLUCOSIDASES $\ldots \ldots \ldots \ldots \ldots \ldots \ldots . \ldots 3$

4.1.5. ANÁLISE CROMATOGRÁFICA POR TROCA IÔNI CA DAS $\beta$-GLUCOSIDASES..................45

4.2. LocalizAÇÃO SUBCELULAR DAS $\beta$-GLUCOSIDASES DE SCYTALIDIUM THERMOPHILUM........47

4.3. PuRIFICAÇÃO daS $\beta$-GLUCOSIDASES de SCYTALI DIUM THERMOPHILUM......................49

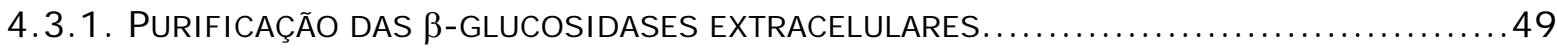

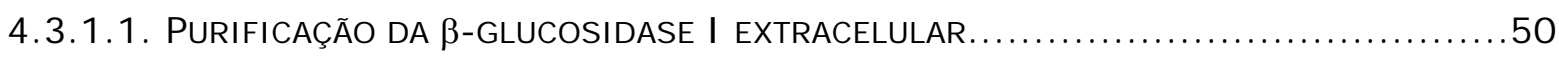

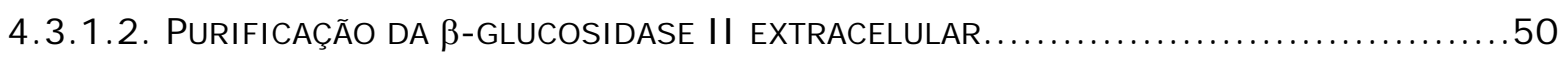

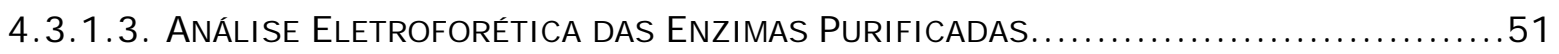

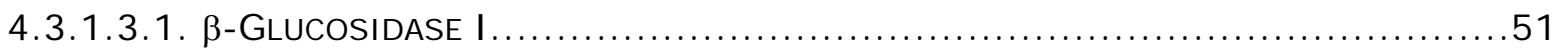

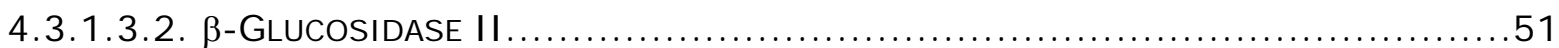

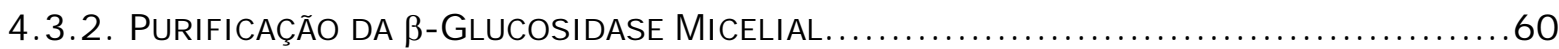

4.3.2.1. ANÁlise ELETROFORÉTICA DA $\beta$-GLUCOSIdASE MICELIAL PURIFICADA...............64

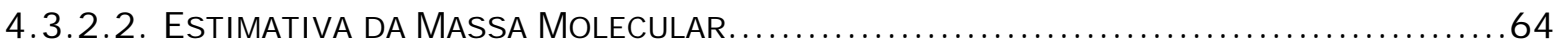

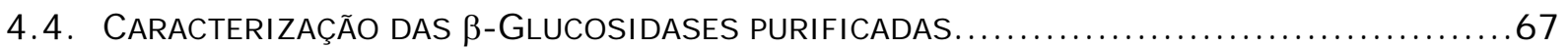

4.4.1. INFLUÊNCIA DA TEMPERATURA E PH NA ATIVIDADE DAS $\beta$-GLUCOSIDASES PURIFICADAS DE

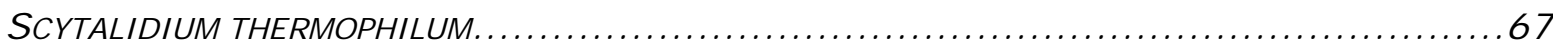

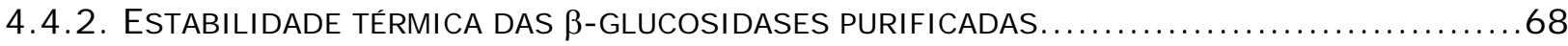

4.4.3. EfEITO DE ÍONS E EDTA SOBRE A ATIVIDADE DAS $\beta$-GLUCOSIDASES PURIFICADAS $\ldots . . .72$

4.4.4. ESPECIFICIDADE AO SUBSTRATO DAS $\beta$-GLUCOSIDASES PURIFICADAS $\ldots \ldots \ldots \ldots \ldots \ldots 72$

4.4.5. EFEITO dE ÁlCOOIS NA ATIVIDADE DAS $\beta$-GLUCOSIDASES PURIFICADAS $\ldots \ldots \ldots \ldots \ldots \ldots . \ldots$

4.4.6. EFEITO DE AÇÚCARES NA ATIVIDADE DAS $\beta$-GLUCOSIDASES PURIFICADAS $\ldots \ldots \ldots \ldots \ldots . \ldots 76$

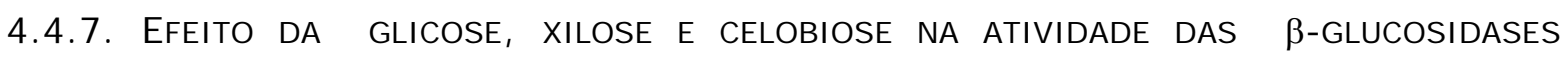

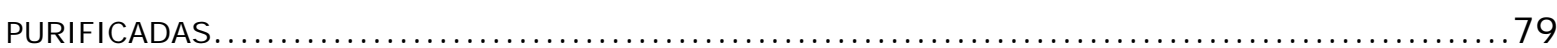

4.4.8. DETERMINAÇÃO DO TEOR DE AÇÚCAR DAS $\beta$-GLUCOSIDASES PURIFICADAS $\ldots \ldots \ldots \ldots \ldots 84$

4.4.9. FoCALIZAÇÃO I SOELÉTRI CA DAS $\beta$-GLUCOSIDASES PURI FICADAS $\ldots \ldots \ldots \ldots \ldots \ldots \ldots . \ldots 4$

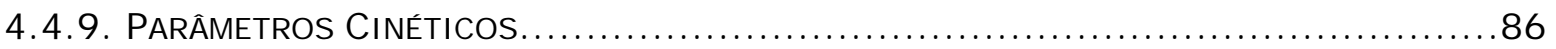

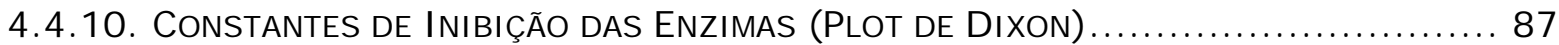

4.4.11. ESTUDO DA $\beta$-GLUCOSIDASE MICELIAL PURIFICADA FRENTE AOS SUBSTRATOS PNP-GLU E

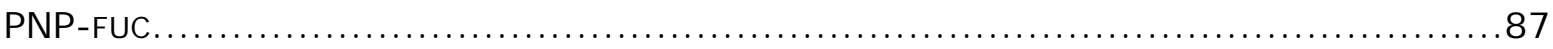

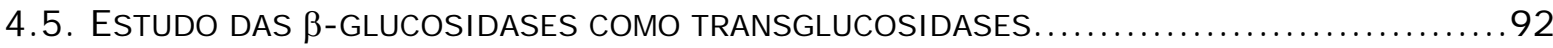

4.5.1. ANÁlISE dOS PROdUTOS DE HIDRÓlISE dAS $\beta$-GLUCOSIDASES PURIFICADAS .............92

5. DISCUSSÃO 98 


\section{ÍNDICE DE FIGURAS}

Sinergismo entre endoglucanases, celobiohidrolases e $\beta$ Figura 1 glucosidases no sistema celulásico de fungos filamentosos.................................................

Figura 2 Fotos em microscopia eletrônica de varredura do Scytalidium thermophilum.

Figura 3 Influência do tempo de crescimento na produção das $\beta$ glucosidases micelial e extracelular

Figura 4 Influência da concentração de avicel e celobiose na produção das $\beta$-glucosidases micelial e extracelular de Scytaldium thermophilum.....................................................

Figura 5 Perfil da eluição das $\beta$-glucosidases de Scytalidium thermophilum em DEAE-celulose.

Figura 6 Perfil cromatográfico da atividade $\beta$-glucosidase extracelular precipitada com $\mathrm{NH}_{2}\left(\mathrm{SO}_{4}\right)_{2}$ e aplicada em coluna de troca iônica DEAE-celulose

Figura 7 Organograma do processo de purificação das $\beta$-glucosidases extracelulares de Scytalidium thermophilum.

Figura 8 Perfil cromatográfico da atividade da $\beta$-glucosidase I (pico I DEAEcelulose) extracelular em coluna de troca iônica CMcelulose.

Figura 9 Perfil cromatográfico da atividade $\beta$-glucosidase II (pico II DEAEcelulose) extracelular de Scytalidium thermophilum em coluna filtração Sephadex G-100 
Figura 10 Perfil eletroforético em gel de poliacrilamida das $\beta$-glucosidases extracelulares produzidas pelo Scytalidium thermophilum.

Figura 11 Perfil eletroforético em SDS-PAGE 15\% das $\beta$-glucosidases extracelulares produzidas pelo Scytalidium thermophilum

Figura 12

Determinação da massa molecular das $\beta$-glucosidase extracelular I e II por cromatografia de filtração Sephadex G-100.

Figura 13 Perfil cromatográfico da atividade $\beta$-glucosidásica micelial precipitada com $\mathrm{NH}_{2}\left(\mathrm{SO}_{4}\right)_{2}$ e aplicada em coluna de filtração Sephadex G-100

Figura 14 Perfil cromatográfico da atividade $\beta$-glucosidásica micelial em coluna de troca iônica DEAEcelulose.....

Figura 15 Perfil eletroforético em gel de poliacrilamida da $\beta$-glucosidase micelial produzida pelo Scytalidium thermophilum

Figura 16 Determinação da massa molecular das $\beta$-glucosidase micelial por cromatografia de filtração Sephadex G-100

Figura 17 Efeito da temperatura nas atividades das $\beta$-glucosidases purificadas de Scytalidium thermophilum

Figura 18 Efeito do $\mathrm{pH}$ nas atividades das $\beta$-glucosidases purificadas de Scytalidium thermophilum.

Figura 19 Estabilidade térmica das $\beta$-glucosidases purificadas de Scytalidium thermophilum.

Figura 20 Efeito da glicose e xilose nas atividades das $\beta$-glucosidases 
purificadas de Scytalidium thermophilum.

Figura 21 Efeito da celobiose nas atividades das $\beta$-glucosidases purificadas de Scytalidium thermophilum.

Figura 22 Efeito da xilose na atividade celobiásica das $\beta$-glucosidases purificadas de Scytalidium thermophilum.

Figura 23 Focalização Isoelétrica das $\beta$-glucosidases purificadas de Scytalidium thermophilum.

Figura 24 Determinação dos parâmetros cinéticos $\left(K_{m}\right.$ e $\left.V_{\text {máx }}\right)$ da $\beta$-glucosidase extracelular I purificada.

Figura 25 Cinética da atividade $\beta$-glucosidásica micelial para os substratos PNP-glu e PNP-fuc

Figura 26 Análise dos produtos de hidrólise e transglicosilação da $\beta$ glucosidase extracelular I purificada em TLC...........

Figura 27 Análise dos produtos de hidrólise e transglicosilação da $\beta$ glucosidase micelial purificada em TLC.

Figura 28 Análise dos produtos de hidrólise e transglicosilação da $\beta$ glucosidase micelial purificada em TLC na presença de PNP-glu e xilose.

Figura 29 Localização subcelular por imunofluorescência do Scytalidium thermophilum. 


\section{Í NDI CE DE TABELAS}

Tabela 1

Influência das diferentes fontes de carbono na produção das $\beta$ glucosidases de Scytaldium thermophilum.

Tabela 2

Influência da glicose associada a diferentes fontes de carbono na produção da $\beta$-glucosidase micelial de Scytalidium thermophilum.

Influência de diferentes fontes de carbono na produção e Tabela 3 exportação da $\beta$-glucosidase micelial de Scytalidium thermophilum pré-crescido em meio $M_{8}$ suplementado com glicose $1 \%$

Efeito da adição de ciclo-heximida aos meios de reincubação na Tabela 4 produção da $\beta$-glucosidase micelial de Scytalidium thermophilum.

Tabela 5 Localização subcelular da $\beta$-glucosidase em células de Scytalidium thermophilum crescidas em glicose como fonte de carbono.

Tabela 6 Localização subcelular da $\beta$-glucosidase em células de Scytalidium thermophilum crescidas em avicel como fonte de

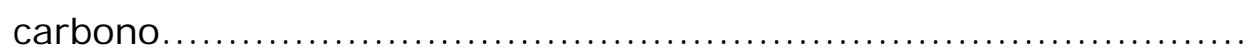

Purificação das $\beta$-glucosidases extracelulares de Scytalidium Tabela 7 thermophilum.

Purificação da $\beta$-glucosidase micelial de Scytalidium Tabela 8 thermophilum.

Efeito de íons metais nas $\beta$-glucosidases purificadas de Scytalidium Tabela 9 thermophilum. 
Tabela 10 Especificidade ao substrato das $\beta$-glucosidases purificadas de

Scytalidium thermophilum................................... 75

Efeito "in vitro" de álcoois nas atividades das $\beta$-glucosidases purificadas de Scytalidium thermophilum........................ 77

Tabela 12 Efeito “in vitro" de açúcares nas atividades das $\beta$-glucosidases purificadas de Scytalidium thermophilum..

Tabela 13 Determinação dos parâmetros cinéticos $\left(K_{m}\right.$ e $\left.V_{\text {máx }}\right)$ da $\beta$ glucosidase extracelular I purificada..................... 90

Tabela $14 \begin{aligned} & \text { Parâmetros cinéticos da } \\ & \text { Scytalidium thermophilum. }\end{aligned}$ 


\section{LISTA DE ABREVI ATURAS}
Abs Absorbância
AE Atividade Específica
CMC Carboximetilcelulose
DEAE Dietilaminoetil
DNS Ácido- 3,5-dinitrosalicílico
EDTA Ácido etilenodiaminotetracético
ELISA Enzyme linked immunosorbent assay
GOD Glicose oxidase
HPLC High Performance Liquid Chromatography
IgG Imunoglobulina $G$
kDa Kilo dalton
Ki Constante de Inibição
$\mathbf{K}_{\mathbf{m}} \quad$ Constante de Michaelis Menten
$\mathbf{K}_{\mathbf{0 , 5}} \quad$ Constante de afinidade aparente
OPD o-fenilenediamino diidroclorito
PAGE Gel de poliacrilmaida
PBS Solução tampão fosfato salina
PMSF Fluoreto de fenil metil sulfônico
PNP p-nitrofenol
q.s.p. Quantidade suficiente para
rpm Rotações por minuto
SDS Dodecil sulfato de sódio
Temed $\mathrm{N}, \mathrm{N}, \mathrm{N}^{\prime}, \mathrm{N}^{\prime}$ - tetrametiletilenodiamina
Tris Tris-(hidroximetil)aminometano
V Volts
$\mathbf{V}_{\text {máx }} \quad$ Velocidade Máxima
$\mathbf{V} / \mathbf{v} \quad$ Volume por volume 
UNI DADES

$\begin{array}{ll}{ }^{\circ} \mathbf{C} & \text { Grau Celcius } \\ \mathbf{c m} & \text { Centímetro } \\ \mathbf{g} & \text { Grama } \\ \mathbf{m A} & \text { Miliampére } \\ \mathbf{m g} & \text { Miligrama } \\ \mathbf{m I} & \text { Mililitro } \\ \mathbf{m i n} & \text { Minuto } \\ \mathbf{m m} & \text { Milímetro } \\ \mathbf{M} & \text { Molar } \\ \mathbf{m} \mathbf{M} & \text { Milomolar } \\ \mathbf{m U} & \text { Miliunidade } \\ \eta \mathbf{m o l e s} & \text { Nanomoles } \\ \eta \mathbf{g r a m a} & \text { Nanograma } \\ \mu \mathbf{g} & \text { Micrograma } \\ \mu \mathbf{m o l e s} & \text { Micromoles } \\ \mu \mathbf{L} & \text { Microlitro } \\ \mathbf{n m} & \text { Nanômetro } \\ \mathbf{U} & \text { Unidade de Atividade enzimática }\end{array}$




\section{RESUMO}

A celulose é a mais abundante fonte de carbono presente na madeira e nos resíduos agrícolas, e a sua hidrólise completa é realizada pela ação sinergística de diferentes enzimas, como: as endo-1,4- $\beta$-D-glucanase, exo-1,4- $\beta$-glucanase e $\beta$-glucosidase ou celobiase. O presente trabalho descreve algumas propriedades fisiológicas e bioquímicas do sistema $\beta$-glucosidásico do fungo termofílico Scytalidium thermophilum. Tal fungo foi isolado originalmente do solo da índia e gentilmente cedido pelo Dr. G. Straastma (Holanda). O meio $M_{8}$ favoreceu a produção das $\beta$-glucosidases. Entre os açúcares testados como fonte de carbono, avicel e celobiose foram os melhores indutores das $\beta$-glucosidases extracelular e micelial. Quando o fungo foi crescido em dois estágios, observou-se inicialmente a repressão da síntese por glicose e a indução por avicel ou celobiose. Utilizando-se ciclo-heximida, observou-se a síntese "de novo" das proteínas. A $\beta$-glucosidase extracelular foi purificada utilizando-se um fracionamento protéico e uma coluna de troca-iônica DEAE-celulose, de onde foram obtidos duas atividades enzimáticas denominadas $\beta$-glucosidases I e II. A $\beta$-glucosidase I foi aplicada em coluna de troca iônica CM-celulose, enquanto que a $\beta$-glucosidase II foi aplicada em Sephadex G-100. A $\beta$-glucosidase I foi purificada 2 vezes com $4.0 \%$ de recuperação, ao passo que a $\beta$-glucosidase II foi purificada 2,4 vezes com $2.0 \%$ de recuperação. A $\beta$-glucosidase micelial foi purificada utilizando-se um choque térmico, fracionamento protéico, coluna de filtração Sephadex G-100 e uma coluna troca-iônica DEAE-celulose. Foi purificada 23 vezes com recuperação de $25 \%$. A $\beta$-glucosidases extracelular I e micelial apresentaram um temperatura ótima aparente de 70 e $60^{\circ} \mathrm{C}$ e um $\mathrm{pH}$ de 5.5 e 6.0 , respectivamente. Ambas enzimas foram inibidas por $\mathrm{Ag}^{+2} \mathrm{e}^{+2}$. A $\beta$-glucosidases extracelular I e micelial possuem um peso molecular de $40.7 \mathrm{kDa}$ e 
39kda (SDS-Page) e 57 kDa e 33,8 kda (Sephadex G-100), respectivamente. A $\beta$ glucosidase extracelular I foi capaz de hidrolisar PNP-glu, PNP-xil, celobiose, xilana e CMC, enquanto que a $\beta$-glucosidase micelial hidrolisou PNP-glu, PNP-fuc, PNP-xil, PNPgal, ONPG e lactose. Ambas enzimas foram ativadas por glicerol a 1M. A $\beta$-glucosidase extracelular I foi ativada por xilose, frutose e lactose, e se mostrou resistente a glicose $50 \mathrm{mM}$, enquanto que a $\beta$-glucosidase micelial foi ativada por glicose e xilose. $\beta$ glucosidases extracelular I e micelial apresentaram um PI de 4.0 e 6.5, respectivamente. Os parâmetros cinéticos estimados para a $\beta$-glucosidase extracelular I foram de $K_{m} 4,33$ e $0,342 \mathrm{mM}$ e $V_{\text {máx }}$ de 5,37 e 2,0 4 moles $/ \mathrm{min} / \mathrm{mg}$ prot. para celobiose e PNP-glu, respectivamente. O valor de Ki (Constante de Inibição) foi de $71 \mathrm{mM}$ para glicose. Para a $\beta$-glucosidase micelial, os valores de $K_{m}$ e $V_{\text {máx }}$ foram de $0,29 m M$ e $13,27 \mu \mathrm{moles} / \mathrm{min} / \mathrm{mg}$ prot; $0,5 \mathrm{mM}$ e $7,25 \mu \mathrm{moles} / \mathrm{min} / \mathrm{mg}$ prot e $1,61 \mathrm{mM}$ e $4,12 \mu \mathrm{moles} / \mathrm{min} / \mathrm{mg}$ prot para os substratos PNP-glu, PNP-fuc e celobiose, respectivamente. Na presença de glicose e xilose os valores de $K_{m}$ e $V_{\text {máx }}$ foram de $1,26 \mathrm{mM}$ e $40,04 \mu \mathrm{moles} / \mathrm{min} / \mathrm{mg} . \mathrm{prot}$, e $1,33 \mathrm{mM}$, e $30,49 \mu \mathrm{moles} / \mathrm{min} / \mathrm{mg}$ prot, respectivamente para o PNP-glu. O valor de Ki (Constante de Inibição) foi de 1,32mM para celobiose. A análise dos produtos de hidrólise das $\beta$-glucosidases extracelular I e micelial foram anlisadas em TLC, e revelaram que ambas enzimas realizam hidrólise quando celobiose foi utilizada a $10 \mathrm{mM}$, e transglicosilação quando celobiose foi utilizada a $250 \mathrm{mM}$. Os resultados aqui apresentados demonstram importante papel importante do Scytalidium como produtor de $\beta$-glucosidase com potencial na sacarificação enzimática da celulose. 


\section{SUMMARY}

Cellulose is the most abundant carbon source found in woods and waste residues. In nature the complete hidrolysis of cellulose occurs by the sinergistic action of several enzymes such endo-1,4- $\beta$-D-glucanase, exo-1,4- $\beta$-glucanase e $\beta$-glucosidase or cellobiase. The present work describe some physiological and biochemical properties of $\beta$-glucosidase system from thermophilic fungus Scytalidium thermophilum. The fungus was gift to Dr. Straastma (Mushroom Experimental Station, The Netherlands). The culture medium $M_{8}$ enhance the production of $\beta$-glucosidase. Among carbohydrates tested as carbon source, avicel and cellobiose were the best inducers of $\beta$-glucosidase extracellular and mycelial. When the fungus was grown in two stages, observed the repression by glucose, and induction by avicel or cellobiose. The presence of cycloheximide inhibited the syntesis of $\beta$-glucosidase, suggesting that the enzyme produced in the presence of indutors required " de novo " synthesis. Extracellular $\beta$-glucosidase was purified using the precipitation with $75 \%$ amonium sulfate, ion exchange cromatography column DEAE-cellulose, and were obtained two activities: $\beta$-glucosidase extracellular I and II. The $\beta$-glucosidase I was applied to a CM-cellulose colunm, while $\beta$-glucosidase II was applied to a Sephadex G-100 colunm. The $\beta$-glucosidase II was purified two times and $4 \%$ yield, and the $\beta$-glucosidase II was purified 2,4 times and $2 \%$ yield. The mycelial $\beta$-glucosidase was purified using the termic treatment, a precipitation with $75 \%$ amonium sulfate followed by Sephadex G-100 and DEAEcellulose. The enzyme was purified 23 time with $23 \%$ yield. The $\beta$-glucosidase extracellular II and mycelial shown optima of temperature and $\mathrm{pH}$ of $60^{\circ} \mathrm{C}$ and $70^{\circ} \mathrm{C}$, 4.4 and 6.0, respectively. $\mathrm{Hg}^{+2}$ and $\mathrm{Ag}^{+2}$ ions were strong inhibitors of $\beta$-glucosidase extracellular I and mycelial. The molecular weight of $\beta$-glucosidase extracellular I and mycelial was stimated as $40.7 \mathrm{KDa}$ and 39KDa (SDS-PAGE) and 57kDa and $33.8 \mathrm{kDa}$ (Sephadex G-100). The $\beta$-glucosidase extracellular I hydrolyzed PNP-glu, PNP-xyl, 
cellobiose,xylan and CMC, while $\beta$-glucosidase mycelial hydrolyzed PNP-fuc, PNP-xyl, PNP-gal, ONPG and lactose. Both enzymes were activeted by glycerol 1M. The $\beta$ glucosidase extracellular I was activeted by xylose, fructose and lactose, and show strong at glucose $50 \mathrm{mM}$. The $\beta$-glucosidase mycelial was activeted by glucose and xylose. $\beta$-glucosidase extracellular I and mycelial shows PI 4.0 and 6.5, respectively. The kinects studies reveled for $\beta$-glucosidase extracellular I a $\mathrm{Km}$ of 4,33 and $0,342 \mathrm{mM}$ and Vmáx of 5,37 and 2,0 $\mu$ moles/min/mg prot for cellobiose and PNP-glu, respectively. The Ki values obtained from Dixon plots was $71 \mathrm{mM}$ for glucose. To $\beta$-glucosidase mycelial the $\mathrm{Km}$ and and Vmáx were $0,29 \mathrm{mM}$ e $13,27 \mu \mathrm{moles} / \mathrm{min} / \mathrm{mg}$ prot; $0,5 \mathrm{mM}$ e $7,25 \mu \mathrm{moles} / \mathrm{min} / \mathrm{mg}$ prot and $1,61 \mathrm{mM}$ and $4,12 \mu \mathrm{moles} / \mathrm{min} / \mathrm{mg}$ prot for PNP-glu, PNPfuc and cellobiose, respectively. Using xylose or glucose the $\mathrm{Km}$ and Vmáx was $1,26 \mathrm{mM}$ e $40,04 \mu \mathrm{moles} / \mathrm{min} / \mathrm{mg} . \mathrm{prot}$, and $1,33 \mathrm{mM}$, e $30,49 \mu \mathrm{moles} / \mathrm{min} / \mathrm{mg}$ prot, respectively for PNP-glu. The Ki values obtained from Dixon plots was $1,32 \mathrm{mM}$ using cellobiose. The products of hydrolisis of cellobiose by the action of purified enzymes glucosidase extracellular I and mycelial were analised in thin-layer-cromatography, and show hydrolisis of cellobiose at $10 \mathrm{mM}$, and transglycosilation reaction when cellobiose was using at $250 \mathrm{mM}$. The intrinsic biochemical and regulatory properties the $\beta$ glucosidase system of Scytalidium support the idea that organism may be useful for biotechnological applications. 


\section{2- OBJETIVOS}

O objetivo deste trabalho está centrado no estudo fisiológico e bioquímico das $\beta$ glucosidases (extracelular e micelial) produzidas pelo fungo termofílico Scytalidium thermophilum, visando demonstrar que a eficiência celulolítica do organismo estaria estritamente relacionada com as propriedades diferenciais destas enzimas. Para isso as enzimas foram purificadas e caracterizadas em suas propriedades físico-químicas e cinéticas. Algumas metas foram seguidas na tentativa de atingirmos o objetivo do trabalho:

1. Estudar a produção das $\beta$-glucosidases pelo Scytalidium thermophilum

2. Purificar e caracterizar cineticamente as maiores frações com atividade $\beta$ glucosidásica

3. Caracterizar as propriedades físico-químicas das enzimas na tentativa de explicar as diferenças bioquímicas por ela exibidas.

4. Verificar nas $\beta$-glucosidases do Scytalidium atividade de transglicosilação, já que essas enzimas são conhecidas por catalisarem além das reações de hidrólise, as reações de transferência.

5. Produção de anticorpos da $\beta$-glucosidase extracelular I

6. Determinação da localização subcelular da $\beta$-glucosidase extracelular I por imunofluorescência 


\subsection{NHAGEM UTI LI ZADA}

Para a realização deste trabalho foi utilizado o Scytalidium thermophilum linhagem 77.7.8, isolado do solo da Índia e gentilmente cedido pelo Dr. G. Straastma do "Mushroom Experimental Station" (Holanda).

\subsection{Condições de CRESCI Mento}

\subsubsection{MANUTENÇÃO da LI NHAGEM EM MEI O SÓli do}

A linhagem foi mantida em laboratório em tubos de ensaio contendo $5 \mathrm{ml}$ de meio sólido, composto por $4 \%$ de farinha de aveia Quaker e 1,8\% de ágar (Peralta et al, 1990). Após a esterilização, os meios de cultura foram solidificados de forma inclinada. Os inóculos foram feitos utilizando uma alça de platina e as culturas mantidas a $40^{\circ} \mathrm{C}$ por 7 dias e posteriormente conservadas em geladeira, sendo utilizadas até 30 dias de estocagem. Os conídios formados foram colhidos por suspensão aquosa, acrescentando-se $10 \mathrm{ml}$ de água destilada estéril em cada tubo estoque, raspando-se a superfície da cultura com a alça de platina. Nessas condições, $1 \mathrm{ml}$ dessa suspensão, contendo aproximadamente $10^{5}$ a $10^{6}$ esporos, foi utilizado para inóculo em meio líquido.

\subsubsection{Composi ÇÃo do MEIO LíQUI do}

O cultivo foi realizado em frascos de Erlenmeyers com capacidade cinco vezes maior que o do volume de meio. O meio utilizado foi o Czapek modificado, denominado de M8, cuja composição está descrita abaixo: 


\begin{tabular}{|c|c|}
\hline 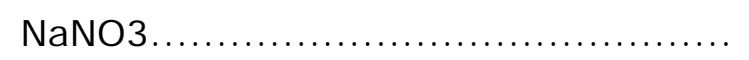 & $0,2 \%$ \\
\hline 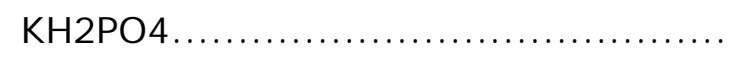 & $0,1 \%$ \\
\hline 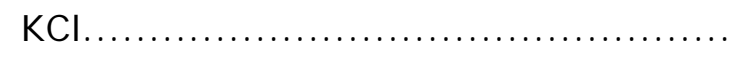 & $0,1 \%$ \\
\hline MgSO4.7H2O............................ & $0,05 \%$ \\
\hline FeSO4.7H2O............................. & $0,01 \%$ \\
\hline ZnSO4.7H2O............................ & $0,03 \%$ \\
\hline Extrato de levedura........................... & $0,8 \%$ \\
\hline
\end{tabular}

\subsection{Crescimento em Meio Lí Quido}

O fungo foi então inoculado no meio de cultivo M8, com agitação constante de 100 rpm com as fontes de carbono desejadas a 1\%, por tempos variados conforme indicado para cada experimento.

O crescimento foi realizado de duas formas distintas: no primeiro o fungo foi crescido em um único estágio, onde os esporos foram adicionados ao meio para obtenção do micélio, ou em um sistema de dois estágios, onde o fungo cresce em condições de repressão por glicose a $1 \%$ e posteriormente os micélios são lavados assepticamente com água bidestilada e transferidos para um novo meio de cultura com a fonte de carbono adequada.

\subsection{Obtenção da massa mi celi al e do meio de cultura}

A massa micelial crescida nas condições descritas anteriormente foi separada do meio de cultivo por filtração à vácuo utilizando funil de Büchener e papel de filtro Whatman $n^{\circ} 1$. Essa massa obtida foi então lavada com 2 volumes de água destilada e prensada entre folhas de papel de filtro para retirar o máximo possível de água embebida. Posteriormente, o micélio foi mantido à baixa temperatura $\left(-12^{\circ} \mathrm{C}\right)$ para 
posterior utilização. Depois de congelado, o micélio foi macerado com 2 volumes de areia lavada no ácido, em um cadinho de porcelana até a ruptura total das células. O macerado foi ressuspenso em determinado volume de água destilada, suficiente para obter-se uma suspensão não muito viscosa. A areia e restos de células foram removidos por centrifugação a $10.000 \mathrm{rpm}$ a $4^{\circ} \mathrm{C}$ por 15 minutos. O sobrenadante dessa centrifugação foi denominado extrato bruto e utilizado como fonte de enzima intracelular. O meio de cultura que continha a enzima extracelular solúvel também foi conservado à baixa temperatura até sua utilização.

\subsection{DETERMI NAÇÃO DAS ATI VI DADES ENZI MÁTI CAS}

\subsubsection{Determi NAÇÃo DA ATI VI DADE $\beta$-GLUCOSI DASE}

A atividade $\beta$-glucosidásica foi detectada através do método descontínuo utilizando-se o substrato sintético p-nitro-fenil- $\beta$-D-glucopiranosídeo. A mistura da reação foi constituída de $0,4 \mathrm{ml}$ do substrato $(2 \mathrm{mg} / \mathrm{ml})$ dissolvido em tampão Mcllvaine (1921) $\mathrm{pH} 5.0$ e $0,1 \mathrm{ml}$ da enzima convenientemente diluída. A mistura foi incubada a $60^{\circ} \mathrm{C}$ por um tempo máximo de 60 minutos e a reação bloqueada pela adição de $1 \mathrm{ml}$ de tetraborato de sódio saturado. Controles sem adição da enzima (brancos) foram incluídos em cada experimento, determinando-se assim a hidrólise espontânea do PNPglu nas condições de ensaio. A concentração do p-nitrofenol liberado foi estimada espectofotometricamente em A410nm. A unidade (U) foi definida como a quantidade de enzima necessária para hidrolisar 1 nanomol do substrato por minuto de reação $(\eta \mathrm{moles} / \mathrm{min} / \mathrm{mL})$, nas condições de ensaio. A atividade específica $(A E)$ foi definida como número de unidades enzimáticas totais por miligrama de proteína total (U/mg proteína). 


\subsubsection{DetermI NAÇÃO DA ATI VI DADE $\beta$-GALACTOSI DASE E $\beta$-XI LOSI DASE}

As atividades $\beta$-galactosidásica e $\beta$-xilosidásica foram estimadas através do uso dos substratos sintéticos PNP-Gal ( $p$-nitrofenil- $\beta$-D-galactopiranosídeo) e PNP-xil ( $p$ nitrofenil- $\beta$-D-xilopiranosídeo), repectivamente. Os substratos foram diluídos em tampão Mcllvaine $\mathrm{pH}$ 5.0. Os demais passos foram idênticos aos descritos no item anterior para a $\beta$-glucosidase.

\subsubsection{Dosagem de Celobi ASE e LACTASE}

A atividade de celobiase e lactase foi quantificada pela glicose liberada durante a hidrólise dos respectivos substratos. A mistura continha $100 \mu \mathrm{l}$ da enzima e $100 \mu \mathrm{l}$ de substrato $100 \mathrm{mM}$ em tampão $\mathrm{Mcllvaine} \mathrm{pH}$ 5.0. A mistura foi incubada a $70^{\circ} \mathrm{C}$ por um período de até 30 minutos e interrompida em banho de água fervente por 3 minutos. A glicose formada foi determinada pelo Método da glicose-oxidase (Bergmeyer \& Bernt, 1974) utilizando o kit Labtest. A leitura foi feita em absorbância 550nm. Uma unidade de enzima foi definida como a quantidade de enzima capaz de liberar 1 micromol de glicose por minuto de reação ( $\mu \mathrm{moles} / \mathrm{min} / \mathrm{mL})$, nas condições de ensaio. A atividade específica $(A E)$ foi definida como número de unidades enzimáticas totais por miligrama de proteína total (U/mg proteína).

\subsubsection{Dosagem de Xi lanase, AVI Celase e CMCASE}

A atividade das enzimas foi medida pela liberação do açúcar redutor, pelo método de ácido 3,5-dinitrosalicílico (DNS) (Miller, 1959).

A mistura da reação foi constituída de $2,5 \mathrm{~mL}$ de solução de xilana, avicel e CMCelulose 10mg/mL em tampão Mcllvaine $\mathrm{pH} 5.0$ e 2,5 mL da enzima, convenientemente diluída. Após a incubação a $60^{\circ} \mathrm{C}$, nos tempos desejados, alíquotas de $1 \mathrm{~mL}$ eram retiradas e adicionadas a $1 \mathrm{~mL}$ de DNS para interromper a reação. A mistura foi aquecida em banho de água fervente, por 5 minutos e diluída em $10 \mathrm{~mL}$ de 
água destilada. A leitura foi feita em absorbância 540nm. A quantidade de açúcar redutor liberado foi estimado através de uma curva padrão. Uma unidade de enzima foi definida como a quantidade de enzima capaz de liberar 1 micromol de glicose por minuto de reação ( $\mu$ moles/min/mL), nas condições de ensaio.

\subsection{DOSAGEM PROTÉI CA}

\subsubsection{DOSAGEM COLORI MÉTRI CA}

As proteínas foram estimadas pelo Método de Lowry (Lowry et al., 1951) utilizando-se soroalbumina bovina como padrão.

\subsubsection{DOSAGEM ESPECTROFOTOMÉTRI CA (A280nm)}

A proteína nos tubos coletados das colunas de cromatografia foi estimada a A280nm utilizando-se o espectrofotômetro Du-7 da Beckman.

\subsection{PuRificaÇão das EnZI MAS}

\subsubsection{PURI FI CAÇÃo da $\beta$-GluCosi dase extracelular}

O fungo foi cultivado em Meio M8 tendo avicel 1\% como fonte de carbono por 96 horas a $40^{\circ} \mathrm{C}$ sob agitação para obtenção da $\beta$-glucosidase extracelular. O filtrado do meio de cultura (aproximadamente $800 \mathrm{ml}$ ) foi dialisado contra água por 24 horas a $4^{\circ} \mathrm{C}$ e em seguida liofilizado. A amostra liofilizada foi dissolvida em água e precipitada com fracionamento protéico de $75 \%$ de sulfato de amônio "overnight". Posteriormente amostra foi centrifugada 20 minutos a $10.000 \mathrm{rpm}$ e o precipitado obtido dialisado contra água e em seguida contra tampão fosfato de sódio monobásico $100 \mathrm{mM}$ pH 6.8 . A fração foi aplicada em coluna de troca iônica DEAE- celulose ( $14 \mathrm{~cm} \times 1.8 \mathrm{~cm})$, préequilibrada com o mesmo tampão e eluída com gradiente de $\mathrm{NaCl}$. Frações de $5 \mathrm{ml}$ 
foram coletadas por tubo, sendo estas submetidas à leitura de proteína a A280nm e a atividade de $\beta$-glucosidase.

Dessa coluna foram obtidas 2 frações de atividade $\beta$-glucosidásica, uma que não é retida na coluna de troca iônica denominada $\beta$-glucosidase I, e outra que é eluída com gradiente de $\mathrm{NaCl}$, denominada $\beta$-glucosidase II.

\subsubsection{Purifi CaÇão da $\beta$-Glucosidase extracelular I (PI co I DEAE-Celulose)}

As frações que não interagiram na DEAE-celulose e que continham alta atividade enzimática foram reunidas, dialisadas novamente contra tampão acetato de sódio $20 \mathrm{mM}$ pH 5.0 e aplicado em coluna de troca iônica CM-celulose ( $14 \times 1.8 \mathrm{~cm}$ ) préequilibrada com o mesmo tampão e eluída com o gradiente de $\mathrm{NaCl}(0-0,5 \mathrm{M})$. $\mathrm{Nas}$ frações obtidas foram dosadas a atividade de $\beta$-glucosidase e acompanhadas com leituras em A280nm, e as frações que continham altas atividades enzimáticas foram reunidas dialisadas contra água e concentradas por liofilização. O material concentrado foi dissolvido em água destilada e conservado em congelador a $-12^{\circ} \mathrm{C}$. A pureza da amostra foi analisada em gel de poliacrilamida (PAGE).

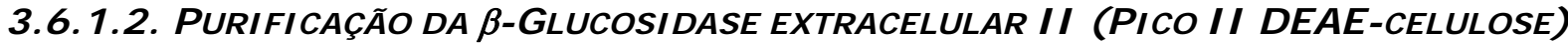

As frações obtidas a partir da eluição com o gradiente de $\mathrm{NaCl}$ da DEAE-celulose foram reunidas, dialisadas contra água, e em seguida liofilizadas. Posteriormente, o material foi dissolvido em $4 \mathrm{ml}$ de tampão fosfato de sódio monobásico $100 \mathrm{mM}$ pH 6.0 mais $100 \mathrm{mM}$ de $\mathrm{NaCl}$ e aplicados em coluna de filtração Sephadex G-100 ( $87 \mathrm{~cm}$ X 2cm ) pré-equilibrada com o mesmo tampão. Foram coletadas frações de 1,5 ml por tubo nas quais foram determinadas atividade de $\beta$-glucosidase acompanhadas de leitura de proteínas a A280nm. As frações que continham alta atividade $\beta$-glucosidásica foram reunidas e concentradas por liofilização. O material concentrado foi dissolvido em água destilada e conservado em congelador $\mathrm{a}-12^{\circ} \mathrm{C}$. 


\subsubsection{PURI FI CAÇÃo dA $\beta$-GLUCOSI dASE I NTRACELULAR.}

O fungo foi cultivado em meio M8, tendo avicel $1 \%$ como fonte de carbono, por 48 horas a $40^{\circ} \mathrm{C}$, com agitação constante para a obtenção da $\beta$-glucosidase intracelular. O micélio foi macerado com areia na presença de PMSF 2mM e centrifugado como já descrito no item 3.4. O sobrenadante obtido foi deixado 20 minutos a $50^{\circ} \mathrm{C}$ e em seguida em banho de gelo (choque térmico) e centrifugado nas mesmas condições descritas anteriormente. O sobrenadante foi precipitado com $75 \%$ de sulfato de amônio "overnight", e novamente centrifugado. O precipitado obtido foi ressuspendido em um pequeno volume de tampão fosfato de sódio monobásico $100 \mathrm{mM}$ pH 6.0 e $100 \mathrm{mM}$ de $\mathrm{NaCl}$ e dialisado contra o mesmo tampão. A amostra foi aplicada em coluna de filtração Sephadex G-100 ( $87 \times 2 \mathrm{~cm}$ ), pré-equilibrada com o mesmo tampão. A eluição foi efetuada com o mesmo tampão, coletando-se $1,5 \mathrm{ml}$ por tubo com um fluxo de $20 \mathrm{~mL} /$ hora. Nas frações obtidas foram dosadas a atividade enzimática, seguidas de leitura a A280nm.

As frações eluídas na Sephadex G-100, como descrito na etapa anterior, com atividade $\beta$-glucosidásica foram reunidas, dialisadas contra tampão fosfato de sódio 100mM pH 6.8 "overnight" a $4^{\circ} \mathrm{C}$, e aplicado em coluna troca iônica DEAE-celulose equilibrada com o mesmo tampão. As proteínas retidas na coluna foram eluídas com um gradiente linear de 0 a $1 \mathrm{M}$ de cloreto de sódio $(\mathrm{NaCl})$. As frações coletadas foram dosadas quanto a atividade $\beta$-glucosidásicas seguidas de leitura a A280 nm. Assim como na $\beta$-glucosidase extracelular obtivemos dois picos de atividade, uma que não adere a resina e outra que é eluída com gradiente de $\mathrm{NaCl}$.

As frações com atividade $\beta$-glucosidásica que foram eluídas com gradiente de $\mathrm{NaCl}(0-0,5 \mathrm{M} \mathrm{NaCl})$ foram reunidas, dialisadas contra água "overnight" a $4^{\circ} \mathrm{C}$ e liofilizadas. O material foi dissolvido em água destilada e conservado em congelador a $12^{\circ} \mathrm{C}$ 


\subsection{DETERMI NAÇÃO DA PUREZA DAS FRAÇõES PURI FI CADAS}

\subsubsection{ELETROFORESE EM GEL DE POLI ACRI LAMI DA EM CONDI ÇÕES NÃO-DESNATURANTES}

(PAGE).

A determinação da pureza das preparações foi feita através de corridas eletroforéticas em géis de poliacrilamida (PAGE).

\subsubsection{PAGE PARA PROTEÍ NAS BÁSICAS}

As eletroforeses em condições não-desnaturantes foram realizadas em gel poliacrilamida conforme metodologia básica de Reisfeld (1962), para proteínas básicas.

O gel numa concentração de $6 \%$ de acrilamida foi polimerizado em placas de vidro $(9,5 \times 8,0 \mathrm{~cm})$. As amostras a serem analisadas eletroforeticamente foram diluídas em tampão de amostra (tampão de corrida diluído 1:10), pH 4,5, verde de metila $0,002 \%$ e glicerol $10 \%$.

As eletroforeses foram realizadas em tampão de corrida, $\mathrm{pH}$ 4,5 (constituído de $3,12 \mathrm{~g}$ de $\beta$-alanina e $0,8 \mathrm{ml}$ de ácido acético glacial em $1000 \mathrm{ml}$ de água destilada) durante 4-5 horas, a temperatura ambiente. A corrente aplicada foi de $70 \mathrm{~mA}$ e uma voltagem constante de $120 \mathrm{~V}$, mantida até o final da corrida eletroforética.

O gel foi corado com Comassie Blue R-250 para coloração de proteínas.

\subsubsection{PAGE PARA PROTEÍ NAS ÁCI DAS}

As eletroforeses não-desnaturantes foram realizadas em gel de poliacrilamida conforme metodologia básica de Davis (1964), para proteínas ácidas.

O gel em uma concentração de $8 \%$ de acrilamida foi polimerizado em tubos $(0,6$ x $8.0 \mathrm{~cm}$ ). As amostras a serem analizadas eletroforeticamente foram diluídas em Tampão de Amostra (Tris-Base 0,065M, Azul de Bromofenol 0,002\%; Glicerol 10\%), pH 6.8. 
As eletroforeses foram realizadas em Tampão de corrida pH 8.9 (constituído de Tris $50 \mathrm{mM}$ e Glicina $36 \mathrm{mM}$ ) durante $4-5$ horas, a temperatura ambiente. A corrente aplicada foi de $5 \mathrm{~mA}$ por tubo mantida até o final da corrida eletroforética.

Os géis foram retirados e a revelação das proteínas foi feita com Comassie Blue R-250 (Sigma).

\subsubsection{ELETROFORESE EM GEL DE POLI ACRI LAMI DA EM CONDIÇÕES DESNATURANTES (SDS- PAGE)}

A fim de se confirmar os dados obtidos através da eletroforese em gel de poliacrilamida em condições não-desnaturantes (PAGE), também foram realizadas eletroforeses em gel de poliacrilamida em condições desnaturantes (SDS-PAGE), segundo metodologia de Laemmli (1970).

Foram utilizados géis em placa $(9,5 \mathrm{~cm} \times 8,0 \mathrm{~cm})$ na concentração de $15 \%$ de acrilamida. As amostras foram diluídas 1:1 em tampão de amostra (glicerol 10\%, SDS $7 \%$, azul de bromofenol 0,002\%, $\beta$-mercaptoetanol $10 \%$ e Trizma $0,12 \mathrm{M} \mathrm{pH} \mathrm{6,75)} \mathrm{e}$ aquecidas durante 5 minutos em água fervente. A eletroforese foi realizada a temperatura ambiente na presença de Tampão Trisma 0,025M, Glicina 0,19M e SDS $0,1 \%, \mathrm{pH} 8,3$. Utilizou-se uma corrente de $70 \mathrm{~mA} / \mathrm{placa}$ e uma voltagem constante de 120V/placa.

Os géis foram retirados da placa e a revelação das proteínas foi feita com Comassie Blue R-250 (Sigma).

\subsection{Determi naÇÃo dAS ATI VI DADES $\beta$-GLUCOSI dÁSI CAS NO GEL DE POLI ACRI LAMI DA}

Os géis de poliacrilamida submetidos a eletroforese foram testados quanto a presença de atividade $\beta$-glucosidase e comparados com géis corados para proteínas com Comassie-Blue por dois métodos: 


\subsubsection{HI DRÓLISE DE SUBSTRATOS PRODUZI NDO COMPOSTOS I NSOLÚVEIS}

Para detecção da atividade da $\beta$-glucosidase II, foi feito um gel de poliacrilamida para proteínas ácidas, como descrito no item 3.7.1.2. Após a corrida, o gel foi lavado com $25 \%$ de ácido isopropílico em tampão Mc. Ilvaine pH 5.0 por 30 minutos e três vezes com o mesmo tampão (20 minutos cada vez).

Após esse tratamento, o gel foi mergulhado numa solução de 6-bromo-naftil- $\beta$ D-glucopiranosídeo em tampão Mcl lvaine (1921) pH 5.0, com 0,07mg/ml de Fast Blue B. Em seguida o gel foi incubado a $50^{\circ} \mathrm{C}$ por aproximadamente 1 hora, até o aparecimento da banda de atividade.

\subsubsection{Fati amento do gel de Poli aCRI lami da}

Para detecção da atividade da $\beta$-glucosidase extracelular II e $\beta$-glucosidase intracelular, foram feitos géis em duplicatas (PAGE). Após a corrida um gel foi corado para proteínas com Comassie Blue e o outro era picotado em fatias de $25 \mathrm{~mm}$, macerados com o auxílio de um bastão de vidro e incubado com o substrato PNP-glu $(2 \mathrm{mg} / \mathrm{mL}$, dissolvido em $\quad$ tampão $\quad$ Mcl lvaine pH 5.5) por uma hora, e a reação bloqueada com $1 \mathrm{ml}$ de tetraborato de sódio saturado. A leitura feita em A410nm.

\subsection{Determi nação da MAsSa Molecular das $\beta$-glucosi dases I nTRA E eXtracelular}

As massas moleculares das $\beta$-glucosidases purificadas foram estimadas através de filtração em gel, utilizando-se uma coluna Sephadex G-100 ( 87 x 2,0cm ), equilibrada com tampão fosfato de sódio monobásico $100 \mathrm{mM}$ pH 6.0 e $\mathrm{NaCl} 100 \mathrm{mM}$. A cromatografia foi desenvolvida com um fluxo de $20 \mathrm{~mL} / \mathrm{h}$, coletando-se 1,5 mL por tubo. Os padrões utilizados foram: álcool desidrogenase (150kDa), soroalbumina (66kDa), anidrase carbônica (29kDa) e citocromo C (12,5kDa). 
As massas moleculares das $\beta$-glucosidases foram estimadas através da construção de um gráfico que continha na ordenada a massa molecular dos padrões, e na abscissa a razão $V e / V_{0}$ (onde $V e=$ volume de eluição da coluna e $V o=" v o i d "$ ). $O$ valor de Ve de cada amostra foi considerado como sendo a somatória dos volumes das frações coletadas desde a aplicação da amostra até a fração onde registrava-se maior leitura em A280nm.

\subsection{I nfluênCIA de Diferentes Compostos Iônicos sobre As Atividades $\beta$ - GLUCOSI DÁSI CAS DE SCYTALI DI UM THERMOPHI LUM.}

As atividades $\beta$-glucosidásicas extra e intracelulares foram ensaiadas na presença e ausência de diferentes compostos iônicos. Foi utilizada concentração de 1 e $5 \mathrm{mM}$ para cada íons testado. Os ensaios foram realizados em condições ótimas de pH e temperatura.

\subsection{Determi nação dos Parâmetros Cinéti cos}

Amostras enzimáticas extra e intracelulares purificadas foram utilizadas para a determinação de parâmetros cinéticos utilizando-se PNP-glu, PNP-fuc e celobiose como substratos. O cálculo das constantes cinéticas foi feito utilizando-se o Programa Computacional Sigraf (Leone et al, 1992).

\subsection{FoCALI ZAÇÃo I SOELÉTRICA}

A determinação do PI foi feita utilizando-se a metodologia básica de O' Farrel et al (1983), utilizando-se anfólitos (Pharmalyte) de pH 3-10. A concentração final do gel foi de $6 \%$ e a focagem a $500 \mathrm{~V}$, durante 5 horas a temperatura ambiente. Após a corrida, o gel foi fragmentado em fatias de $0,5 \mathrm{~cm}$ de espessura, as fatias deixadas por uma noite em solução de $\mathrm{KCl} 25 \mathrm{mM}$. Posteriormente, o $\mathrm{pH}$ foi determinado em 
potenciômetro, construindo-se a curva do gradiente. O gel duplicata contendo a amostra foi corado para proteínas com Comassie Blue R-250.

\subsection{Determi NAÇÃo dos CARBoI dRATOS NEUTROS}

O conteúdo de carboidrato das $\beta$-glucosidases purificadas foi estimada através da metodologia do fenol-sulfúrico de Dubbois et al (1956), utilizando-se glicose como padrão. Alíquotas da enzima pura contendo aproximadamente $20 \mu \mathrm{g}$ de proteína foram diluídas a um volume de $2 \mathrm{ml}$ com água destilada. Em seguida, $50 \mu \mathrm{l}$ de fenol $80 \%$ foi adicionado e logo após $5.0 \mathrm{ml}$ de ácido sulfúrico concentrado. Essa mistura foi deixada em repouso por 10 minutos a temperatura ambiente. Após esse período, foi feita a leitura de absorbância a 490nm. Procedimento idêntico foi conduzido com solução padrão de glicose.

\subsection{Cromatografia em Camada Delgada de Síl li Ca}

O produto de hidrólise da celobiose pela ação das $\beta$-glucosidases purificadas, foi analisado em camada delgada de sílica (TLC) usando a Sílica Gel 60 da Merk. O sistema de solvente utilizado foi butanol: piridina: água (6:4:3) por volume. A revelação foi feita com orcinol 0,2\% em ácido sulfúrico: metanol (1:9) e deixado a $100^{\circ} \mathrm{C}$ por aproximadamente 5 minutos.

\subsection{MUNOENSAI O CONTRA A $\beta$-GLUCOSI DASE EXTRACELULAR PURI FI CADA}

\subsubsection{MUNI ZAÇÃO}

Coelhos New Zealand foram imunizados por aplicações de injeções subcutâneas $(0,7 \mathrm{ml})$ no dorso de cada animal contendo a $\beta$-glucosidase purificada diluída na proporção de 1:1 com os Adjuvantes utilizados ou com salina 0,9\%. A imunização seguiu três etapas: na primeira utilizou-se Adjuvante de Freud Completo. Após 21 dias, 
realizou-se a segunda aplicação com o Adjuvante de Freud Incompleto. Passados 21 dias, a terceira aplicação foi realizada com solução salina $0,9 \%$. Em todas as etapas foram utilizadas aproximadamente $300 \mu \mathrm{g} / \mathrm{ml}$ de proteína. Após 7 dias da última aplicação o sangue foi coletado mediante punção cardíaca, sendo mantida a $4^{\circ} \mathrm{C}$ por 1 hora. O soro foi recolhido sem centrifugação e utilizado para a purificação da fração de IgG.

Primeiramente, $17 \mathrm{ml}$ de soro foi mantido a $56^{\circ} \mathrm{C}$ por 30 minutos. Após esse período o soro foi precipitado por adição de $8,5 \mathrm{ml}$ de uma solução de sulfato de amônio saturado, deixado "overnight" a $4^{\circ} \mathrm{C}$ e centrifugado a $3000 \mathrm{~g}$ por 10 minutos. $\mathrm{O}$ precipitado foi ressuspenso com $8,5 \mathrm{ml}$ de sulfato de amônio $40 \%(p / v)$ e novamente centrifugado nas mesmas condições descritas acima. O precipitado foi então dissolvido em $8,5 \mathrm{ml}$ de salina $0,9 \%(\mathrm{p} / \mathrm{v})$ mais tampão fosfato de sódio $0,02 \mathrm{M}, \mathrm{pH} 7,5$, dialisado por 2 dias contra o mesmo tampão e aplicado em uma coluna de DEAE-celulose, equilibrada e eluída com tampão fosfato e descrito acima, onde a fração IgG não interage com a resina. Foi aplicado, então, um gradiente de contínuo de $\mathrm{NaCl}$ de 0 a $1 \mathrm{M}$ em tampão fosfato, para a retirada de IgM e demais proteínas adsorvidas. A fração contendo IgG foi dialisada contra água, liofilizada, ressuspensa em tampão PBS (composto de $\mathrm{NaCl} 0,8 \%(p / v), \mathrm{KCl} 0,02 \%(p / v), \mathrm{Na} 2 \mathrm{HPO} 40,144 \%(p / v), \mathrm{KH} 2 \mathrm{PO} 4$ $0,024 \%(p / v), p H 7.4)$ mais $0,1 \%(p / v)$ de BSA. Após estes procedimentos a amostra foi filtrada (filtro Nalgene $0,45 \mu \mathrm{m}$ ), e utilizada para a quantificação por teste de ELISA dos anticorpos anti- $\beta$-glucosidase.

\subsubsection{TESTE ELI SA (ENZYME-LI NKED I MMUNOSORBENT ASSAY)}

Inicialmente, a amostra do antígeno foi quantificada pelo método de Lowry (item 3.5.1) e diluída em tampão carbonato/bicarbonato ( $\mathrm{Na} 2 \mathrm{CO} 315 \mathrm{mM}$ e $\mathrm{NaHCO} 335 \mathrm{mM}$ de água Milli-Q), pH 7.4. A placa de poliestireno de Corning de alta afinidade foi sensibilizada com o antígeno diluído (máximo $30 \mathrm{ng} /$ poço) durante uma noite a $4^{\circ} \mathrm{C}$. $\mathrm{A}$ 
placa foi lavada 5 vezes com PBS mais Tween 20 0,05\%, bloqueada com $200 \mu$ l/poço de tampão de bloqueio BSA $1 \%(\mathrm{p} / \mathrm{v})$ em PBS por uma hora a $37^{\circ} \mathrm{C}$, e novamente lavada.

A fração de IgG contendo os anticorpos foi diluída seriamente em log de 10 ou log de 2 em tampão diluente (tampão de bloqueio mais Tween 20 0,05\% distribuída nos poços (100 $\mu \mathrm{l} /$ poço) excluindo-se o branco (poço 1 ) da reação, mantido a $4^{\circ} \mathrm{C}$, "overnight". Após esse período a placa foi novamente lavada, e adicionou-se 100 $\mu \mathrm{l} /$ poço da solução de anticorpos conjugados à peroxidase contra imunoglobulinas de coelhos diluído 1:1000 em tampão diluente por 1 hora, a $37^{\circ} \mathrm{C}$. A placa foi novamente lavada como descrito anteriormente. Em seguida, adicionou-se $100 \mu \mathrm{l} /$ poço da solução de substrato OPD (o-fenilenediamino diidroclorito) composto de $10 \mathrm{mg}$ do substrato para $10 \mathrm{ml}$ de diluente de OPD. A placa foi coberta com papel alumínio e deixada a temperatura ambiente de 5 a 15 minutos. A reação enzimática foi interrompida pela adição de $50 \mu \mathrm{l} /$ poço de solução de ácido sulfúrico $16 \%$ (v/v) e a quantificação dos anticorpos realizada em leitor de ELISA com filtro de $490 \mathrm{~nm}$.

\subsection{LOCALI ZAÇÃO SUBCELULAR POR I MUNOMI CROSCOPIA}

Para determinação da localização subcelular da $\beta$-glucosidase extracelular no micélio de Scytalidium thermophilum, o fungo foi crescido em meio M8 suplementado com avicel $1 \%$ por 72 horas, sob agitação constante a $40^{\circ} \mathrm{C}$. Após esse período, 0 micélio foi lavado com tampão PBS, incluído em "tissue freezing medium 402" e cortados em cristato, obtendo-se secções de $10 \mu \mathrm{m}$ de espessura, as quais foram montadas em lâminas de vidro branco gelatinizadas.

As lâminas contendo os cortes foram então lavados inicialmente em tampão PBS com formaldeído 2\% (v/v) durante 15 minutos, e em seguida com apenas PBS (5'). Posteriormente, as lâminas foram lavadas em PBS e glicina $100 \mathrm{mM}$ para bloqueios dos sítios inespecíficos por 5 minutos, e depois em tampão PBS com BSA 1\% (p/v) para bloqueio das proteínas inespecíficas, por 5 minutos. Posteriormente, foram incubadas 
com o anticorpo primário anti- $\beta$-glucosidase produzido em coelhos New Zealand, diluídos em tampão PBS na proporção 1:1 por uma hora a temperatura ambiente. Após a incubação as lâminas foram lavadas extensivamente com tampão PBS ( 6 vezes de 5 minutos cada), para retirada do excesso dos anticorpos primários e em seguida incubados na presença de anticorpo secundário goat anti-rabbit IgG $(\mathrm{H}+\mathrm{L})$ conjugado com o fluorocromo Alexa 488 por 30 minutos, a temperatura ambiente, em câmara úmida, no escuro. Depois da incubação as lâminas foram novamente lavadas em tampão PBS para a retirada do excesso de anticorpos secundários e montadas em lamínulas com Fluormount G para observação em microscópio de fluorescência. Os controles foram feitos sem a presença do anticorpo primário. 


\section{4- RESULTADOS}

\subsection{PurificaÇÃO dAS $\beta$-GLUCOSIDASES DE SCYTALIDIUM THERMOPHILUM}

Para a possível purificação das enzimas utilizamos o avicel como indutor das $\beta$ glucosidases, já que com esta fonte de carbono obtivemos uma quantidade significativa de atividade $\beta$-glucosidásica. Foi através da cromatografia de troca iônica (DEAEcelulose) que distinguimos pelo menos 2 frações $\beta$-glucosidásicas do Scytalidium, tanto no filtrado como no micélio. Dessa forma inicialmente purificamos as atividades extracelulares, denominadas $\beta$-glucosidases extracelular I e II, e sequencialmente a $\beta$ glucosidase micelial.

\subsubsection{Purificação das $\beta$-glucosidases extracelulares}

Após ter padronizado as condições ótimas de cultivo para produção das $\beta$ glucosidases em meio $M_{8}$ utilizando-se avicel como fonte de carbono, as enzimas foram purificadas até sua homogeneidade eletroforética em gel de poliacrilamida (PAGE). Na Tabela 7 observa-se o resumo dos passos empregados na purificação das $\beta$ glucosidases extracelular.

O processo de purificação foi obtido utilizando-se fracionamento protéico com $75 \%$ de sulfato de amônio, uma coluna de troca iônica DEAE-celulose (Figura 6). Dessa coluna foram obtidos 2 picos de atividades, denominados $\beta$-glucosidase I (que não interagiu com a resina) e $\beta$-glucosidase II (eluída com aproximadamente $280 \mathrm{mM}$ de $\mathrm{NaCl}$ ). É importante ressaltar que quando inicialmente a amostra foi aplicada em DEAEcelulose (Figura 6) foi confirmado a hipótese da existência de duas $\beta$-glucosidases. 0 primeiro pico que não interagiu com a resina corresponde a 44,7\% da atividade recuperada (dados referentes a partir da precipitação com sulfato de amônio) e foi 
denominado $\beta$-glucosidase I. Na segunda fração denominado $\beta$-glucosidase II obteve-se uma recuperação de $38,5 \%$.

Um organograma do processo de purificação das enzimas extracelulares é demonstrado na Figura 7.

\subsubsection{Purificação da $\beta$-glucosidase I extracelular}

O pico I da DEAE-celulose ( $\beta$-glucosidase I) foi aplicada em coluna de troca iônica CM-celulose, e interagiu fracamente com a resina nas condições utilizadas, sendo eluída logo após o "void" da coluna (Figura 8). Nesta etapa a enzima foi purificada 2 vezes com um rendimento de $4 \%$ e uma atividade específica de 736 ๆmoles/mg prot (Tabela 7). Posteriormente a amostra foi dialisada contra água, liofilizada dissolvida em água destilada e estocada em pequenas alíquotas a $-12^{\circ} \mathrm{C}$ até o momento do uso. Armazenada dessa forma a enzima foi estável por mais de 6 meses.

\subsubsection{Purificação da $\beta$-glucosidase II extracelular}

Após a $\beta$-glucosidase II (pico II DEAE-celulose) ter sido eluída com 280mM de $\mathrm{NaCl}$ foi concentrada e purificada até sua homogeneidade utilizando-se uma coluna de filtração Sephadex G-100 (Figura 9). Esta Figura mostra ainda que a enzima foi eluída num pico de atividade logo após o "void" da coluna e distante dos picos majoritários de proteína. Com esse procedimento a amostra foi purificada 2,4 vezes, com uma atividade específica de 830 ๆmoles/mg prot e uma recuperação de aproximadamente 2\%. Assim, como a $\beta$-glucosidase I foi dialisada contra água, liofilizada dissolvida em água destilada e estocada em pequenas alíquotas a $-12^{\circ} \mathrm{C}$ até o momento do uso. Nestas condições a enzima foi estável por mais de 6 meses. 


\subsubsection{Análise Eletroforética das Enzimas Purificadas}

\subsubsection{1. $\beta$-Glucosidase I}

A fração purificada apresentou uma única banda em eletroforese em gel de poliacrilamida 6\% pH 4.3 (Figura 10A) e em condições desnaturantes (Figura 11). A enzima apresentou um peso molecular de $40.7 \mathrm{kDa}$ em SDS-PAGE 15\% e de $57 \mathrm{kDa}$ determinado em coluna de filtração Sephadex G-100 (Figura 12), sugerindo tratar-se de uma proteína monomérica.

A enzima homogênea foi também aplicada em gel de poliacrilamida que, após ser submetido a corrida eletroforética foi cortado em frações de $3 \mathrm{~mm}$. Estas frações foram maceradas em tampão Mc Ilaine pH 6.0 e testadas quanto a capacidade de hidrolisar PNP-glu. Observamos, que o pico de atividade enzimática coincide com a banda corada com Comassie Blue para proteínas (Figura 10 A).

\subsubsection{2. $\beta$-Glucosidase I I}

A enzima apresentou uma única banda em PAGE 8.9 7\% e SDS-PAGE 15\% (Figuras $10 \mathrm{~B}$ e 11) e apresentou um peso molecular de 147 kDa quando determinado em coluna de filtração Sephadex G-100 (Figura 12).

A $\beta$-glucosidase II submetida a eletroforese de poliacrilamida $7 \% \mathrm{pH} 8.9$, foi testada quanto a capacidade de hidrolisar o substrato sintético 6-bromo-naftil- $\beta$ glucopiranosídeo. Esse substrato quando hidrolisado pela enzima produz um composto insolúvel que se deposita no gel de poliacrilamida, possibilitando a visualização e localização da enzima após corrida eletroforética. A hidrólise do 6-bromo-naftil- $\beta$ - 
glucopiranosídeo produziu uma cor avermelhada, e coincide com a banda corada com Comassie Blue para proteínas (Figura 10C).

Tabela 7: Purificação das $\beta$-glucosidases extracelulares de Scytalidium thermophilum.

\begin{tabular}{|c|c|c|c|c|c|}
\hline $\begin{array}{l}\text { Passos de } \\
\text { Purificação }\end{array}$ & $\begin{array}{c}\text { Proteínas } \\
\text { Totais (mg) }\end{array}$ & $\begin{array}{l}\text { Unidades } \\
\text { Totais (U) }\end{array}$ & $\begin{array}{l}\text { Atividade } \\
\text { Específica } \\
\text { (U/mg prot.) }\end{array}$ & $\begin{array}{l}\text { Purificação } \\
\text { (vezes) }\end{array}$ & $\begin{array}{c}\text { Rendimento } \\
(\%)\end{array}$ \\
\hline Bruta liofilizada & 175 & 60200 & 344 & 1 & 100 \\
\hline$\left(\mathrm{NH}_{4}\right)_{2} \mathrm{SO}_{4}(75 \%)$ & 27 & 27936 & 1032 & 3 & 46 \\
\hline $\begin{array}{c}\text { DEAE-celulose } \\
\text { (Pico I) }\end{array}$ & 9 & 12500 & 1388 & 4 & 21 \\
\hline$\beta$-glucosidase I & & & & & \\
\hline $\begin{array}{c}\text { DEAE-celulose } \\
\text { (Pico II) }\end{array}$ & 12 & 10750 & 896 & 3 & 18 \\
\hline$\beta$-glucosidase II & & & & & \\
\hline $\begin{array}{c}\text { CM-celulose } \\
\beta \text {-glucosidase I }\end{array}$ & 3 & 2430 & 736 & 2 & 4.0 \\
\hline $\begin{array}{l}\text { Sephadex G-100 } \\
\beta \text {-glucosidase II }\end{array}$ & 1,28 & 1062 & 830 & 2,4 & 2 \\
\hline
\end{tabular}

Condições: $O$ fungo foi crescido em meio $M_{8}$ com $1 \%$ de avicel por um período de 96 horas a $40^{\circ} \mathrm{C}$ sob agitação constante para obtenção do filtrado extracelular. 


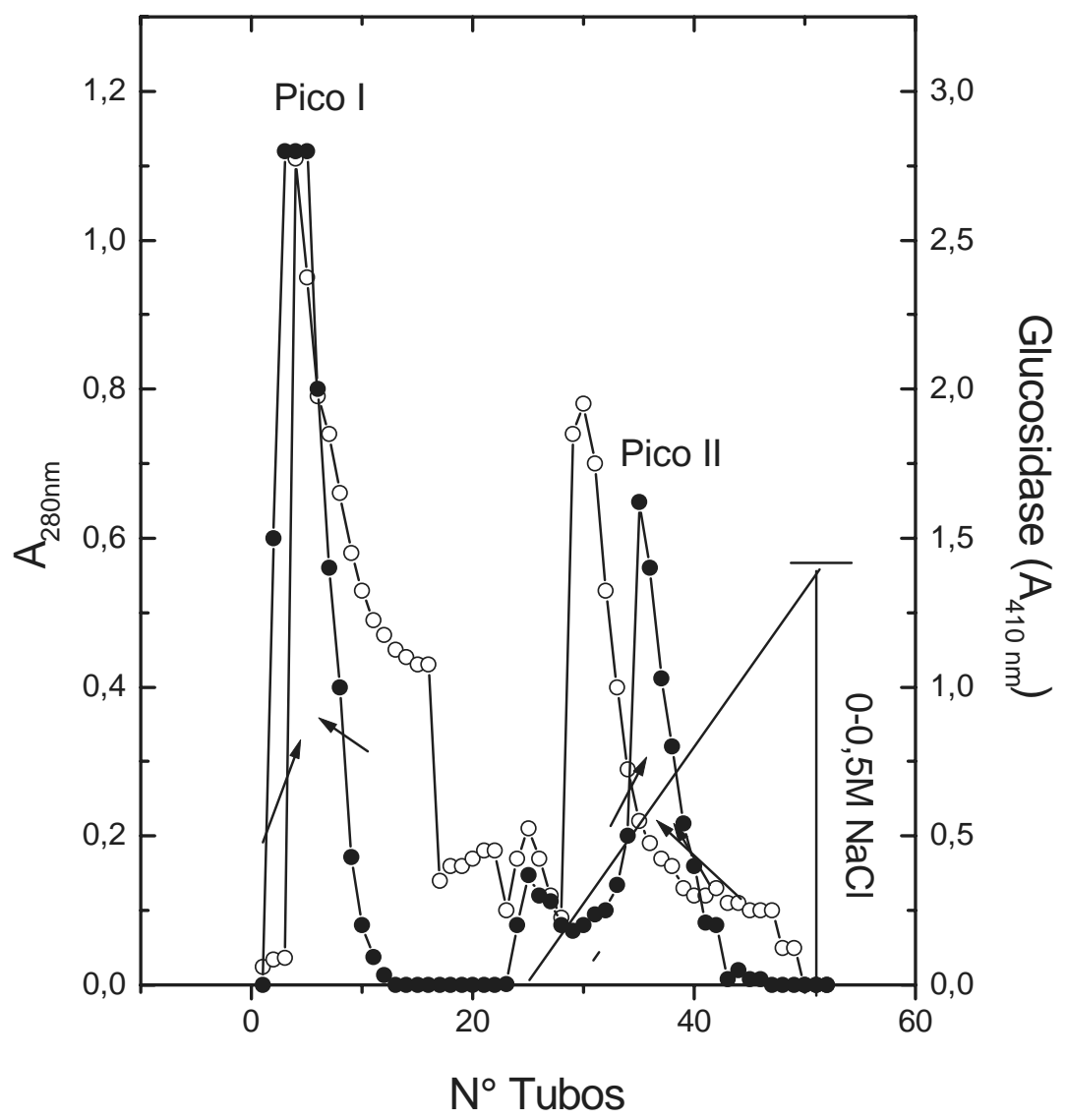

Figura 6: Perfil cromatográfico da atividade $\beta$-glucosidase extracelular precipitada com $\mathrm{NH}_{2}\left(\mathrm{SO}_{4}\right)_{2}$ e aplicada em coluna de troca iônica DEAE-celulose. A coluna ( $14 \times 1,8 \mathrm{~cm}$ ) foi equilibrada com tampão fosfato monobásico de sódio $100 \mathrm{mM}$ pH 6.8 e eluída com gradiente de $\mathrm{NaCl}$. Frações de $5 \mathrm{ml}$ foram coletados por tubo com um fluxo de $60 \mathrm{~mL} / \mathrm{hora}$. As setas indicam os tubos selecionados para a purificação. $A_{280 n m}(0) A_{410 \mathrm{~nm}}(\bullet)$. 
Figura 7: Organograma do processo de Purificação das $\beta$-glucosidases extracelulares de Scytalidium thermophilum.

Filtrado Extracelular (Bruto)
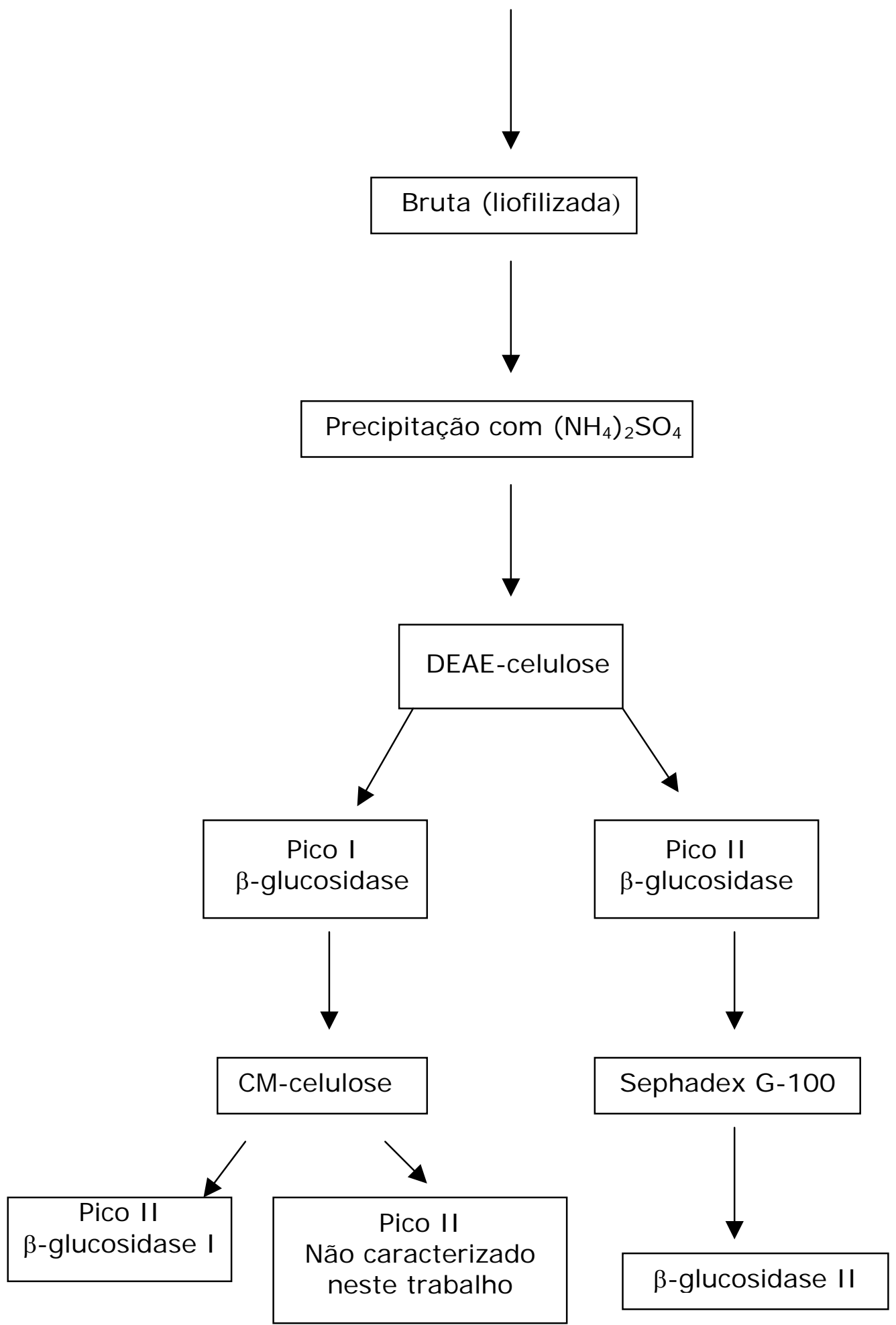


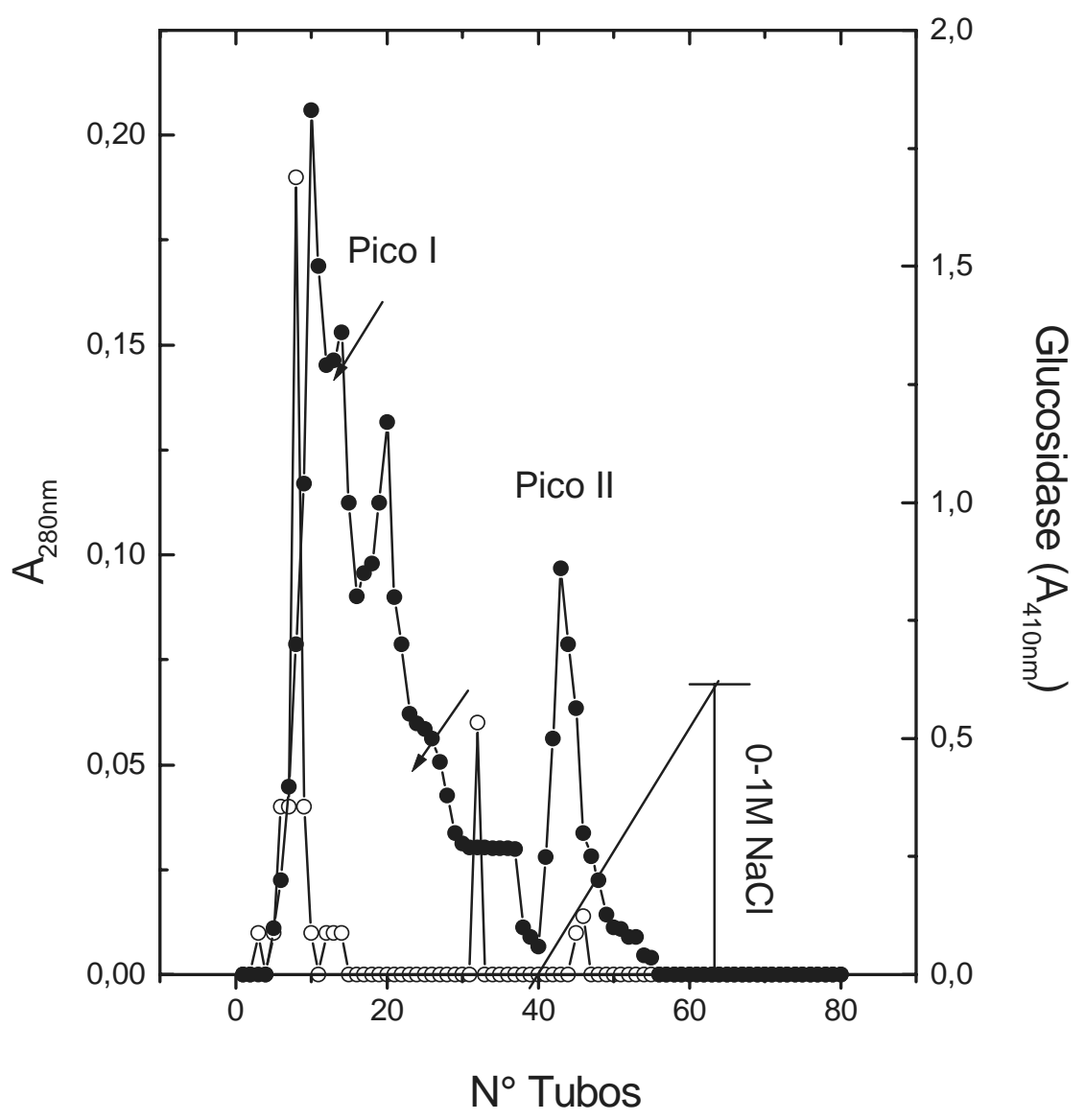

Figura 8: Perfil cromatográfico da atividade $\beta$-glucosidase I (pico I DEAE-celulose) extracelular em coluna de troca iônica CM-celulose. A coluna ( $13 \times 1,5$ cm ) foi equilibrada com tampão acetato de sódio $20 \mathrm{mM}$ pH 5.0 e eluída com o mesmo tampão e gradiente de $\mathrm{NaCl}$. Frações de $5 \mathrm{ml}$ foram coletados por tubo com um fluxo de $50 \mathrm{~mL} /$ hora. $A_{280 n m}(0) A_{410 n m}(\bullet)$. As setas indicam as frações reunidas. 


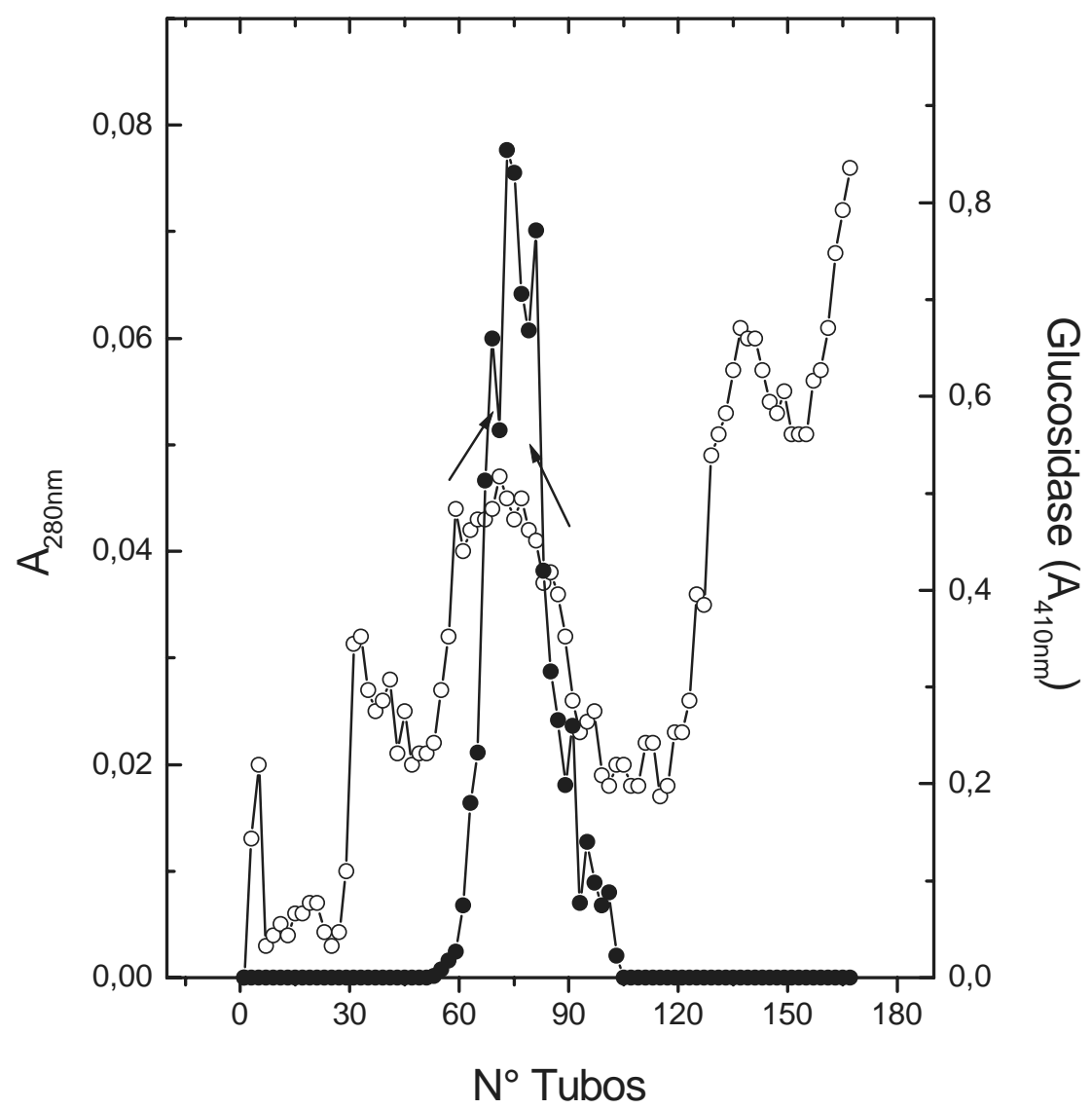

Figura 9: Perfil cromatográfico da atividade $\beta$-glucosidase II (pico II DEAE-celulose) extracelular de Scytalidium thermophilum em coluna Sephadex G-100. A coluna ( $87 \times 2 \mathrm{~cm}$ ) foi equilibrada com tampão fosfato monobásico de sódio 100mM pH 6.0 com $100 \mathrm{mM}$ de $\mathrm{NaCl}$. Frações de 1,5ml foram coletados por tubo com um fluxo de $20 \mathrm{~mL} / \mathrm{h}$. $A_{280 \mathrm{~nm}}$ (o) $A_{410 \mathrm{~nm}}(\bullet)$. As setas indicam as frações reunidas. 


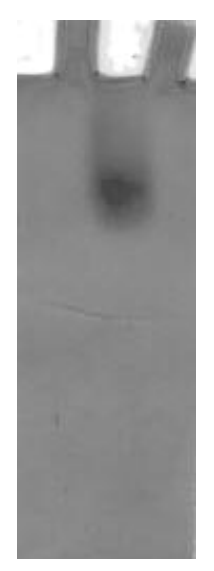

A

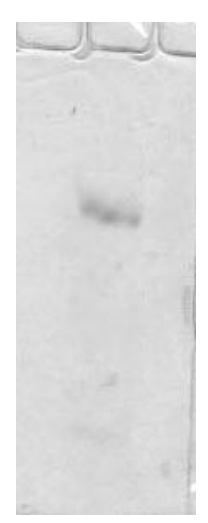

B

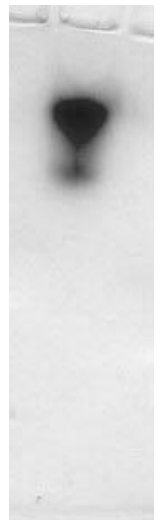

C

Figura 10: Perfil eltroforético em gel de poliacrilamida das $\beta$-glucosidases extracelulares produzidas pelo Scytalidium thermophilum.

(A) PAGE 4.3 - $15 \mu \mathrm{g}$ da glucosidase I; (B) PAGE 8.9- $14 \mu \mathrm{g}$ da glucosidase II, e (C) Atividade da glucosidase II utilizando o substrato sintético 6bromo-naftil-glucopiranosídeo. Os géis A e B foram corados para proteínas com Comassie Brilhant Blue R-250. 


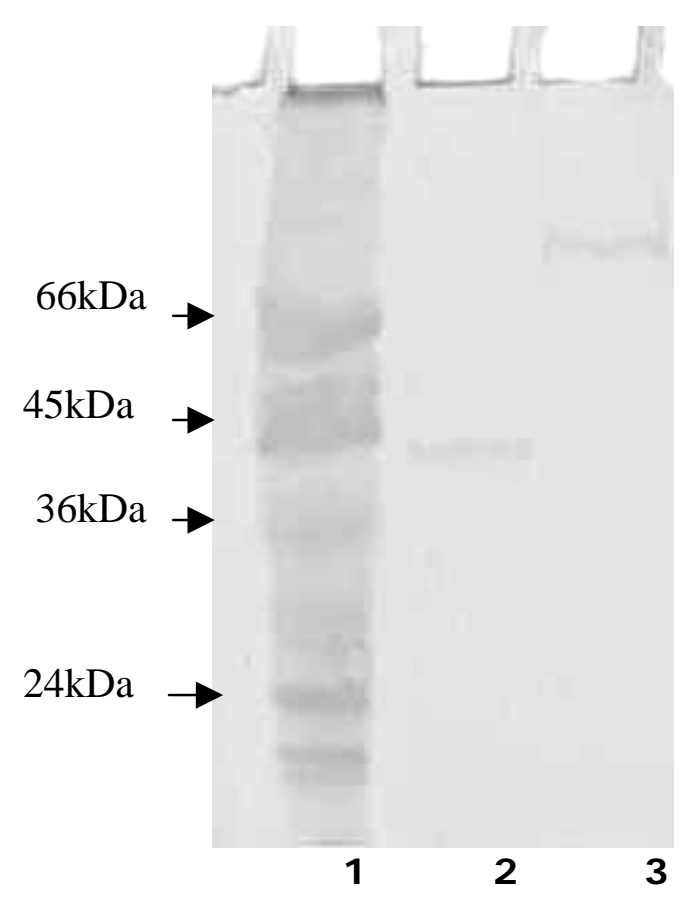

Figura 11: Perfil eletroforético em SDS-PAGE $15 \%$ da $\beta$-glucosidases extracelulares produzidas pelo Scytalidium thermophilum.

Raia 1: Padrão ; Raia 2: Glucosidase I e Raia 3: Glucosidase II 


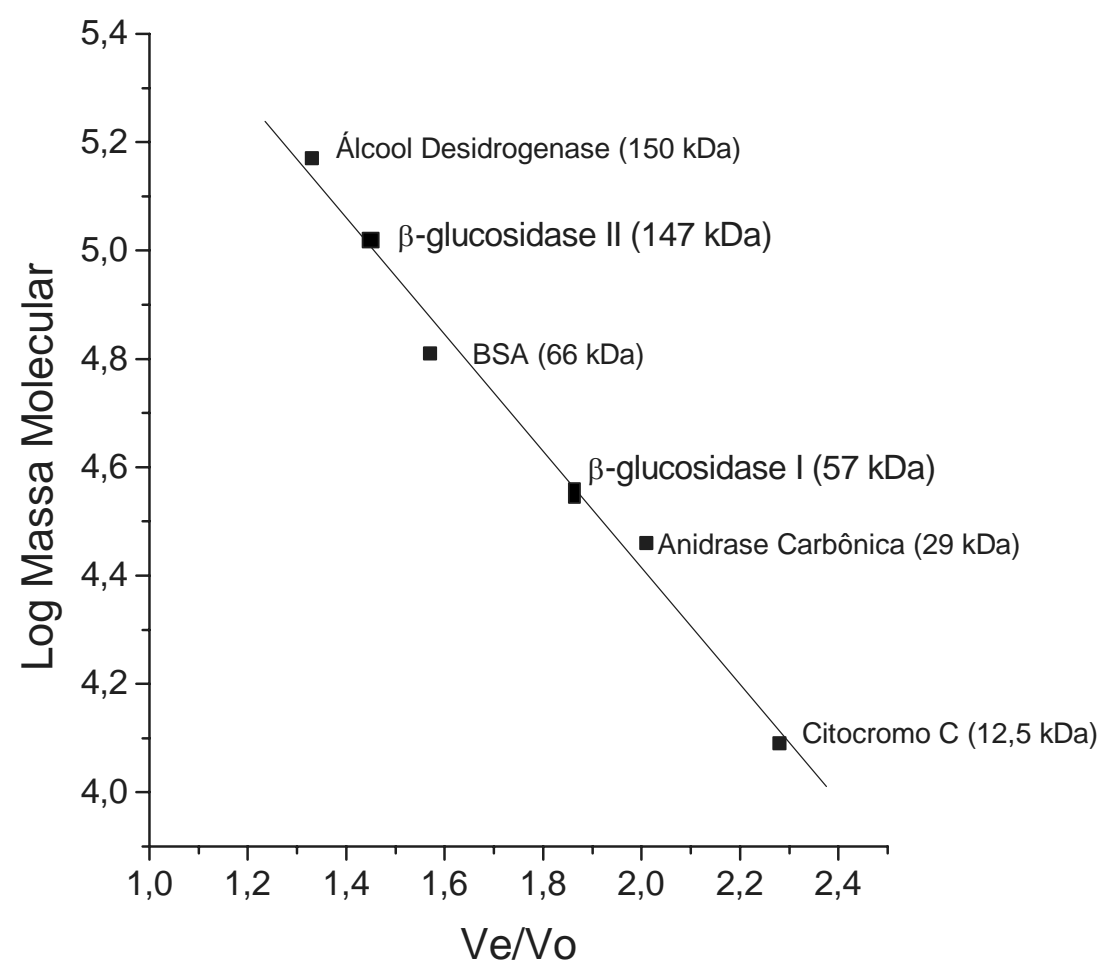

Figura 12: Determinação da massa molecular da $\beta$-glucosidase I e II por cromatografia de filtração Sephadex G-100. A coluna ( $87 \times 2 \mathrm{~cm})$ foi eluída com tampão fosfato monobásico de sódio $100 \mathrm{mM}$ pH $6.8 \mathrm{com} 100 \mathrm{mM}$ de $\mathrm{NaCl}$ com um fluxo de $20 \mathrm{~mL} / \mathrm{h}$ coletando-se $1,5 \mathrm{ml}$ por tubo. 


\subsubsection{Purificação da $\beta$-Glucosidase Micelial}

Pode-se observar na Tabela 8 a seqüência da operação empregada na purificação da enzima. Obteve-se um rendimento de 25,3\% e uma purificação de 23 vezes e uma atividade específica de 9000ๆmoles/mg prot., após a última coluna cromatográfica. É importante ressaltar a eficiência do fracionamento protéico no processo de purificação enzimática, visto que há uma considerável diminuição do número de proteínas totais do extrato micelial.

A Figura 13 representa o perfil cromatográfico da $\beta$-glucosidase micelial em Sephadex G-100, após fracionamento protéico e diálise. Nesta figura pode-se observar que a enzima foi eluída num pico único de atividade e distante do picos maiores de proteína. As frações contendo maiores atividades enzimáticas foram então reunidas, dialisadas e aplicadas em coluna de troca iônica DEAE-celulose (Figura 14). Após a eluição da amostra, com aproximadamente $230 \mathrm{mM}$ de $\mathrm{NaCl}$ pode-se confirmar a hipótese da existência de duas $\beta$-glucosidases. A primeira atividade glucosidásica que não interage com a resina, representa aproximadamente $15 \%$ da atividade total, e não foi caracterizada devido seu baixo rendimento.

As frações eluídas com $\mathrm{NaCl}$, indicadas pelas setas na Figura 14 foram então reunidas, dialisadas contra água e utilizada para análise de pureza em gel de poliacrilamida (PAGE). Posteriormente foram estocadas em pequenas alíquotas a $-12^{\circ} \mathrm{C}$ sendo utilizadas para caracterização físico-química. 
Tabela 8: Purificação da $\beta$-glucosidase micelial de Scytalidium thermophilum.

\begin{tabular}{|c|c|c|c|c|c|}
\hline $\begin{array}{l}\text { Passos de } \\
\text { Purificação }\end{array}$ & $\begin{array}{c}\text { Proteínas } \\
\text { Totais (mg) }\end{array}$ & $\begin{array}{l}\text { Unidades } \\
\text { Totais (U) }\end{array}$ & $\begin{array}{l}\text { Atividade } \\
\text { Específica } \\
\text { (U/mg prot.) }\end{array}$ & $\begin{array}{c}\text { Purificação } \\
\text { (vezes) }\end{array}$ & $\begin{array}{c}\text { Rendimento } \\
(\%)\end{array}$ \\
\hline Bruta & 398,4 & 156500 & 392,8 & 1,0 & 100,0 \\
\hline $\begin{array}{l}\text { Choque Térmico } \\
\left(20^{\prime} \text { a } 50^{\circ} \mathrm{C}\right)\end{array}$ & 271,6 & 145700 & 536,5 & 1,4 & 93,0 \\
\hline$\left(\mathrm{NH}_{4}\right)_{2} \mathrm{SO}_{4} 75 \%$ & 72,6 & 50600 & 697 & 1,8 & 32,3 \\
\hline Sepahdex G-100 & 10,6 & 51500 & 4858 & 12,4 & 33,0 \\
\hline DEAE-celulose & 4,4 & 39600 & 9000 & 23,1 & 25,3 \\
\hline
\end{tabular}

Condições: $O$ fungo foi crescido em Meio $M_{8}$ com $1 \%$ de Avicel por um período de 48 horas a $40^{\circ} \mathrm{C}$ sob agitação constante para obtenção da massa micelial. 


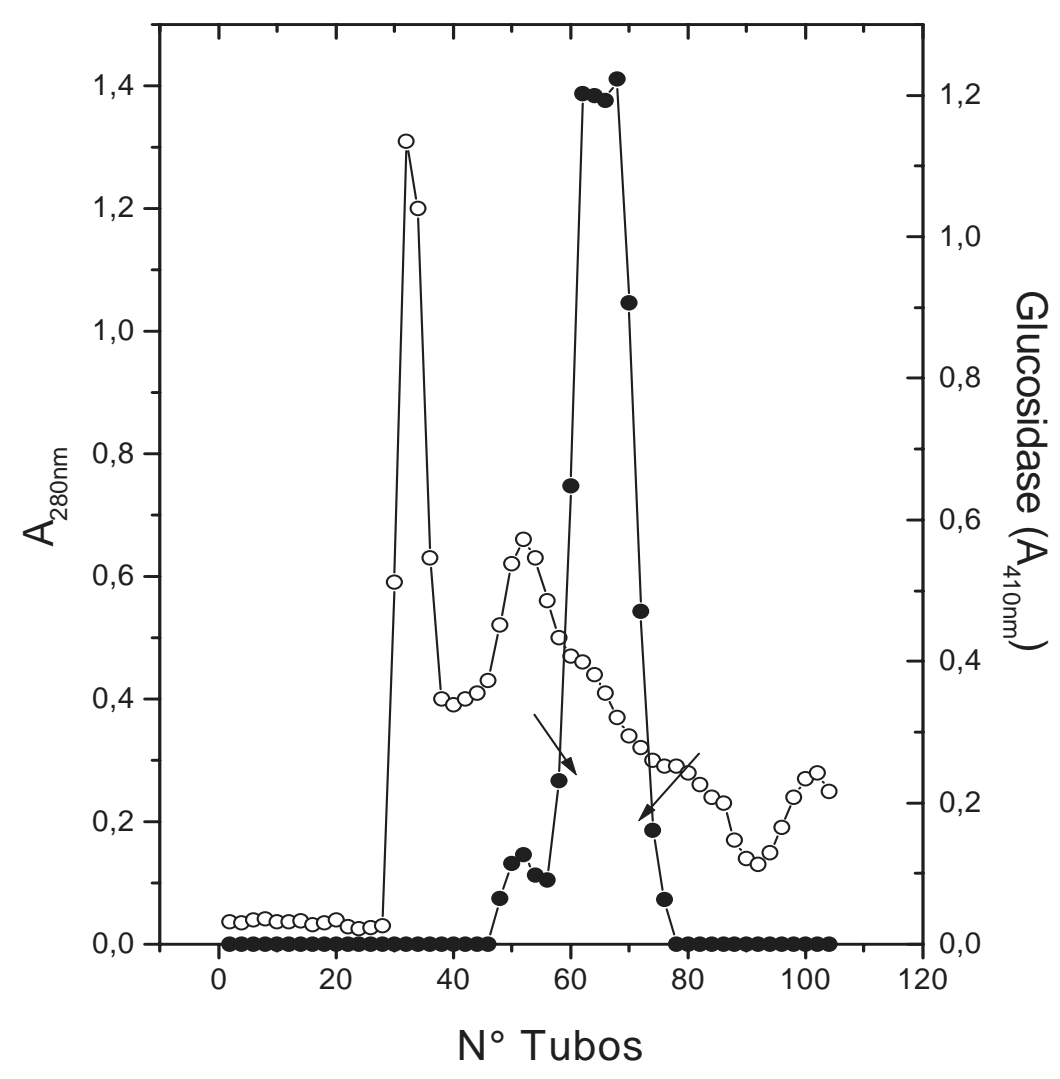

Figura 13: Perfil cromatográfico da atividade $\beta$-glucosidásica micelial precipitada com $\mathrm{NH}_{2}\left(\mathrm{SO}_{4}\right)_{2}$ e aplicada em coluna de filtração Sephadex G-100. A coluna ( $87 \times 2 \mathrm{~cm}$ ) foi equilibrada com tampão fosfato monobásico de sódio $100 \mathrm{mM}$ pH 6.0 com $100 \mathrm{mM}$ de $\mathrm{NaCl}$, com fluxo de $20 \mathrm{~mL} /$ hora. Frações de $1.5 \mathrm{~mL}$ foram coletadas por tubo. $\mathrm{A}_{280 \mathrm{~nm}}(\mathrm{o}) \mathrm{A}_{410 \mathrm{~nm}}(\bullet)$. As setas indicam as frações reunidas. 


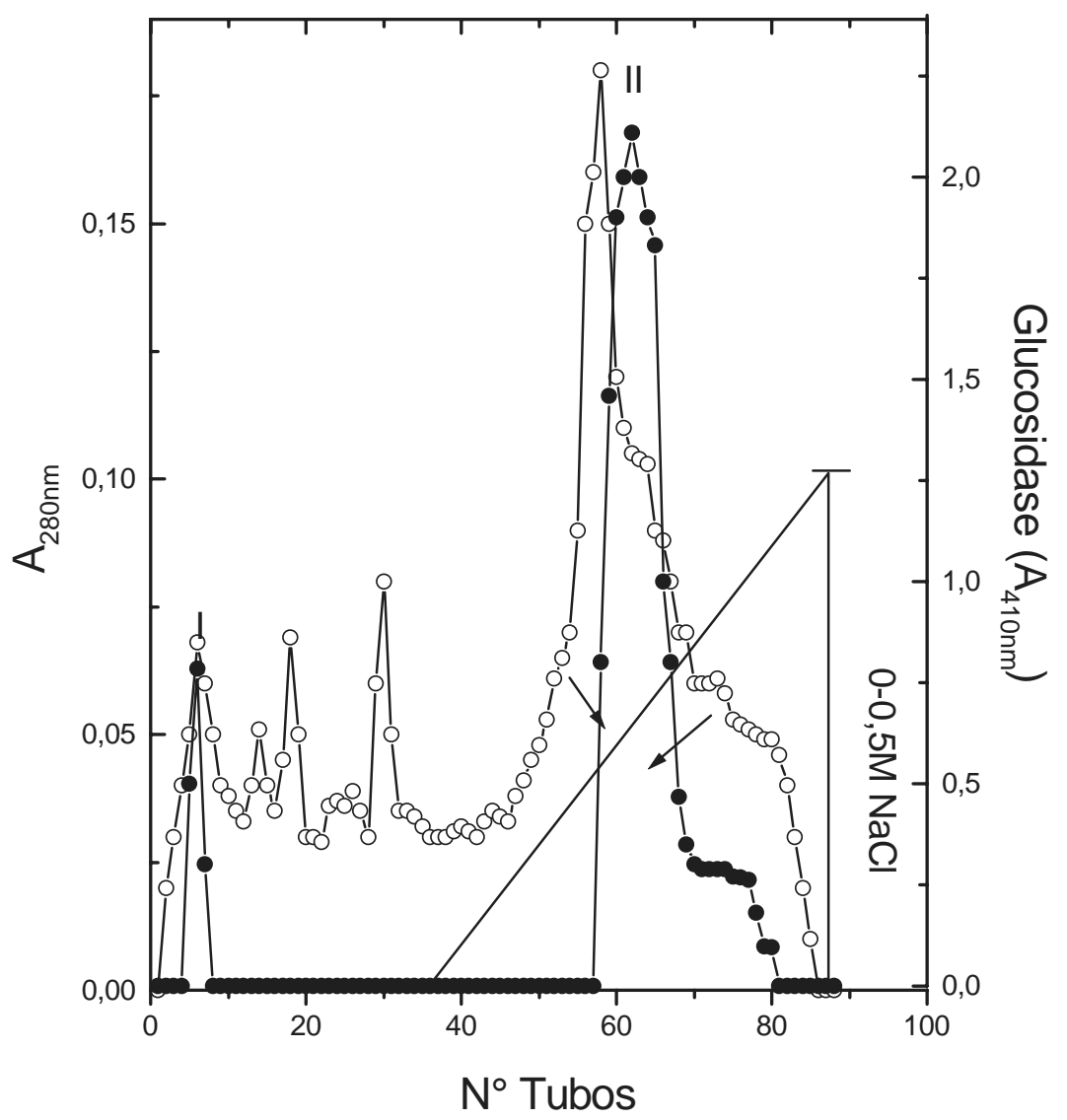

Figura 14: Perfil cromatográfico da atividade $\beta$-glucosidásica micelial em coluna de troca iônica DEAE-celulose. A coluna $(13 \times 2 \mathrm{~cm}$ ) foi equilibrada com tampão fosfato de sódio pH 6.8 100mM e eluída com o mesmo tampão e gradiente de $\mathrm{NaCl}$. Frações de $5 \mathrm{~mL}$ foram coletados por tubo. $\mathrm{A}_{280 \mathrm{~nm}}$ ( o ) $\mathrm{A}_{410 \mathrm{~nm}}(\bullet)$. As setas indicam as frações reunidas. 


\subsubsection{Análise eletroforética da $\beta$-Glucosidase Micelial purificada}

O primeiro critério de pureza empregado foi a análise eletroforética da $\beta$ glucosidase em gel de poliacrilamida em condições não-desnaturantes (PAGE 8.9). Conforme observado na Figura 15A, a enzima purificada apresenta uma única banda protéica após o gel ter sido corado para proteínas utilizando-se o corante Comassie Blue R-250. A atividade enzimática no gel foi evidenciada após o gel ter sido picotado em fatias de $25 \mathrm{~mm}$, incubado com o substrato PNP-glu por 1 noite a $50^{\circ} \mathrm{C}$ e, posteriormente a reação bloqueada com tetraborato de sódio saturado, e a leitura feita em $A_{410 n m}$. A banda protéica obtida coincide com a banda de atividade (resultados não mostrados).

A análise de pureza também foi evidenciada em condições desnaturantes (SDSPAGE) em gel de poliacrilamida (Figura 15B). A enzima exibiu uma única banda em SDS-PAGE quando corada por Comassie Blue R-250 e apresentou um peso molecular estimado de 39kDa. Os dados obtidos em eletroforeses desnaturantes e nãodesnaturantes indicam a homogeneidade da enzima, que a partir daí pode ser caracterizada nas suas propriedades físico-química.

\subsubsection{Estimativa da Massa Molecular}

Para estimativa da massa molecular da $\beta$-glucosidase foi empregado uma coluna de filtração Sephadex G-100 e análise em gel de poliacrilamida SDS-PAGE (como já demonstrado no item anterior). Através da Figura 16 e 15B estimou-se a massa molecular nativa da enzima em 33,8 kDa em coluna de filtração e 39 kDa em SDSPAGE, respectivamente. 


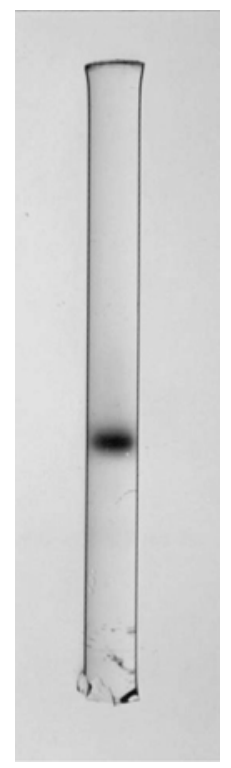

\section{6kDi $66 \mathrm{kDa}$ \\ $45 \mathrm{kDa} \quad 45 \mathrm{kDa}$ \\ $29 \mathrm{kDa} \quad 29 \mathrm{kDa}$}

Figura 15: Perfil eletroforética em gel de poliacrilamida da $\beta$-glucosidase micelial produzida por Scytalidium thermophilum. (A) PAGE $8.98 \%-13 \mu g ;$; (B) SDS-PAGE 15\%: Raia 1: Padrão de Peso Molecular; Raia 2: $8 \mu \mathrm{g} \beta$ glucosidase micelial. 


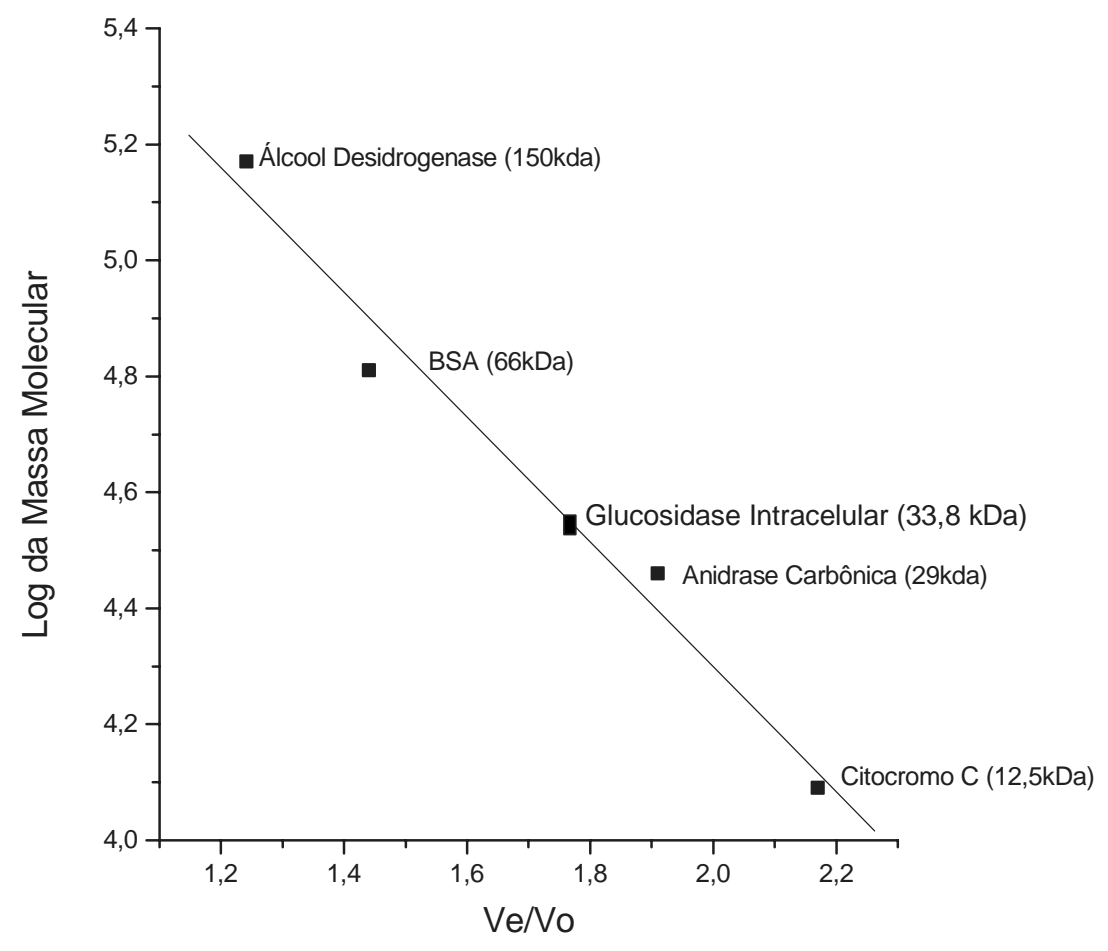

Figura 16: Determinação da massa molecular da $\beta$-glucosidase micelial por cromatografia de filtração Sephadex G-100. A coluna ( $87 \times 2 \mathrm{~cm}$ ) foi eluída com tampão fosfato de sódio monobásico $100 \mathrm{mM} \mathrm{pH} 6.0 \mathrm{com} \mathrm{NaCl}$ $100 \mathrm{mM}$ com um fluxo de $20 \mathrm{~mL} / \mathrm{h}$ coletando-se $1,5 \mathrm{~mL}$ por tubo. 


\subsubsection{Influência da temperatura e pH na atividade das $\beta$-glucosidases purificadas de Scytalidium thermophilum}

Temperatura

Para a determinação da temperatura ótima, as $\beta$-glucosidases foram incubadas com o substrato PNP-glu em diferentes temperaturas, variando-se de 35 a $80^{\circ} \mathrm{C}$ (extracelular) e 40 a $70^{\circ} \mathrm{C}$ (micelial). Como demonstrado na Figura 17, foi obtido uma temperatura de 70 e $60^{\circ} \mathrm{C}$ para as enzimas extra I e micelial, respectivamente, para hidrólise do PNP-glu. Em temperaturas abaixo da ótima aparente $\left(60^{\circ} \mathrm{C}\right.$ e $\left.50^{\circ} \mathrm{C}\right)$ observa-se que as enzimas apresentam cerca de $75-80 \%$ das suas atividades enzimáticas. Em temperaturas superiores a temperaturas ótimas das enzimas, observamos um rápido decréscimo das atividades $\beta$-glucosidásicas.

$\mathrm{pH}$

Como descrito em material e métodos a atividade das $\beta$-glucosidases purificadas foi medida utilizando-se tampão Mcllvaine $\mathrm{pH} 3.0$ a 8.0. A atividade ótima da $\beta$ glucosidase extracelular I foi obtida em pH 5.5 embora a enzima tenha se mostrado relativamente estável entre os pHs 5.5-6.5 (Figura 18A) com aproximadamente 90\% da atividade enzimática. Já a atividade micelial mostrou maior eficiência na faixa de pH de 6.0-6.5, como demonstrado na Figura 18B. 


\subsubsection{Estabilidade térmica das $\beta$-glucosidases purificadas}

Enzimas que toleram altas temperaturas são de grande interesse, já que possuem vantagens em processos industriais, evitando possíveis contaminações bacterianas, além de serem facilmente armazenadas e manuseadas.

Para se determinar a estabilidade térmica das enzimas purificadas frente a diferentes temperaturas, as amostras foram incubadas em água destilada por até 1 hora a diferentes temperaturas na ausência dos substratos. Em intervalos prédeterminados alíquotas foram retiradas e ensaiadas em condições ótimas de temperatura e $\mathrm{pH}$.

Pode-se notar na $\beta$-glucosidase extracelular I (Figura 19A) que após 15 minutos a $70^{\circ} \mathrm{C}$, a enzima perdeu cerca de $32 \%$ da atividade e após 60 minutos apenas $6 \%$ da atividade enzimática estava presente.

Como demonstrado na Figura $19 \mathrm{~B}$, observa-se a $50^{\circ} \mathrm{C}$ que nos 10 primeiros minutos a $\beta$-glucosidase micelial perde cerca de $28-30 \%$ da atividade enzimática e depois, sua atividade é mantida até 60 minutos, pelo menos. Contudo, a enzima quando incubada na presença de tampão aumenta a sua estabilidade em aproximadamente $40 \%$. 

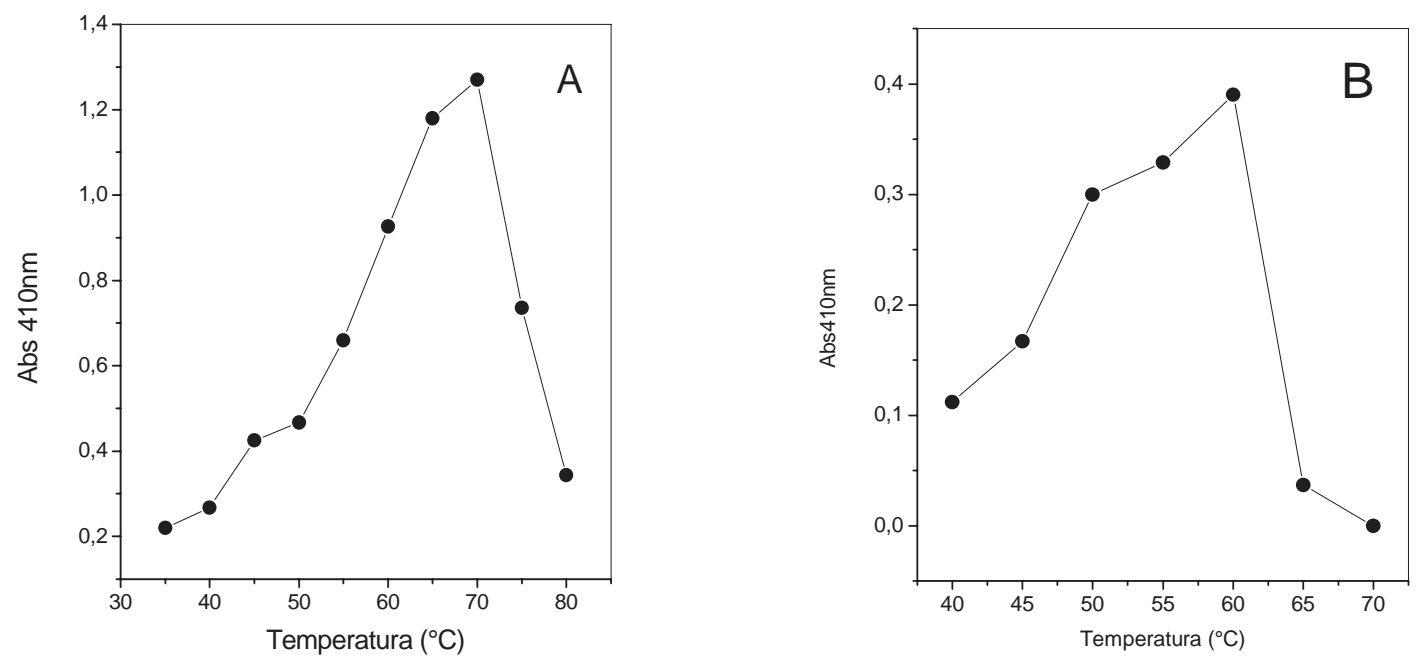

Figura 17: Efeito da temperatura nas atividades das $\beta$-glucosidase purificadas de Scytalidium thermophilum. (A) $\beta$-glucosidase extracelular I (B) $\beta$ glucosidase micelial. As enzimas foram convenientemente diluídas e incubadas em diferentes temperaturas $\left(35\right.$ a $80^{\circ} \mathrm{C}$ para $\mathrm{A}$ e 35 a $70^{\circ} \mathrm{C}$ para B). As atividades foram determinadas em ensaios com até 10 minutos de incubação. 

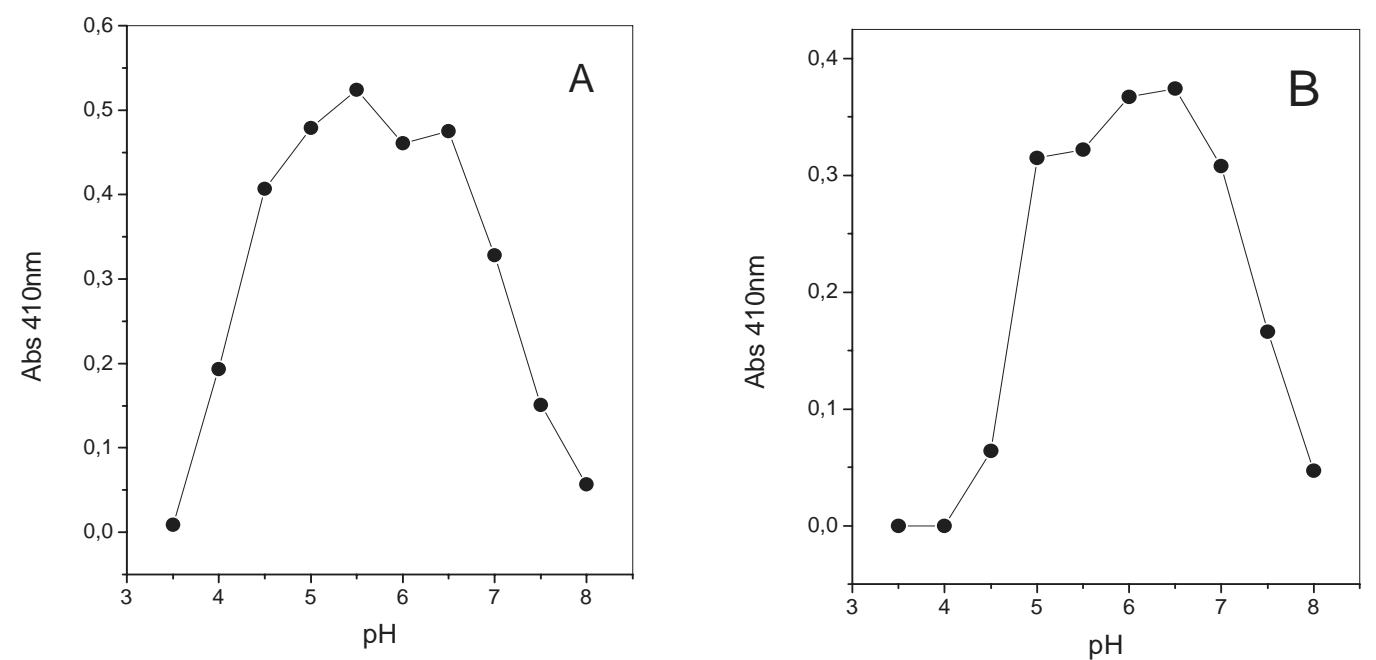

Figura 18: Efeito do $\mathrm{pH}$ nas atividades das $\beta$-glucosidase purificadas de Scytalidium thermophilum. (A) $\beta$-glucosidase extracelular I (B) $\beta$-glucosidase micelial. As enzimas foram convenientemente diluídas em tampão Mcl lvaine (1921) em $\mathrm{pH}$ de 3.0 a 8.0 a $50^{\circ} \mathrm{C}$, e as atividades determinadas em ensaios com 10 minutos de incubação. 

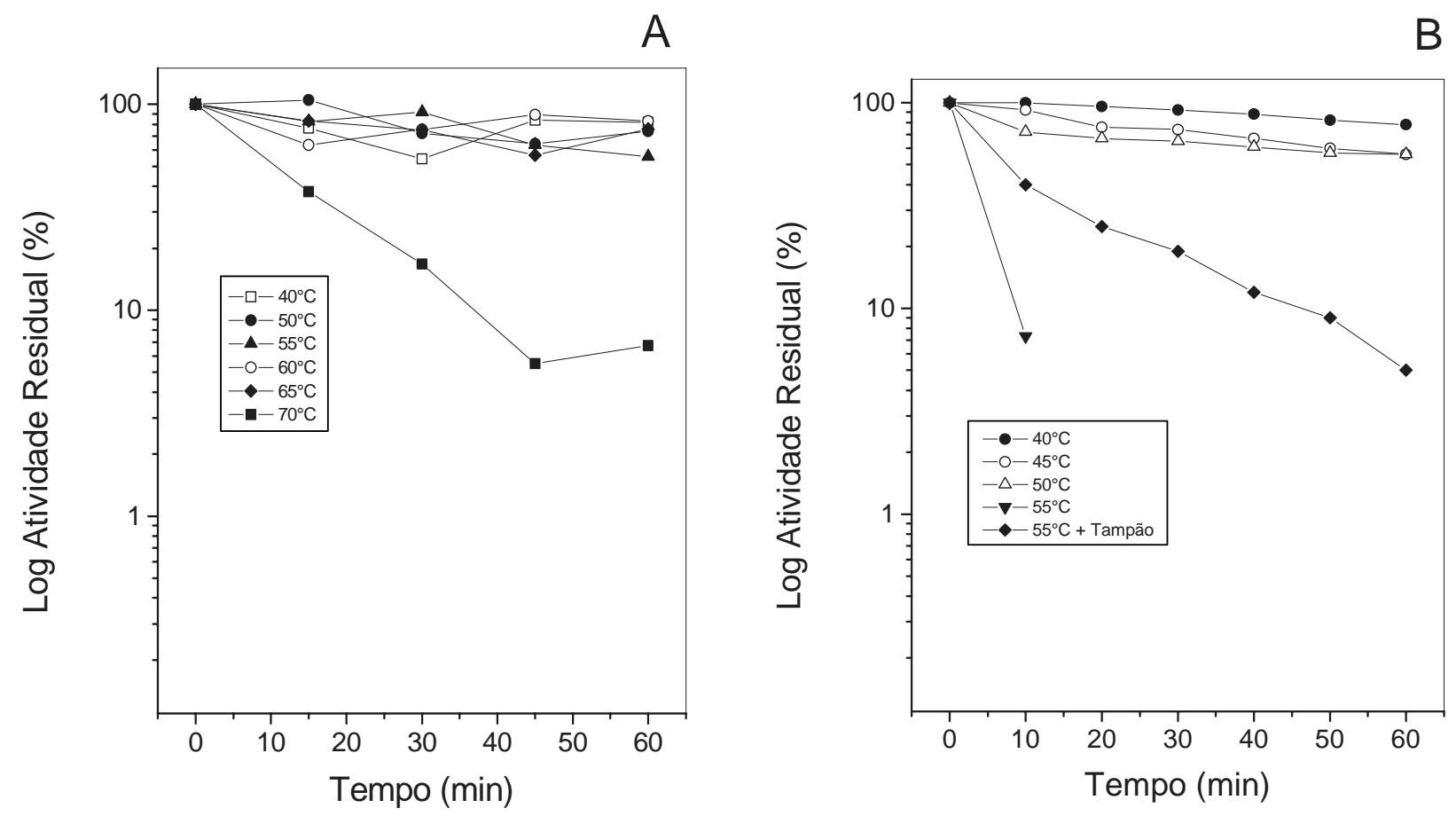

Figura 19: Estabilidade térmica das $\beta$-glucosidases purificadas de Scytalidium thermophilum. (A) $\beta$-glucosidase extracelular I (B) $\beta$-glucosidase micelial. As enzimas foram dissolvidas em água em diferentes temperaturas por até 60 minutos, retirando-se alíquotas a cada 15 minutos. Após esse período a atividade enzimática foi dosada nas condições ótimas de temperatura e pH. 


\subsubsection{Efeito de íons e EDTA sobre a atividade das $\beta$-glucosidases purificadas}

O efeito de diversos íons metálicos foram testados, determinando-se a atividade $\beta$-glucosidásica numa concentração final de 1 e $5 \mathrm{mM}$ em associação com o substrato PNP-glu, em condições ótimas de $\mathrm{pH}$ e temperatura. A Tabela 9 demonstra as atividades relativas observadas. Dos íons testados a $1 \mathrm{mM}$, a maioria não teve efeito significativo sobre as atividades enzimáticas. No entanto, ambas enzimas ( $\beta$ glucosidases extra I e micelial) foram sensíveis aos íons $\mathrm{AgNO}_{3}$ e $\mathrm{HgCl}_{2}$ onde pode-se observar uma drástica inibição das atividades enzimáticas, fato observado em muitas enzimas estudadas (Peralta et al, 1997), que são inibidas pela presença de metais pesados, quando adicionados ao meio de reação. Íons como $\mathrm{CuSO}_{4}, \mathrm{AlCl}_{3}, \mathrm{CuCl}_{2}, \mathrm{FeSO}_{4}$, $\mathrm{CoCl}_{2}$ também reduziram a atividade enzimática micelial em $68,48,58,76$ e $60 \%$ respectivamente, quando utilizados a $5 \mathrm{mM}$.

Uma pequena ativação (aproximadamente 16\%) foi observada para $\beta$ glucosidase extracelular para os íons $\mathrm{BaCl}_{2}, \mathrm{KCl}, \mathrm{MnCl}_{2}$ e EDTA. Os valores obtidos de íons quando utilizados a 5mM mostram que a ativação ou inibição das enzimas purificadas apresentam propriedades distintas.

\subsubsection{Especificidade ao substrato das $\beta$-glucosidases purificadas}

O estudo da especificidade das $\beta$-glucosidases purificadas foi realizado testandose vários substratos, dentre esses substratos naturais como avicel e xilana e sintéticos como PNP-glu (Tabela 10). Dentre os substratos testados, as enzimas foram capazes de hidrolisar uma quantidade razoável de substratos, contudo vale ressaltar que a maioria dos substratos testados hidrolisados pelas enzimas apresentam ligações glicosídicas do 
tipo $\beta$-1,4. A $\beta$-glucosidase extracelular I foi capaz de hidrolisar substratos como PNPglu, PNP-xil, celobiose, xilana e CMC.

A enzima micelial hidrolisou eficientemente substratos sintéticos como PNP-glu e PNP-fuc, e a celobiose como substrato natural. Contudo, ainda pode-se observar uma atividade menor em relação aos substratos PNP-xil, PNP-gal, PNP-ara, ONPG, e lactose. 
Tabela 9: Efeito de íons metais nas $\beta$-glucosidases purificadas de Scytalidium thermophilum.

\begin{tabular}{|c|c|c|c|c|}
\hline \multirow[b]{2}{*}{ Íons } & \multicolumn{2}{|c|}{$\begin{array}{c}\text {-Glucosidase } \\
\text { extracelular I (\%) }\end{array}$} & \multicolumn{2}{|c|}{$\begin{array}{l}\beta \text {-Glucosidase } \\
\text { micelial (\%) }\end{array}$} \\
\hline & $1 \mathrm{mM}$ & $5 \mathrm{mM}$ & $1 \mathrm{mM}$ & $5 \mathrm{mM}$ \\
\hline Controle & 100 & 100 & 100 & 100 \\
\hline $\mathrm{AgNO}_{3}$ & 2 & 0 & 0 & 0 \\
\hline $\mathrm{AlCl}_{3}$ & 103 & 91 & 109 & 52 \\
\hline $\mathrm{BaCl}_{2}$ & 101 & 116 & 118 & 69 \\
\hline $\mathrm{CaCl}_{2}$ & 109 & 109 & 117 & 83 \\
\hline $\mathrm{CoCl}_{2}$ & 107 & 93 & 113 & 40 \\
\hline $\mathrm{CuCl}_{2}$ & 109 & 113 & 81 & 42 \\
\hline EDTA & 113 & 118 & 103 & 90 \\
\hline $\mathrm{FeSO}_{4}$ & 101 & 119 & 122 & 24 \\
\hline $\mathrm{HgCl}_{2}$ & 3 & 0 & 0 & 0 \\
\hline $\mathrm{KCl}$ & 108 & 111 & 105 & 85 \\
\hline $\mathrm{MgCl}_{2}$ & 106 & 100 & 121 & 97 \\
\hline $\mathrm{MnCl}_{2}$ & 95 & 117 & 119 & 45 \\
\hline $\mathrm{NH}_{4} \mathrm{Cl}$ & 115 & 116 & 113 & 71 \\
\hline $\mathrm{ZnCl}_{2}$ & 110 & 104 & 131 & 53 \\
\hline $\mathrm{CuSO}_{4}$ & 105 & 88 & 91 & 52 \\
\hline
\end{tabular}

Condições: Os íons foram adicionados ao meio de reação na concentração final de 1 e 5mM. Os resultados são expressos em relação ao controle.

Os valores representam a média de 4 experimentos. 
Tabela 10: Especificidade ao substrato das $\beta$-glucosidases purificadas de Scytalidium thermophilum.

Substrato ( concentração)

\section{$\beta$-Glucosidase \\ extracelular I}

(U/ mg prot.)
$\beta$-Glucosidase

micelial

( U/ mg prot.)

\begin{tabular}{lcc}
\hline PNP- $\beta$-glucopiranosideo $(2 \mathrm{mg} / \mathrm{ml})$ & 862 & 890 \\
PNP- $\beta$-xilopiranosideo $(2 \mathrm{mg} / \mathrm{ml})$ & 112 & 140 \\
PNP- $\beta$-manopiranosideo $(2 \mathrm{mg} / \mathrm{ml})$ & $\mathrm{ND}$ & $\mathrm{ND}$ \\
PNP- $\beta$-fucopiranosideo $(2 \mathrm{mg} / \mathrm{ml})$ & $\mathrm{ND}$ & 700 \\
PNP- $\alpha$-glucosideo $(2 \mathrm{mg} / \mathrm{ml})$ & $\mathrm{ND}$ & $\mathrm{ND}$ \\
ONPG $(2 \mathrm{mg} / \mathrm{ml})$ & $\mathrm{ND}$ & 200 \\
PNP- $\alpha$-arabinofuranosideo $(2 \mathrm{mg} / \mathrm{ml})$ & $\mathrm{ND}$ & 700 \\
Xilana $(10 \mathrm{mg} / \mathrm{ml})$ & 17 & $\mathrm{ND}$ \\
CMC $(10 \mathrm{mg} / \mathrm{ml})$ & 5 & $\mathrm{ND}$ \\
Avicel $(10 \mathrm{mg} / \mathrm{ml})$ & $\mathrm{ND}$ & $\mathrm{ND}$ \\
Lactose $(10 \mathrm{mg} / \mathrm{ml})$ & $\mathrm{ND}$ & 900 \\
Celobiose $(10 \mathrm{mg} / \mathrm{ml})$ & 412 & 380 \\
Sacarose & ND & ND \\
Trealose $(10 \mathrm{mg} / \mathrm{ml})$ & $\mathrm{ND}$ & $\mathrm{ND}$ \\
Maltose $(10 \mathrm{mg} / \mathrm{ml})$ & $\mathrm{ND}$ \\
Sacarose $(10 \mathrm{mg} / \mathrm{ml})$ & $\mathrm{ND}$ \\
Xilobiose $(10 \mathrm{mg} / \mathrm{ml})$ & & ND \\
\hline
\end{tabular}

Condições: As $\beta$-glucosidases purificadas foram incubada por até 2 horas minutos nas condições ótimas de pH e temperatura, com os diferentes substratos.

ND: não detectável pelo método utilizado.

Os valores representam a média de 4 experimentos. 


\subsubsection{Efeito de álcoois na atividade das $\beta$-glucosidases purificadas}

A Tabela 11 demonstra os resultados de experimento no qual diferentes álcoois foram adicionados ao meio de reação para a determinação da atividade $\beta$-glucosidásica. Observa-se que as enzimas apresentaram a maior ativação na presença de glicerol como aceptor (203\% e $180 \%)$ para as atividades $\beta$-glucosidásicas extra I e micelial, respectivamente.

A enzima extracelular apresentou ativação pela maioria dos álcoois testados, com exceção do álcool isopropílico e manitol. Já para atividade micelial, a presença de manitol ativa a enzima em 33\%, enquanto metanol inibe a atividade enzimática.

\subsubsection{Efeito de açúcares na atividade das $\beta$-glucosidases purificadas}

A Tabela 12 mostra os resultados obtidos quando diferentes açúcares a $50 \mathrm{mM}$ foram adicionados ao meio de reação contendo PNP-glu como substrato. A atividade da $\beta$-glucosidase extracelular I foi ativada significantemente por xilose, frutose e lactose, sendo que xilose e lactose ativaram a enzima em 40 e $80 \%$, respectivamente. Uma pequena ativação também foi observada na presença de celobiose. A enzima mostrouse resistente à glicose $50 \mathrm{~mm}$. Maltose e sorbose inibiram ligeiramente a atividade da $\beta$ glucosidase extracelular I.

Para a $\beta$-glucosidase micelial, glicose e xilose foram aqueles que causaram maior ativação enzimática, aumentando cerca de 2.0 e 1.9 vezes a atividade. Celobiose inibiu a atividade enzimática em aproximadamente $80 \%$. Os demais açúcares, não afetaram significantemente a atividade enzimática sobre o PNP-glu. 
Tabela 11 : Efeito "in vitro" de álcoois nas atividades das $\beta$-glucosidases purificadas de Scytalidium thermophilum.

\begin{tabular}{lcc}
\hline \multicolumn{1}{c}{ Adição ( 1M) } & $\begin{array}{c}\beta \text {-Glucosidase } \\
\text { extracelular I (\%) }\end{array}$ & $\begin{array}{c}\beta \text {-Glucosidase } \\
\text { micelial (\%) }\end{array}$ \\
\hline Controle & 100 & 100 \\
Metanol & 131 & 81 \\
Etanol & 123 & 105 \\
Glicerol & 203 & 180 \\
n-Butanol & 129 & 100 \\
I so-propílico & 100 & 105 \\
Manitol & 100 & 133 \\
\hline
\end{tabular}

Condições: Os álcoois foram adicionados ao meio de reação na concentração final de 1M. Os resultados são expressos em relação ao controle. 
Tabela 12: Efeito "in vitro" de açúcares nas atividades das $\beta$-glucosidases purificadas de Scytalidium thermophilum.

\begin{tabular}{lcc}
\hline Adição (50m M) & $\begin{array}{c}\beta \text {-Glucosidase } \\
\text { extracelular I (\%) }\end{array}$ & $\begin{array}{c}\beta \text {-Glucosidase } \\
\text { micelial (\%) }\end{array}$ \\
\hline Controle & 100 & 100 \\
Glicose & 81 & 204 \\
Xilose & 140 & 191 \\
Manose & 115 & 100 \\
Frutose & 133 & 111 \\
Ribose & 107 & 100 \\
Galactose & 115 & 123 \\
Sorbose & 84 & 95 \\
Arabinose & 118 & 97 \\
Lactose & 181 & 92 \\
Celobiose & 120 & 24 \\
Maltose & 70 & 113 \\
Sacarose & 125 & 105 \\
\hline
\end{tabular}

Condições: Os açúcares foram adicionados ao meio de reação na concentração final de 50mM. Os resultados são expressos em relação ao controle. 


\subsubsection{Efeito da glicose, xilose e celobiose na atividade das $\beta$-glucosidases purificadas}

A Figura 20 demonstra os efeito do aumento da concentração de glicose e xilose e mistura equimolar na atividade das $\beta$-glucosidases extracelular I e micelial.

A atividade da $\beta$-glucosidase extracelular I sobre o PNP-glu (Figura 20A) foi inibida drasticamente pela presença de glicose 150mM. Em contrapartida, a reação foi ativada em 2.0 e 1.6 vezes na presença de xilose e celobiose a 50 e 150mM, respectivamente (Figura 20A e Figura 21A). O efeito da xilose na atividade celobiásica, foi analisado utilizando o método da glicose oxidase, pela quantificação da glicose liberada (GOD). Na Figura 22A, observa-se um aumento de 1.4 vezes para uma concentração de 100-200mM de xilose.

$\mathrm{Na}$ Figura 20B, observa-se que glicose e xilose exibem efeito máximo na atividade enzimática da $\beta$-glucosidase micelial em uma concentração de 150mM, aumentando a razão de hidrólise do PNP-glu de 2.6 a 2.4 vezes, respectivamente para xilose e glicose. Na presença de 500 e $700 \mathrm{mM}$, respectivamente para xilose e glicose, a atividade da $\beta$-glucosidase micelial contra o PNP-glu foi idêntica a reação enzimática na ausência dos ativadores (dados não mostrados). A mistura equimolar de glicose e xilose não exibiu efeito aditivo.

Com base nos resultados obtidos, pode-se calcular os valores de constante de afinidade aparente $K_{0,5}$ para glicose e xilose. Foram encontrados valores de 36,69 e 43,24 mM para glicose e xilose, respectivamente.

O efeito da xilose na atividade celobiásica está demonstrada na Figura 22B. Observa-se um aumento de 2.1 vezes para uma concentração de 100-200mM de xilose e a atividade não foi inibida até uma concentração de 500mM (dados não mostrados). O efeito positivo da glicose na atividade celobiásica ( 2.3 vezes) também foi analisado em HPLC (dados não mostrados). A hidrólise do PNP-glu pela $\beta$-glucosidase micelial foi 
inibida drasticamente por celobiose (Figura 21B), sugerindo competição entre os substratos sintéticos e natural. 

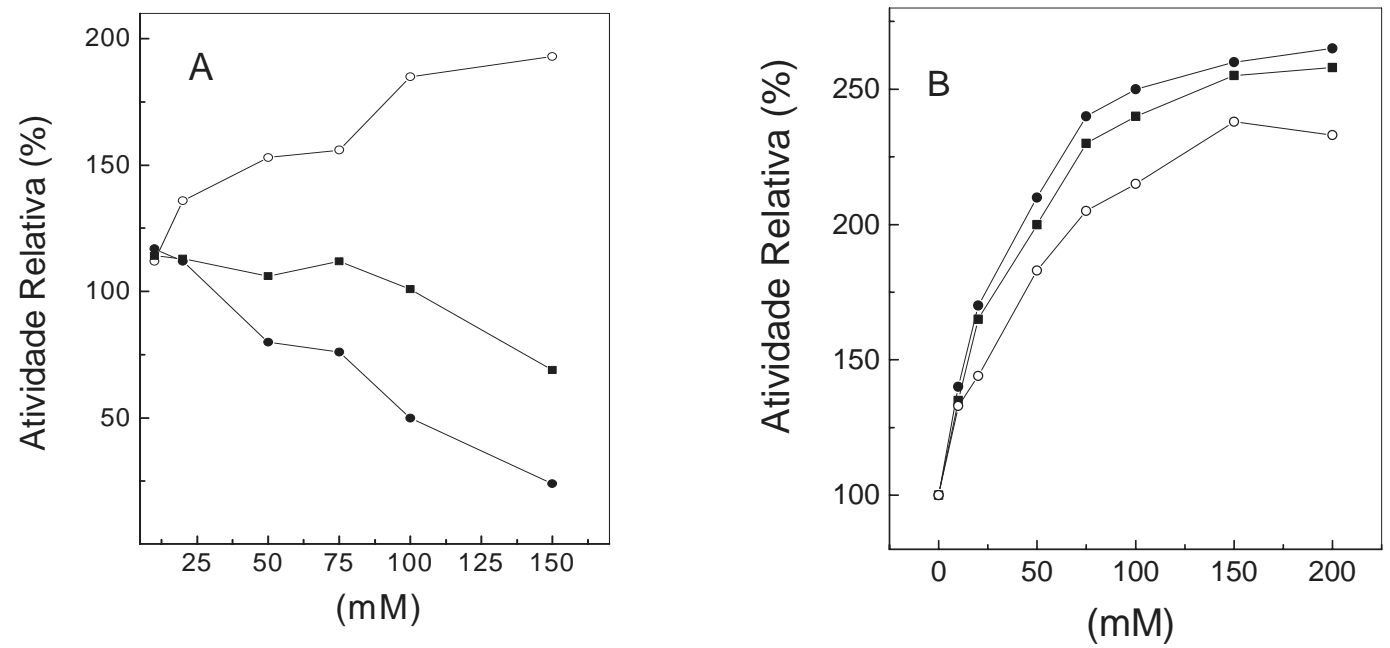

Figura 20: Efeito da glicose e xilose nas atividades das $\beta$-glucosidases purificadas de Scytalidium thermophilum. (A) $\beta$-glucosidase extracelular (B) $\beta$-glucosidase micelial. Símbolos: (•) glicose; (O) xilose; ( $\square)$ mistura equimolar 

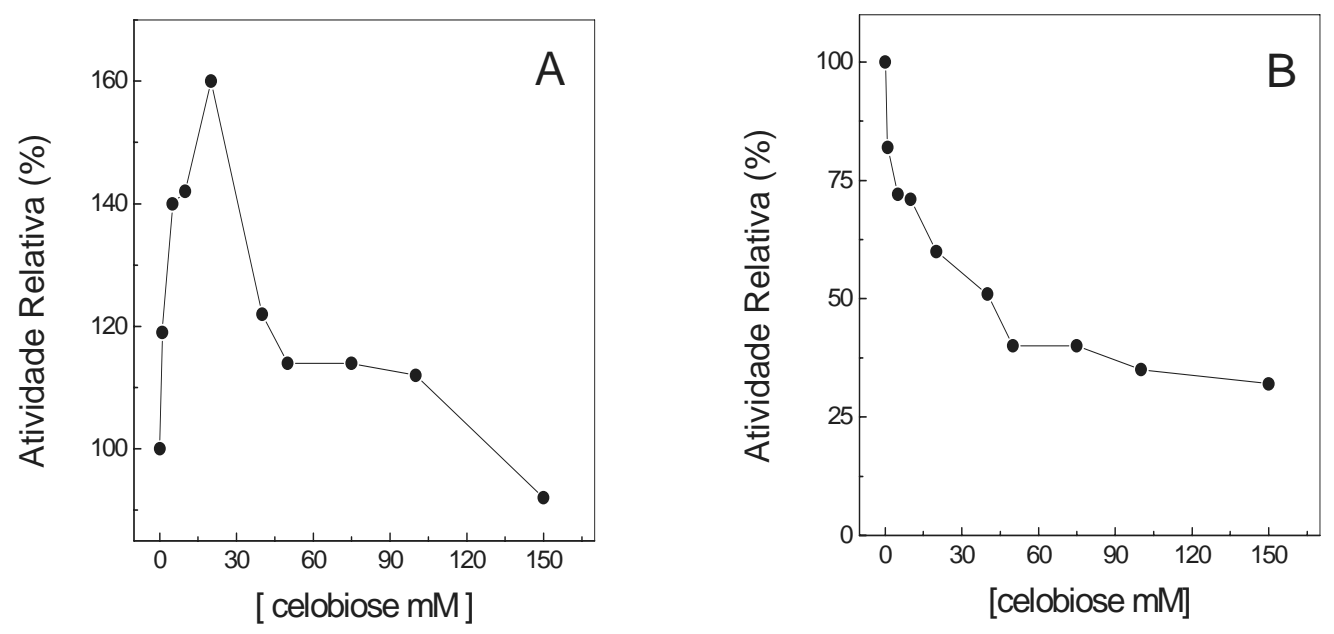

Figura 21: Efeito da celobiose nas atividades das $\beta$-glucosidases purificadas de Scytalidium thermophilum. (A) $\beta$-glucosidase extracelular (B) $\beta$-glucosidase micelial. A atividade enzimática foi dosada em Tampão Mcllvaine com PNPglu ( $2 \mathrm{mg} / \mathrm{mL})$ adicionando-se diferentes concentrações de celobiose. 

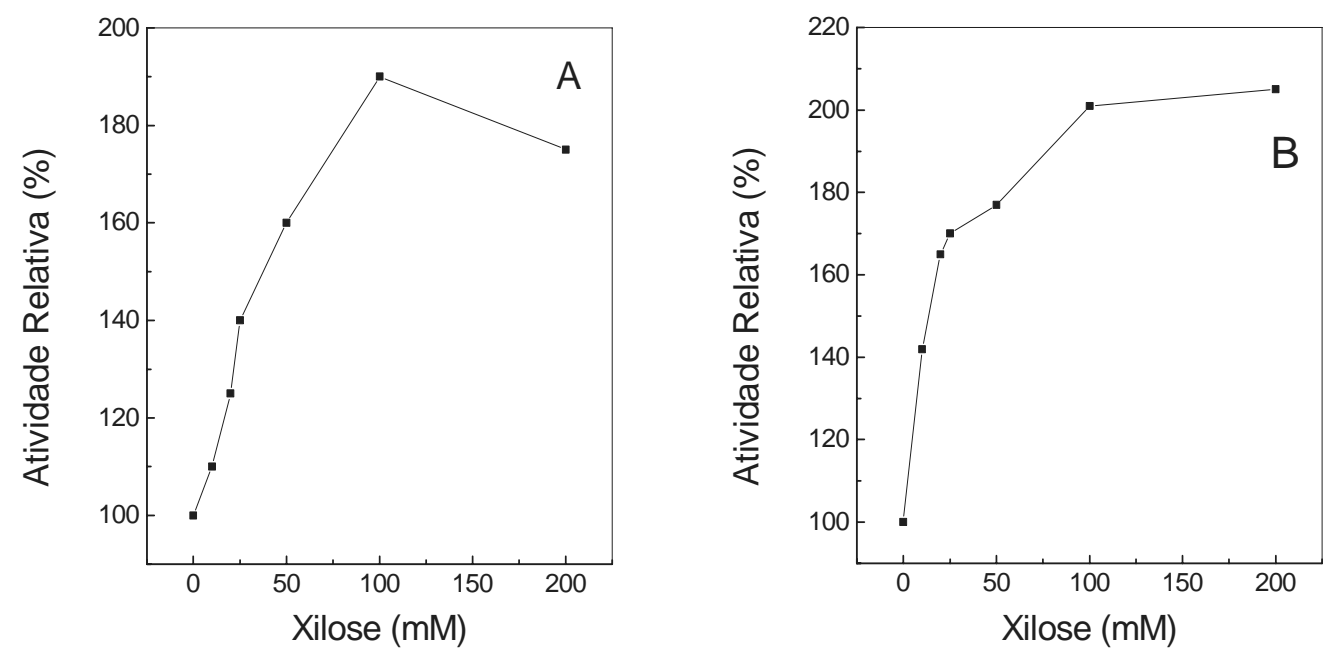

Figura 22: Efeito da xilose na atividade celobiásica das $\beta$-glucosidases purificadas de Scytalidium thermophilum. A atividade enzimática foi dosada em Tampão Mcl lvaine (1921) e celobiose $(10 \mathrm{mg} / \mathrm{mL})$, com diferentes concentrações de xilose, utilizando-se o método da glicose oxidase. (A) $\beta$-glucosidase extracelular (B) $\beta$-glucosidase micelial. 


\subsubsection{Determinação do teor de açúcar das $\beta$-glucosidases purificadas}

O experimento foi realizado segundo a metodologia descrita por Dubbois et al (1956), utilizando-se glicose como padrão.

Foi encontrado um valor estimado em $65 \%$ e $15 \%$ de açúcar presente nas $\beta$ glucosidases extra e micelial purificadas, respectivamente.

Para confirmação dos dados de presença de açúcar nas proteínas, um experimento em gel de poliacrilamida (PAGE) foi realizado utilizando-se tratamento com isopropanol e coloração com bromotimol, como descritos em material e Método. Tais resultados (dados não mostrados) evidenciaram que ambas enzimas ( $\beta$-glucosidases extra I e micelial) são glicoproteínas, e que a coloração da banda no gel é proporcional a quantidade de açúcar presente na amostra.

\subsubsection{Focalização I soelétrica das $\beta$-glucosidases purificadas}

O ponto isoelétrico das $\beta$-glucosidases foi determinado por focalização isoelétrica em gel de poliacrilamida 6\%, utilizando-se Pharmalyte de 3.0-10.0, seguindo-se a metodologia de O'Farrel (1983). Os resultados obtidos revelaram um PI de 4.0 e 6.5, para as $\beta$-glucosidases extra I e micelial, respectivamente (Figura 23A e 23B). 
$\mathrm{PI}=4.0$

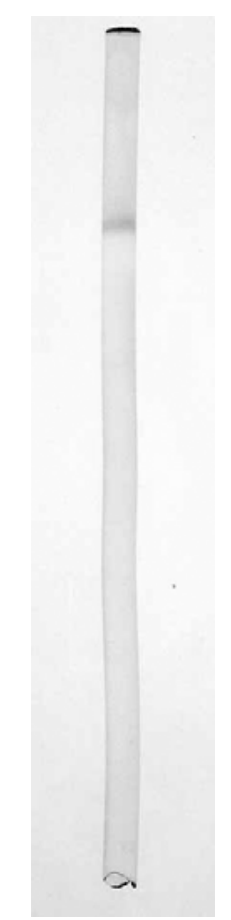

A

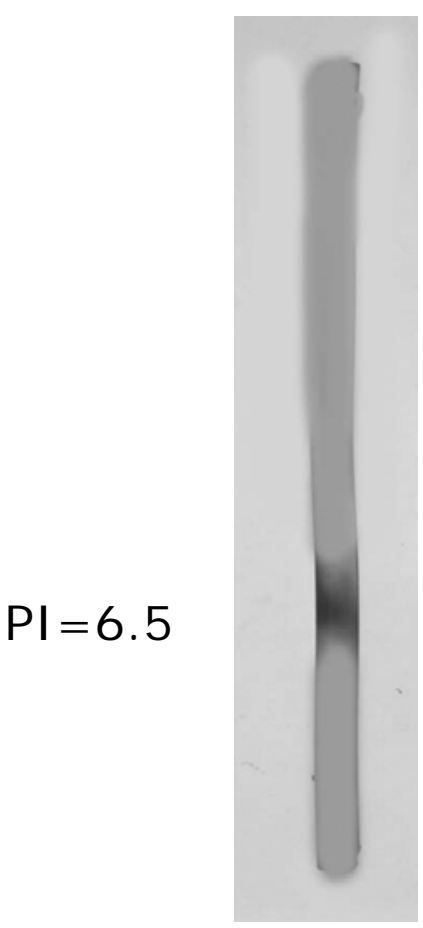

B

Figura 23: Focalização Isoelétrica das $\beta$-glucosidases purificadas de Scytalidium thermophilum. (A) $\beta$-glucosidase extracelular I; (B) $\beta$-glucosidase micelial 


\subsubsection{Parâmetros Cinéticos}

Após a purificação das $\beta$-glucosidases produzidas pelo Scytalidium thermophilum, determinação de temperatura e pH ótimos, passamos a trabalhar com as constantes cinéticas $K_{m}$ e $V_{\text {máx, }}$ para um maior esclarecimento das propriedades intrínsicas destas proteínas. Os substratos utilizados foram aqueles em que as enzimas apresentaram maior atividade (Tabela 10), PNP-glu, PNP-fuc e celobiose.

Nas Figuras 24A e 24B estão ilustradas as representações de Lineweaver Burk e Hanes para a $\beta$-glucosidase extracelular I. A enzima apresentou valores de $K_{m}$ e $V_{\text {máx }}$ de $4,33 \mathrm{mM}$ e 5,37 $\mu$ moles.min/mg prot e $0,342 \mathrm{mM}$ e 2,0 $\mu$ moles.min/mg prot respectivamente, para celobiose e PNP-glu. A eficiência catalítica $\left(V_{\text {máx }} / K_{m}\right)$ da enzima foi de 5,84 e 1,24 para PNP-glu e celobiose, respectivamente (Tabela 13).

Os valores de $K_{m}$ e $V_{\text {máx }}$ da $\beta$-glucosidase micelial para os substratos celobiose, PNP-glu e PNP-fuc foram de 1,61 e 4,12 $\mu$ moles.min/mg prot., 0,29 e 13,27 $\mu$ moles.min/mgprot. e 0,5 e 7,25 $\mu$ moles. min/mg prot., respectivamente, utilizando-se do Programa Computacional Sigraf (Leone et al, 1992) (Tabela 14). A presença de xilose e glicose no meio de reação contendo PNP-glu como substrato, aumentou ambos valores de $K_{m}$ e $V_{\text {máx }}$ (Tabela 14), encontrando-se valores de $K_{m}$ de 1,26 e 1,33mM e $V_{\text {máx }}$ de 40,04 e 30,49 $\mu$ moles.min/mg prot. para hidrólise do PNP-glu na presença de glicose e xilose, respectivamente. A eficiência catalítica $\left(V_{\text {máx }} / K_{m}\right)$ da enzima foi de 45,76, 14,5 e 2,56 e 1,24 para PNP-glu, PNP-fuc e celobiose, respectivamente. O sumário dos valores de $K_{m}$ e $V_{\text {máx }}$ podem ser observados na Tabela 14. 


\subsubsection{Constantes de I nibição das Enzimas (Plot de Dixon)}

As Tabelas 13 e 14 mostram as constantes de inibição-Plot de Dixon quando as enzimas purificadas foram testadas com PNP-glu e glicose ou celobiose, respectivamente.

Foram encontrados valores de $K_{i} 71 \mathrm{mM}$ e $1.32 \mathrm{mM}$, para glicose ( $\beta$-glucosidase extracelular I) e celobiose ( $\beta$-glucosidase micelial), respectivamente.

\subsubsection{1. estudo da $\beta$-glucosidase micelial purificada frente aos substratos PNP-glu e PNP-fuc}

O estudo da $\beta$-glucosidase micelial foi examinada pelo método cinético de mistura de substratos (Thorn, 1949), usando os substratos PNP-glu e PNP-fuc nas concentrações de $2 \mathrm{mg} / \mathrm{ml}$ e uma mistura dos dois substratos. O resultado obtido na Figura 25 mostra que a velocidade de hidrólise da mistura não foi aditiva, quando comparada com as velocidades das reações determinadas usando um único substrato. 

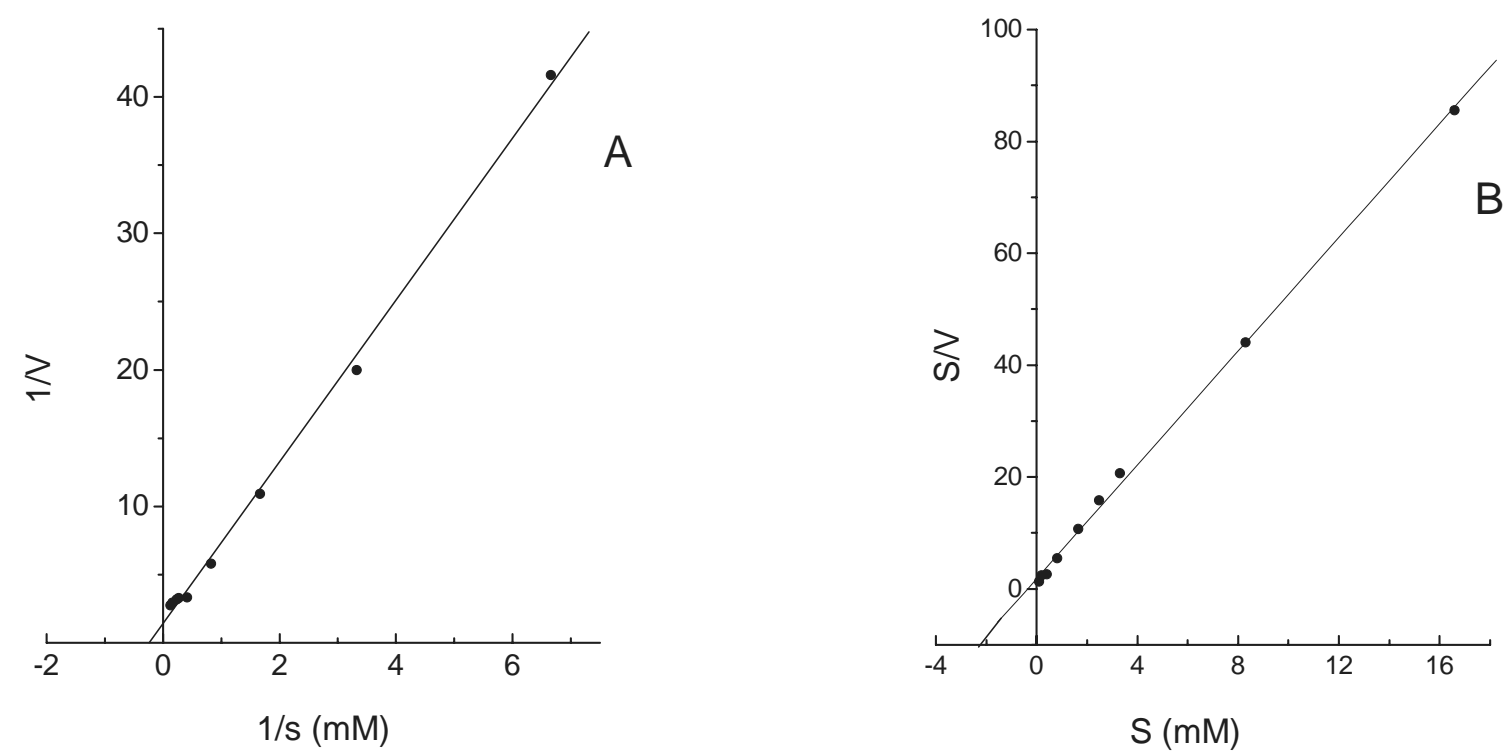

Figura 24: Determinação dos parâmetros cinéticos $(\mathrm{Km})$ da $\beta$-glucosidase extracelular I purificada. Os ensaios foram realizados com os diferentes substratos ( $A$ : celobiose e B: PNP-glu) em tampão M. Ilvaine $\mathrm{pH} 5.5$ a $70^{\circ} \mathrm{C}$. 
Tabela 13: Determinação dos parâmetros cinéticos $\left(K_{m}\right.$ e $\left.V_{\text {máx }}\right)$ da $\beta$-glucosidase extracelular I purificada.

\begin{tabular}{lccccc}
\hline Substrato & \multicolumn{5}{c}{ Parâmetros Cinéticos } \\
\hline & Adição & $\mathbf{K}_{\mathbf{m}}(\mathbf{m M})$ & $\mathbf{V}_{\text {máx }}$ & $\mathbf{V m a ́ x} / \mathbf{K m}$ & $\mathbf{K i}$ ( mM) \\
& & & & & \\
Celobiose & - & 4,33 & 5,37 & 1,24 & \\
PNP-glu & - & 0,342 & 2,0 & 5,84 & 71 \\
PNP-glu & Glicose & & & & \\
\hline
\end{tabular}

Condições: Os ensaios foram realizados com os diferentes substratos (celobiose; PNPglu) em Tampão Mcl lvaine (1921) pH 5.5 a $70^{\circ} \mathrm{C}$.

$\bigvee_{\text {máx }}$ está expresso em $\mu$ moles de produto ( $p$-nitrofenol ou glucose) por $\mathrm{min} / \mathrm{mg}$ proteína. 
Tabela 14: Parâmetros cinéticos da $\beta$-glucosidase micelial purificada de Scytalidium thermophilum

\begin{tabular}{|c|c|c|c|c|c|}
\hline Substrato & Adição & $K_{m}(m M)$ & $\begin{array}{c}\mathbf{V}_{\text {máx }}(\mathrm{U} \mathbf{~ m g} \\
\left.\text { prot }^{-1}\right)\end{array}$ & $\mathbf{V}_{\text {máx }} / \mathbf{K}_{\mathbf{m}}$ & $\begin{array}{c}\mathrm{K}_{\mathrm{i}} \\
(\mathrm{mM})\end{array}$ \\
\hline $\begin{array}{l}\text { PNP-glu (0.15- } \\
10 \mathrm{mM})\end{array}$ & - & 0.29 & 13.27 & 45.76 & \\
\hline $\begin{array}{l}\text { PNP-fuc }(0,15- \\
10 \mathrm{mM})\end{array}$ & & 0,5 & 7,25 & 14,5 & \\
\hline $\begin{array}{l}\text { Celobiose }(0.5- \\
10 \mathrm{mM})\end{array}$ & - & 1.61 & 4.12 & 2.56 & \\
\hline $\begin{array}{l}\text { PNP-glu }(0.15- \\
10 \mathrm{mM})\end{array}$ & Glicose (80mM) & 1.26 & 40.04 & 31.78 & \\
\hline $\begin{array}{l}\text { PNP-glu }(0.15- \\
10 \mathrm{mM})\end{array}$ & Xilose (100mM) & 1.33 & 30.49 & 22.92 & \\
\hline $\begin{array}{l}\text { PNP-glu }(0.15- \\
10 \mathrm{mM})\end{array}$ & $\begin{array}{l}\text { Celobiose }(0.5- \\
\qquad 15 \mathrm{mM})\end{array}$ & - & - & - & 1.32 \\
\hline
\end{tabular}

Condições: Os ensaios foram realizados com os diferentes substratos (celobiose; PNPglu) em Tampão Mcl lvaine (1921) $\mathrm{pH} 5.5$ a $60^{\circ} \mathrm{C}$.

$V_{\text {máx }}$ está expresso em $\mu$ moles de produto ( $p$-nitrofenol ou glucose) por $\mathrm{min} / \mathrm{mg}$ proteína. 


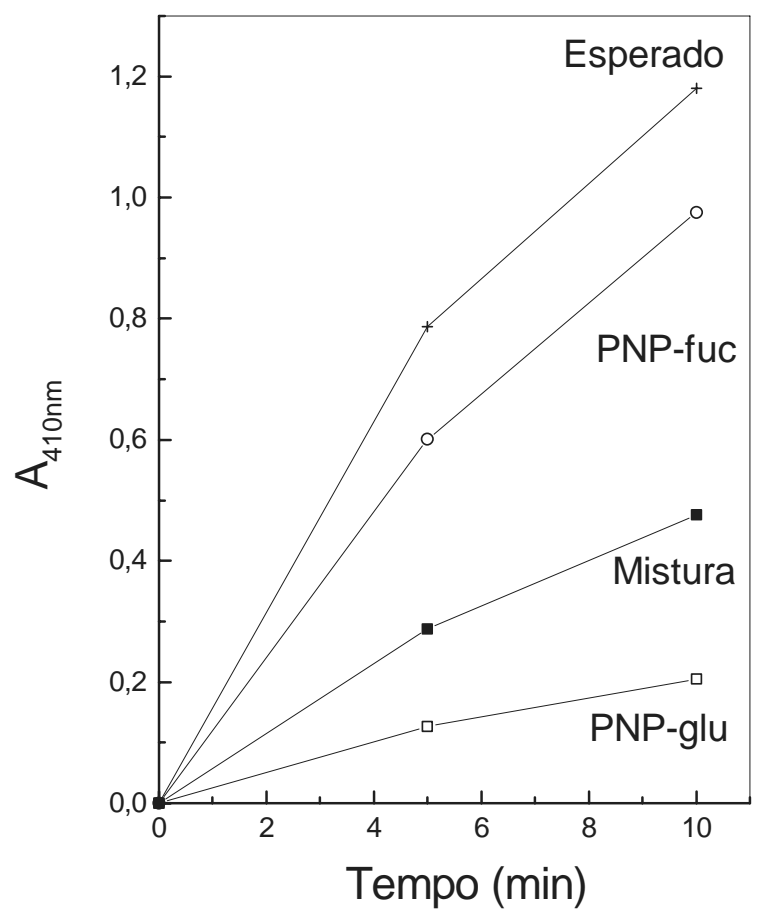

Figura 25: Cinética da atividade $\beta$-glucosidásica micelial para os substratos PNP-glu () e PNP-fuc (O) e mistura dos substratos ( ). O símbolo (+) representa a soma dos valores de hidrólise do PNP-glu e PNP-fuc. 


\subsection{Estudo das $\beta$-glucosidases como transglucosidases}

\subsubsection{Análise dos Produtos de hidrólise das $\beta$-glucosidases purificadas}

As $\beta$-glucosidases são conhecidas por catalisar além de reações de hidrólise, reações de transferência, onde o resíduo de açúcar da molécula do substrato pode ser transferido para outro aceptor hidroxílico, açúcar ou álcool. A análise dos produtos de hidrólise das $\beta$-glucosidases purificadas de Scytalidium foram analisados em cromatografia de camada delgada de sílica (TLC) .

Amostras das enzimas purificadas foram incubadas por diferentes tempos e com diferentes concentrações de celobiose, na presença e ausência de glicose. As Figuras 26 e 27 demonstram os resultados obtidos. Observa-se que ambas enzimas $\beta$-glucosidases extracelular I e micelial realizam hidrólise do substrato em concentração de 10mM, liberando glicose como produto da reação. Contudo, $\beta$-glucosidase micelial na presença de glicose adicionado ao meio de reação aparecem vestígios de outros produtos, possivelmente celotriose e celotetraose, ou seja é confirmada a hipótese de que a enzima na presença de um açúcar como aceptor realize reações de transglicosilação, gerando outros glicosídeos. Como demonstrado na Tabela 12 a $\beta$-glucosidase extracelular foi ativada por xilose utilizando como substrato PNP-glu. A reação quando analisada em TLC (Figura 28) observa-se a presença de produtos gerados por reação de transglicosilação.

$\mathrm{Na}$ presença do substrato em altas concentrações (celobiose $250 \mathrm{mM}$ ), as enzimas $\beta$-glucosidases extracelular I e micelial realizam facilmente reações de transglicosilação, como pode ser observado nas Figuras 26B e 27C. Observa-se nestas Figuras a presença de celotriose e celotetraose, como produto das reações. 
Figura 26: Análise dos produtos de hidrólise e transglicosilação da $\beta$-glucosidase extracelular purificada em TLC. O solvente utilizado foi $n$-butanol:piridina água (6:4:3), e a revelação com metanol e ácido sulfúrico (9:1) e orcinol $0,2 \%$
A- enzima incubada com 10mM de celobiose
B- enzima incubada com $250 \mathrm{mM}$ de celobiose 
Figura 27: Análise dos produtos de hidrólise e transglicosilação da $\beta$-glucosidase micelial purificada em TLC. O solvente utilizado foi $n$-butanol:piridina água (6:4:3), e a revelação com metanol e ácido sulfúrico (9:1) e orcinol $0,2 \%$ A- enzima incubada com 10mM de celobiose

B- enzima incubada com $10 \mathrm{mM}$ de celobiose $+100 \mathrm{mM}$ de glicose

C- enzima incubada com $250 \mathrm{mM}$ de celobiose 
Figura 28: Análise dos produtos de hidrólise e transglicosilação da $\beta$-glucosidase micelial purificada em TLC na presença de PNP-glu e xilose. O solvente utilizado foi n-butanol: piridina água (6:4:3), e a revelação com metanol e ácido sulfúrico (9:1) e orcinol 0,2\%

A- enzima incubada com PNP-glu $2 \mathrm{mg} / \mathrm{mL}+$ xilose 


\subsection{Produção de ANTI Corpos ANTI- $\beta$-GLUCosi dase extracelular}

A produção de anticorpos anti- $\beta$-glucosidase foi realizada utilizando-se coelhos New Zealand devidamente imunizados como descrito em material e métodos, sendo a quantificação dos anticorpos produzidos realizada por teste de ELISA em um espectro com filtro 490nm. A titulação obtida foi igual a 1:1000.

\subsection{LOCALI ZAÇÃO “IN SITU” DA ATI VI DADE $\beta$-GLUCOSI DÁSICA}

Foi possível observar a imunolocalização da $\beta$-glucosidase no micélio de Scytalidium thermophilum. O fungo foi crescido em meio $M_{8}$ suplementado com glicose e avicel como fonte de carbono.

A figura 29, representa a imunolocalização da $\beta$-glucosidase no micélio de Scytalidium thermophilum. O fungo quando crescido em meio suplementado com avicel (C) foi possível observar verificar a imunomarcação da $\beta$-glucosidase somente nos septos ao passo que em meio suplementado com glicose (B) a imunomarcação da enzima ocorre em toda extensão da hifa e está associada a membrana celular e/ou parede celular. 

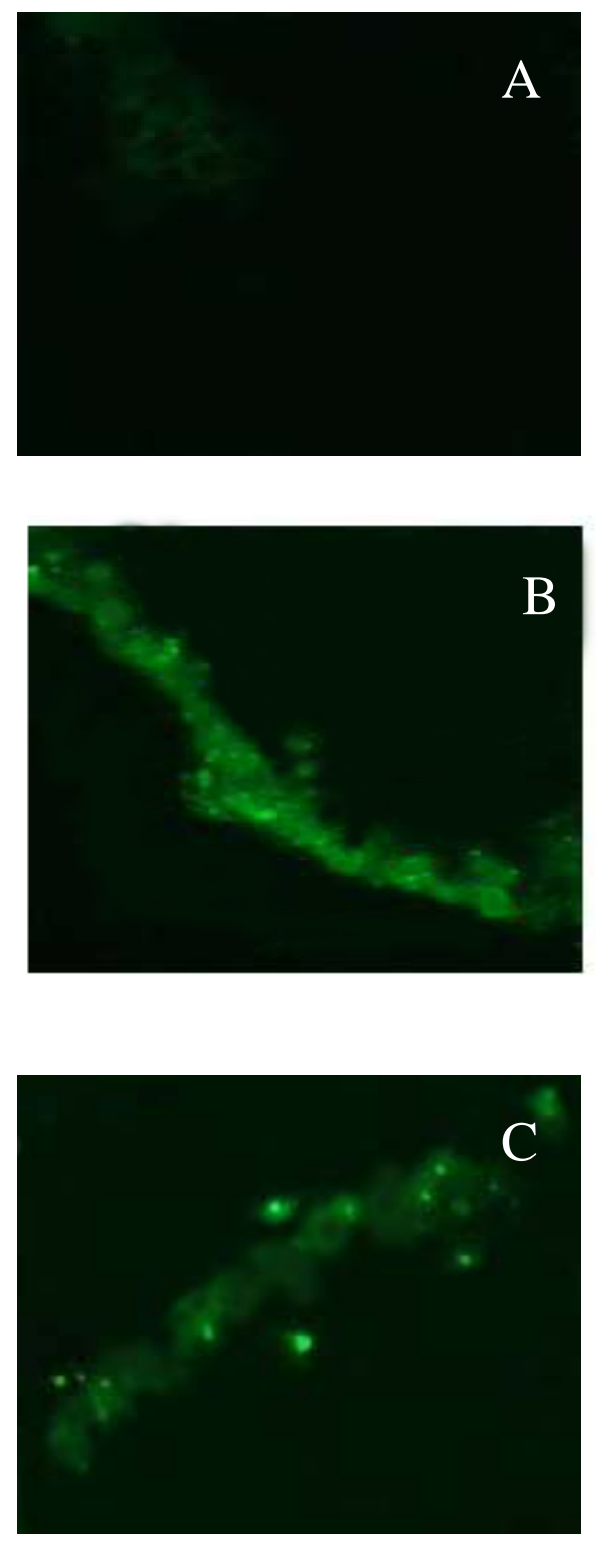

Figura 29: Localização subcelular por imunofluorescência da $\beta$-glucosidase do fungo Scytalidium thermophilum cultivado em meio $M_{8}$ por 72 horas suplementado com glicose (B) e avicel (C). (A) controle sem marcação com anticorpo primário anti- $\beta$-glucosidase (B) marcação por toda extensão da hifa (C) marcação apenas nos septos. 


\section{DISCUSSÃO}

De um modo geral os fungos tem se mostrado como uma importante fonte para obtenção de enzimas, proteínas, polímeros e outros compostos de interesse biotecnológico, que podem ser obtidos a um baixo custo. Assim, estudos que levem a um aumento da produção desse compostos têm sido frequentemente realizados com base na padronização de parâmetros como: tempo de cultivo, composição do meio, fonte de carbono, temperatura e pH, já que existe uma certa escassez desse tipo de informação.

As hidrolases são um grupo de enzimas que catalisam a clivagem das ligações covalentes em moléculas pela reação com a água. Entre as hidrolases estão as proteases que degradam polipeptídeos e as celulases e amilases que degradam polímeros de celulose e amido, respectivamente. A modificação destes polímeros naturais são necessários às indústrias, por exemplo na produção de etanol pela fermentação. As celulases juntamente com as $\beta$-glucosidases são utilizadas para hidrolisar celulose até glicose, e participam eficientemente na conversão natural de resíduos celulósicos ( Béguin \& Aubert, 1994).

Os microrganismos termofílicos são excelentes fontes de enzimas degradadoras de celulose, visto que geralmente são encontradas na decomposição biológica e combustão espontânea de resíduos celulolíticos da natureza. Além disso, possuem complexos enzimáticos estáveis a altas temperaturas, e pouco se tem a respeito da fisiologia e regulação metabólica destes organismos.

Neste trabalho foi utilizado o fungo termofílico Scytalidium thermophilum gentilmente cedido pelo Dr. Straastma (Holanda) e isolado a partir de material em decomposição. Procuramos caracterizar fisiológica e bioquimicamente o sistema $\beta$ glicosidásico deste fungo. 
Inicialmente, foi realizado um estudo para determinação das condições de cultivo a fim de se otimizar a produção das enzimas do complexo $\beta$-glucosidásico produzido pelo fungo. Os maiores níveis enzimáticos foram obtidos quando o fungo foi crescido em meio $M_{8}$ a $40^{\circ} \mathrm{C}$ sob agitação orbital de $100 \mathrm{rpm}$. Posteriormente, parâmetros como tempo de cultivo (Figura 3) e fonte de carbono (Tabela 1) foram analisados, já que se sabe que a produção e a excreção das $\beta$-glucosidases é dependente da fonte de carbono empregada, bem como do $\mathrm{pH}$ e temperatura.

Assim sendo, os maiores níveis de atividade $\beta$-glucosidásica foram obtidos em culturas em que o meio de cultura foi suplementado com avicel (celulose microscristalina) e celobiose quando o fungo foi crescido em um único estágio (Tabela 1), ou inicialmente com glicose e reincubação nas diferentes fontes de carbono quando o fungo foi crescido em dois estágios (repressão-indução-Tabela 3). Assim como muitas $\beta$-glucosidases de diferentes microrganismos ( Peralta et al, 1990; Peralta et al, 1997; Venturi, 2002), as $\beta$-glucosidases do Scytalidum parecem seguir o padrão de repressão-indução para o controle da síntese das enzimas, já que avicel e celobiose foram bons indutores das enzimas e suas sínteses foram reprimidas por glicose (Tabelas 1, 2 e 3).

Nos experimentos em que foi utilizado ciclo-heximida, os dados sugerem que as enzimas sejam resultantes da síntese "de novo" das proteínas, assim como observado para Humicola grisea var thermoidea (Peralta et al, 1990). O processo de secreção das enzimas na presença de avicel e celobiose e como ocorre a sinalização celular, ainda permanece desconhecido. Bhatia et al (2002) propõe que a indução por celulose pode não ser efetuada diretamente pela celobiose, mas por produtos formados após uma reação de transglicosilação, catalisada pela própria $\beta$-glucosidase existentes em quantidades mínimas.

A diferença das fontes de carbono sobre a produção da $\beta$-glucosidase extracelular pode ser observada na localização enzimática subcelular (Tabelas 5 e 6) e 
por imunofluorescência (Figura 31). Na presença de avicel, a enzima permanece associada aos septos, diferentemente de quando empregada glicose, em que a enzima fica restrita a periferia celular. Os resultados obtidos sugerem fortemente que a distribuição enzimática é dependente da fonte de carbono empregada no meio de cultura, e confirmam os resultados obtidos da Tabela 1.

A otimização das condições de cultivo do fungo estudado considerando a produção das $\beta$-glucosidases, bem como a determinação fonte de carbono e tempo de crescimento da atividade enzimática desse fungo, constituíram conhecimentos prévios fundamentais às etapas subsequentes de desenvolvimento deste trabalho.

Para que as indústrias possam utilizar as enzimas isoladas de microrganismos em alguns casos, elas devem antes passar por um processo de purificação. A purificação das $\beta$-glucosidases é um pré-requisito necessário para um completo entendimento de sua natureza e mecanismo de ação. Os métodos usados para a purificação são espécie-específicos, assim uma metodologia usado para purificar uma enzima de um microrganismo não é necessariamente o mais indicado para a $\beta$ glucosidase de um outro organismo.

Inicialmente foi feito uma análise das $\beta$-glucosidases do Scytalidium em coluna de troca iônica DEAE-celulose (Figura 5), quando o meio foi suplementado com avicel como fonte de carbono. Em ambas culturas extracelular e micelial foram detectadas duas atividades enzimáticas. Relatos de inúmeras formas de $\beta$-glucosidases tem sido observado em diferentes microrganismos (Bhatia et al, 2002). Contudo, o significado desta heterogeneidade é difícil de ser esclarecida, podendo ser resultado de modificação do mRNA, limite de proteólise, ou variação no conteúdo de carboidrato, nos genes estruturais e na composição do meio de cultivo (Pandey et al, 2000 Bhatia et al, 2002). 
Após a análise das atividades em DEAE-celulose (Figura 5), padronizamos uma metodologia de purificação das $\beta$-glucosidases visando caracterizá-las em termos físicoquímicos e cinético.

As frações mais abundantes nos extratos celulares e filtrados de culturas foram purificados até sua total homogeneidade eletroforética (Tabelas 7 e 8). É importante ressaltar que as atividades específicas finais das enzimas purificadas, são superiores quando comparadas com as atividades específicas da maioria de outros microrganismos descritos na literatura (Mamma et al, 2004), e marcadamente crescentes à partir do extrato bruto.

Os resultados demonstram que ambas enzimas são glicoproteínas, com $65 \%$ e $15 \%$ para as glucosidases extra I e micelial, respectivamente. A glicosilação em enzimas de fungos termofílicos é muito comum e têm sido relatada em diferentes organismos. Em Chaetomium thermphilum var coprophilum (Venturi, et al 2002) foi encontrado um valor de $73 \%$ de carboidrato para uma $\beta$-glucosidase extracelular, enquanto que em $\mathrm{H}$. grisea var thermoidea (Peralta et al, 1997) esse valor foi de $35 \%$. Normalmente, os carboidratos estão na forma de glicose, glucosamina, manose e galactose (James \& Lee, 1997). Estas enzimas são ricas em resíduos de serina e treonina já que são pontos ideais de glicosilação onde os carboidratos são ligados por ligações O-glicosídicas. A presença de açúcar na molécula confere às enzimas certa estabilidade a desnaturação pelo calor e resistência a proteólise, além de serem importantes na manutenção da estrutura tridimensional de várias proteínas (Eichler, 2001). Geralmente, a remoção destes carboidratos reduz a estabilidade e a atividade da enzima. A glicosilação é uma alteração pós-traducional de grande importância que ocorre no Complexo de Golgi, estando intimamente ligada a secreção via vesículas secretoras. A proteína ao chegar no Complexo de Golgi pode ter três destinos: membrana celular, lisossomos ou meio extracelular. O que determina qual o destino para cada proteína é a marcação presente na mesma. Usualmente, as enzimas 
extracelulares são sempre mais glicosiladas do que as enzimas relacionadas ao micélio ou intracelulares.

Como pode-se observar nas Figuras (11 e 15B) as $\beta$-glucosidases extracelular (I) e micelial purificadas de Scytalidium thermophilum migraram com apenas uma banda protéica em gel de poliacrilamida (SDS-PAGE), e embora apresentem massas moleculares tão próximas (40.7 kda e $39 \mathrm{kDa}$ ), com uma ordem de apenas $1.7 \mathrm{kda}$, algumas características obtidas nos levam a acreditar de que tratam-se de proteínas distintas. Essas enzimas são muito abundantes em fungos celulolíticos, visto que participam da degradação natural da celulose, e já foram bem caracterizadas e estudadas, mostrando que suas massas moleculares variam de 12 a 350 kDa (Bathia et al, 2002).

Tal como ocorre para maioria das reações químicas, a velocidade das reações catalisadas por enzimas aumenta proporcionalmente com a temperatura, dentro de uma faixa na qual a enzima é estável e mantém sua atividade integral. Ainda que as reações catalisadas por enzimas pareçam muitas vezes apresentar um ótimo de temperatura, o pico desse gráfico de atividade contra temperatura surge porque as enzimas sendo proteínas são desnaturadas pelo calor e se tornam inativas à medida que a temperatura é elevada além de um certo ponto. O ótimo aparente de temperatura é assim, resultante de dois processos: o aumento usual na velocidade de reação com a temperatura e o valor crescente de desnaturação térmica da enzima acima de uma temperatura crítica (Lenninger, 1993). As enzimas estudadas (glucosidase extra e micelial) apresentaram uma temperatura ótima de $70^{\circ} \mathrm{C}$ e $60^{\circ} \mathrm{C}$, respectivamente para hidrólise do PNP-glu (Figura 17). Acima destas temperaturas observou-se uma rápido declínio das atividades enzimáticas. Os valores de temperatura ótimas (70 e $60^{\circ} \mathrm{C}$ ) são superiores aquelas obtidas para Aspergillus niger (Dan et al, 2000) e Humicola grisea var thermoidea bgll (Takashima et al, 1999) que apresentaram temperatura ótima de 30 e $55^{\circ} \mathrm{C}$, respectivamente. Contudo, são 
inferiores do que aqueles obtidos para organismos hipertermófilos, como por exemplo Thermatoga maritima (Gabelsberger et al,1993) e Thermatoga neapolitana (Zwerlaw et al, 1997), com temperaturas de 90 e $95^{\circ} \mathrm{C}$, respectivamente.

Um outro parâmetro analisado para classificação enzimática é seu pH ótimo, na qual apresentam atividade ótima aparente. Sabe-se que pequenas variações no pH podem conferir comportamentos diferentes entre proteínas de uma mesma classe. Os valores encontrados de $\mathrm{pH}$ ótimos para $\beta$-glucosidase extra e micelial foram 6.0 e 5.5, respectivamente (Figura 18). O pH ótimo aparente na região ácida, parece ser uma característica geral das glucosidases fúngicas, como pode ser observado em Fusarium oxysporum (Christakopoulos et al, 1994) e C. thermophilum var coprophilum (Venturi et al, 2002).

Uma característica de grande interesse biotecnológico é a termoestabilidade, visto que o uso de enzimas em altas temperaturas diminui uma possível contaminação microbiana e um aumento da capacidade hidrolítica. Sendo estáveis, as enzimas são facilmente armazenadas, manuseadas e transportadas a temperatura ambiente. A estabilidade das enzimas foi testada frente ao substrato PNP-glu e as enzimas extracelular e micelial apresentaram tolerâncias distintas as temperaturas testadas (Figura 19). A uma temperatura de $65^{\circ} \mathrm{C}$ a $\beta$-glucosidase extracelular I é praticamente 3 vezes mais resistente em relação a $\beta$-glucosidase micelial, quando incubada num período máximo de 60 minutos. Observa-se que o perfil da $\beta$-glucosidase micelial a uma incubação de $55^{\circ} \mathrm{C}$ foi monofásico, e confirma a ausência de outras isoenzimas. As enzimas quando incubadas na presença de tampão observa-se o aumento da estabilidade, isso de ocorrer possivelmente devido a proteção dos sítios ativos das enzimas pelo tampão. A $\beta$-glucosidase micelial do H. grisea var. thermoidea (Peralta et al, 1990) apresenta uma meia vida de aproximadamente $15 \mathrm{~min}$ a $55^{\circ} \mathrm{C}$, e é inferior a observada para a $\beta$-glucosidase micelial do Scytalidium que apresentou uma meia vida de 22 min na mesma temperatura. Este é mais um importante dado que vem para 
consolidar a nossa hipótese de que o H. grisea var. thermoidea e o Scytalidium, embora apresentem algumas características morfológicas e fisiológicas parecidas são gêneros e espécies diferentes. E as análises bioquímicas vem para confirmar a nossa hipótese.

Várias teorias têm sido postuladas para explicar as propriedades termoestáveis das enzimas isoladas de fungos termófilos, quando comparadas às enzimas correspondentes de fungos mesófilos. Estas incluem fatores protecionais no interior da célular, alto grau de hidrofobicidade e glicosilação (Koffer, 1957; Prasad \& Maheswari, 1978). Dentre esses fatores o mais aceito por pesquisadores é a presença de carboidratos na estrutura protéica (glicosilação).

Já é sabido que alguns íons como por exemplo cálcio, magnésio e manganês, entre outros são capazes de aumentar a atividade de algumas enzimas ou são essenciais para o funcionamento destas atuando como cofatores. No entanto, as $\beta$ glucosidases parecem ser uma exceção, pois não necessitam obrigatoriamente de íons metálicos para elevar sua atividade. As $\beta$-glucosidases de $\mathrm{S}$. thermophilum foram inibidas drasticamente por $\mathrm{Ag}^{+2}$ e $\mathrm{Hg}^{+2}$, observando-se apenas vestígios de atividade extracelular quando os íons foram utilizados a $1 \mathrm{mM}$ (Tabela 9). A $\beta$-glucosidase extracelular não sofreu efeito da maioria dos íons testados. Em contrapartida a $\beta$ glucosidase micelial é sensível a praticamente a todos os íons quando utilizados a 5mM, destacando-se o $\mathrm{Fe}^{+2}$ que reduz a atividade micelial em aproximadamente $75 \%$, e ativa a $\beta$-glucosidase extracelular em 20\%.O EDTA, agente quelante, também não mostrou ter efeito sobre as enzimas.

A inativação enzimática pela adição de metais é bem conhecida e já foi relatada em $\beta$-glucosidases de fungos termofílicos como $\mathrm{H}$. grisea e C.thermophilum (Peralta et al, 1990; Peralta et al, 1997; Venturi et al, 2002). A inibição é ocasionada pela formação de complexos e/ou oxidação de resíduos específicos, e inibem de forma irreversível a atividade enzimática. O efeito diferenciado dos íons nas atividades 
enzimáticas do Scytalidium é mais um dado importante na nossa hipótese de que se tratam de proteínas distintas.

A $\beta$-glucosidase extracelular de Scytalidium mostrou-se altamente específica para a configuração $\beta$-anomérica das ligações glicosídicas, uma vez que os substratos com configuração $\alpha$-anomérico não foram hidrolisados (Tabela 10 ) e foi capaz de hidrolisar xilana e celobiose como substrato natural. A $\beta$-glucosidase micelial, a exemplo de outras $\beta$-glucosidases descritas na literatura, mostrou uma ampla especificidade com respeito a $\beta$-glicosídeos ( $\beta$-galactosídeo, $\beta$-glucosídeo, $\beta$-fucosídeo, $\beta$-xilosídeo), indicando uma perda da especificidade em relação a C4 e C6 dos substratos, e ainda hidrolisou o substrato PNP- $\alpha$-arabinofuranosídeo. Além disso, foi capaz de hidrolisar eficientemente lactose e celobiose como substratos naturais.

A relação $V_{\text {máx }} / K_{m}$, o parâmetro mais eficiente com respeito a eficiência catalítica, revelaram uma alta especificidade das enzimas extracelular e micelial por $\beta$-glucosídeo, e devido sua ampla especificidade em relação ao substrato hidrolisado, podemos classificá-las como $\beta$-glicosidases.

Como observado na Tabela 11, observa-se que ambas enzimas são ativadas significantemente na presença de álcool. Essa ativação ocorre através da transferência de resíduos glicosil para grupos hidroxil de álcoois e fenóis. Neste caso, os álcoois e fenóis atuariam como moléculas aceptoras da metade $\beta$-glicosil formada durante a catálise da $\beta$-glucosidase (Wallenfels \& Malhotra, 1961). Caso a quebra do complexo seja velocidade limitante, um aumento da velocidade da reação pode ser esperado se um aceptor superior à água for adicionado ao sistema. Em muitas $\beta$-glucosidases quando o álcool é adicionado ao sistema, reações de transglicosilção são geradas, resultando a síntese de novos oligossacarídeos. Observou-se que ambas enzimas tiveram suas atividades aumentadas na presença de glicerol com aumento de 2 e 1.8 vezes, para as $\beta$-glucosidases extra I e micelial, respectivamente. Em contrapartida a atividade micelial foi reduzida em $20 \%$ na presença de metanol, enquanto que a 
extracelular foi ativada em $30 \%$. Manitol ativa a $\beta$-glucosidase micelial em $30 \%$ e não tem efeito significativo para extracelular. Inversamente do que ocorre com metanol, o etanol e o n-butanol ativam a $\beta$-glucosidase extracelular e não tem efeito na atividade micelial. Em Fusarium oxysporum (Christakopoulos et al, 1994) também foi possível observar o aumento das atividades enzimáticas quando diferentes álcoois foram adicionados ao sistema.

As enzimas foram ativadas por alguns açúcares (Tabela 12), num fenômeno semelhante aos obtidos na presença de álcoois. A $\beta$-glucosidase extracelular foi inibida na presença de glicose, e ativada por celobiose, quando PNP-glu era usado como substrato. A representação de Dixon obtida para a $\beta$-glucosidase extracelular I, sugere que a glicose seja um inibidor competitivo, com um Ki de 71mM (Tabela 13). A $\beta$ glucosidase extracelular foi ativada por baixas concentrações de celobiose, sugerindo a existência de mais de um sítio catalítico. Em contrapartida, a $\beta$-glucosidase micelial foiativada na presença de glicose e xilose, e drasticamente inibida por celobiose, com um Ki de 1.32mM (Tabela 14). A inibição por celobiose, neste caso, pode indicar competição entre o substrato sintético e o natural por um único sítio catalítico.

Com base nos valores de Constante de Inibição (Ki) obtidos para ambas enzimas, observa-se que a celobiose é um inibidor muito mais potente $(\mathrm{Ki}=1.32 \mathrm{mM}-\beta-$ glucosidase micelial) do que a glicose $(\mathrm{Ki}=71 \mathrm{mM}-\beta$-glucosidase extracelular $\mathrm{I})$. Dos trabalhos publicados, poucas são as $\beta$-glucosidases produzidas por fungos filamentosos, tolerantes a glicose, só tendo isso descrito em bactérias (Perez-Pons et al, 1995; Zanoelo et al, 2004). Este é então, o primeiro trabalho, que descreve uma $\beta$ glucosidase micelial de fungo termofilico ativada simultaneamente por xilose e glicose.

Os valores de focalização isoelétrica para as $\beta$-glucosidases extra I e micelial são respectivamente 4.0 e 6.5 (Figura 23) e são compatíveis com a maioria de $\beta$ glucosidases descritas na literatura (Bhatia et al, 2002). Esse é mais um dado importante que vem para reforçar a nossa hipótese de que o nosso trabalho envolve $\beta$ - 
glucosidases distintas produzidas por um mesmo organismo, e com propriedades diferentes das $\beta$-glucosidases do Humicola grisea var. thermoidea, que anteriormente acreditava-se ser o Scytalidium thermophilum ( Straastma \& Samson, 1993).

No que se refere a determinação dos parâmetros cinéticos, observou-se que ambas enzimas possuem maior afinidade para o substrato sintético PNP-glu com $\mathrm{K}_{\mathrm{m}}$ e $\bigvee_{\text {máxde }} 0,345 \mathrm{mM}$ e $2,0 \mu$ moles $/ \mathrm{mg} \operatorname{prot}^{-1}$ e $0,29 \mathrm{mM}$ e 5,37 $\mu \mathrm{moles} / \mathrm{mg}$ prot $^{-1}$ para as atividades $\beta$-glucosidase extra e micelial, respectivamente. Observa-se também que a $\beta$-glucosidase micelial hidrolisou eficientemente os substrato sintético PNP-fuc com $K_{m}$ e $V_{\text {máx de }} 0,5 \mathrm{mM}$ e $7,25 \mu$ moles $/ \mathrm{mg} \operatorname{prot}^{-1}$. Quando a $\beta$-glucosidase micelial foi ensaiada com PNP-glu na presença de glicose ou xilose, observou-se um $K_{m}$ e $V_{\text {máx }}$ de 1,26mM e $40,04 \mu \mathrm{moles} / \mathrm{mg} \operatorname{prot}^{-1}$ e $1,33 \mathrm{mM}$ e $30,49 \mu \mathrm{moles} / \mathrm{mg} \operatorname{prot}^{-1}$. Com base nesses resultados, conclui-se que a enzima perde certa especificidade pelo substrato PNP-glu embora tenha um aumento na sua velocidade de hidrólise. Esses resultados são dados com base na eficiência catalítica $\left(\mathrm{V}_{\text {máx }} / \mathrm{K}_{\mathrm{m}}\right)$ (Tabela 14$)$. O valor de $\mathrm{K}_{0,5}$ obtido para a $\beta$ glucosidase micelial foi de 36,69 e 43,29mM, para glicose e xilose, respectivamente. Dentre as glucosidases estudadas observa-se uma maior preferência por substratos sintéticos com $K_{m s}$ variando de 0,05 a $2 \mathrm{mM}$ (Bathia, 2002). As $\beta$-glucosidases de $H$. grisea e C. thermophilum, parentes próximos do Scytalidium apresentaram $K_{m}$ e $V_{\max }$ de 0,12 e $3,24 \mathrm{mM}, 0,76$ e $3,13 \mathrm{mM}$ e para os substratos PNP-glu e celobiose, respectivamente (Peralta et al, 1997; Venturi et al, 2002).

Em estudos realizados utilizando-se misturas dos substratos PNP-Glu e PNP-fuc (Figura 25) para $\beta$-D-glucosidase micelial observou-se que os valores não foram interacionais. Esse é um dado importante para confirmar a eficiência no processo de purificação e a total ausência de contaminantes na amostra.

No estudo das enzimas como transglucosidases, observou-se (Figuras 26, 27 e 28) que as enzimas são capazes de sintetizar novos glicosídeos em altas concentrações de celobiose, e hidrolise em baixas concentrações. Contudo, na presença de xilose ou 
glicose ( $\beta$-glucosidase micelial) a síntese desses glicosídeos é acelerada, mesmo em baixas concentrações de celobiose. Como demonstrado por Wallenfels \& Malhotra, (1961) a síntese desses glicosídeos é resultante de reações de transglicosilações na presença de açúcar ou álcool como aceptor. As mesmas reações foram analisadas em HPLC e detectou-se novos glicosídeos sintetizados (dados não mostrados), contudo não se conseguiu quantificar os produtos das reações de transglicosilação.

Com base do exposto até aqui, foi possível observar diferenças significativas entre as $\beta$-glucosidases estudadas que vieram confirmar a nossa hipótese de que as $\beta$ glucosidases produzidas pelo Scytalidium são proteínas distintas, e com propriedades diferentes das produzidas pelo Humicola grisea var thermoidea (Peralta et al, 1990; Peralta et al, 1997).

Os resultados também demonstram o importante papel do Scytalidium como produtor efetivo de $\beta$-glucosidases com potencial na sacarificação enzimática da celulose. A inibição das $\beta$-glucosidases por glicose é uma questão levantada por muitos pesquisadores, uma vez que compromete a sacarificação enzimática da celulose pelo acúmulo de celobiose. Em $\beta$-glucosidases de diversas fontes, a glicose atua como um inibidor competitivo da enzima e poucos são os trabalhos que evidenciam um aumento significante da atividade $\beta$-glucosidásica na presença de glicose ou xilose (Riou et al, 1998). Contudo, observou-se que a $\beta$-glucosidase micelial do Scytalidium teve um aumento pronunciado da sua atividade na presença glicose ou xilose. Esse efeito até o presente momento não é totalmente compreendido, mas vale ressaltar que a enzima produzida Scytalidium possui grande interesse biotecnológico, principalmente relacionado a conversão natural da celulose em monômeros de glicose, e produção de combustível (etanol) por fermentação.

Além do efeito positivo da glicose na $\beta$-glucosidase micelial de Scytalidium, a ampla especificidade e a complexidade cinética da enzima, tornam-se interessantes estudos que direcionem para elucidação dos seus mecanismos de ação. É importante 
ressaltar também a capacidade de síntese de novos glicosídeos através de reações de transglicosilação, além da tolerância a altas temperaturas possivelmente relacionada a presença de carboidratos na molécula.

\section{6- REFERÊNCIAS BIBLIOGRÁFICAS}

ANDRADE, C.M.M.C.; PEREIRA JR., N.; ANTRANIKIAN G. (1999). Extremely thermophilic microorganisms and their polymer-hidrolytic enzymes. Rev. Microbiol. 30(4): 1-18.

AQUINO, A. C. M.M.; JORGE, J. A.; TERENZI, H, F.; POLIZELI, M. L. T. M. (2001). Thermostable glucose-tolerant glucoamylase produced by the thermophilic fungus Scytalidium thermophilum. Folia Microbiol. 45(6): 11-16.

AQUINO, A. C. M.M.; JORGE, J. A.; TERENZI, H, F.; POLIZELI, M. L. T. M. (2003). Studies on a thermostable $\alpha$-amylase from the thermophilic fungus Scytalidium thermophilum. AppL. Microbiol Biotechnol. 61(4):323-328.

BÉGUIN, P. \& AUBERT, J. P. (1994). The biological degradation of cellulose. FEMS Microbiol. Rev. 13: 25-58.

BERGEM, L. E. R.\& PETTERSON, G. (1975). Location and formation of cellulases in Trichoderma viride. J. Appl. Bact. 42: 65-75.

BERGMEYER, H. U. \& BERNT, E. (1974). In Methodos of Enzymatic Analysis. Edited by HU Bergemeyer. New Bermeyer. New York: Verlag-chimie/ Academic Press. 3: 12051215. 
BHATIA, Y; MISHRA, S; BISARIA, V. S. (2002). Microbial $\beta$-Glucosidases: Cloning, Properties and Applications. Crit. Rev. in Biotechnol. 22(4): 375-407.

BISSET, F. \& STENBERG, D. (1988). Immobilization of Aspergillus $\beta$-glucosidase on chitosan. Appl. and Env. Microbiol. 35 (4): 750-755.

BROCK, T. D. (1978). Thermophilic microorganism and life at high temperatures. Springer-verlag, NY.

BUSTO. M. D. \& PEREZ-MATEOS. (2000). Characterization of a $\beta$-glucosidase extracted soil fractions. Eur. J. Soil. Sci. 51: 193-200.

CHIRICO, W. J. \& BROWN JR., R. D. (1987). Purification and characterization of a $\beta$ glucosidase from Trichoderma reesei. Eur. J. Biochem. 165: 333-341.

CHRISTAKAPOULOS, P.; GOODDENOUGH, P. W.; KEKOS, D., MACRIS, B. J.; CLAEYSSENS, M.; BHAT, M. K. (1994). Purification and characterization of an extracellular $\beta$-glucosidase with transglicosylation and exo-glucosidase activities from Fusarium oxysporum. Eur. J. Biochem. 224: 379-385.

COONEY, D. G \& EMERSON, R. (1964). Thermophilc fungi: an account of their biology, activities and classification. San Francisco- W.H.Freman, 1964.

dan, S.; Marton, T.; Bravdo, B. A.He. S.; Withers, S. G.; Shoserov, O. (2000). Cloning, expresion, characterization and nucleophile identification of family 3 Aspergillus niger $\beta$-glucosidase. J. Biol. Chem. 275: 4973-4980. 
DAVIS, B.J. (1964). Disc Electrophoresis-II- Methods and application to human serum proteins. Ann. N. Y. Acad. Sci. 121: 404-427.

DE BRUYNE, C. K.; AERTS, G. M,; GUSSEM, R. L. (1979). Hydrolisis of aryl- $\beta$-Dglucopyranosides and $\beta$-D-xylopiranosides by an induced $\beta$-D-glucosidase from Stachybotrys atra. Eur. J. Biochem. 102: 257-267.

DEMIRJIAN, D. C.; MÓRIS-VARAS, F.; CASSIDY, C. S. (2001). Enzymes from extremophiles. Curr. Opinion Chem. Biology. 5: 144-151.

DESPHANDE, V.; ERIKSSON, K.E. AND PETTERSON, B. (1988). Production, purification and partial characterization of $1,4-\beta$-glucosidase enzyme from Sporotrichum pulverulentum. Eur. J. Biochem. 90: 191-198.

DIXON, M. \& WEBB, E. C. (1964).Enzymes. 75-80 and 315-330. $2^{\mathrm{a}}$ Ed. Academic Pres. Inc., Publishers, New York.

DUBBOIS, M.; GILLES, K. A.; HAMILTON, J. K.; REBERS, P. A.; SMITH, F. (1956).Colometric method for determination of sugars and related subst. Anal. Chem. 28: 350-356.

EICHLER, J. ( 2001). Biotechnological uses of archael extremoenzymes. Biotecnol. Adv. 19: 261-278.

ERIKSSON, K. E. (1981). Cellulases of fungi.In: Trends in the Biology of fermentations for fuels and chemicals. Basic Life Sciences. 18: 19-31. 
FERREIRA, H.; MARANA, S. R.; TERRA, W. R.; FERREIRA, C. (2001). Purification, molecular cloning, and prperties of a $\beta$-glycosidase isolated from midgut lumen of Tenebrio molitor (Coleoptera) larvae. Ins. Biochem. Mol. Biol. 31: 1065-1076.

GABELSBERG, J.; LIEBL, W.; SCHLEIFER, K. H. (1993). Purification and properties of a recombinant $\beta$-glucosidase of the hyperthermophilic bacterium Thermatoga maritima. Appl. Microbiol. Biotechnol. 40: 44-52.

GUIMARÃES, L.H.; TERENZI, H.F.; POLIZELI, M.L.T.M. (2001) Thermostable conidial and mycelial alkaline phosphatases from the thermophilic fungus Scytalidium thermophilum. J. Ind. Microbiol. Biotechnol. 27: 265-270.

GOPALAN, V.; DANIELS, L. B.; GLEW, R. H.; CLAEYSSENSI, M. (1989). Kinetic analysis of the interaction of alkylglycosides with two human $\beta$-glicosidases. Biochem. J. 262: $541-548$.

GROVER, A. K \& CUSHLEY, R. J. (1977). Studies on almond emulsin $\beta$-D-glucosidase-IIkinetic evidence for independent glucosidase and galactosidase sites. Biochim. Biophys. Acta. 482: 109-124.

HAMES, B. D. \& RICKWOOD, D. (1985). Gel electrophoresis of proteins. 5. Ed. Washington: IRL Press. cap. 1, p.1-86.

HARRIS, S. D.; MORREL, J. L.; HAMER, L. E. (1994). Identification and characterization of Aspergillus nidulans mutants defective in cytokinesis. Genet. 136: 517-532.

HEYWORTH, R.\& WALKER, P. G. (1961). I dentity of a $\beta$-glucosidase and $\beta$-galactosidase in sweet-almond emulsin. Biochem. J. 80: 44p. 
HEYWORTH, R.\& WALKER, P. G. (1962). Almond-emulsin $\beta$-D-glucosidase and $\beta$-Dgalactosidase. Biochem. J. 83: 331-335.

IGARASHI, K.; TANI, T.; KAWAL, R.; SAMEJIMA, M. (2003). Family $3 \beta$-glucosidase from cellulose-degrading culture of the white-rot fungus Phanerochaete chrysosporium is a glucan 1,3- $\beta$-glucosidase. J. Biosc. Bioeng. 95 (6): 572-576.

IWASHITA, K.; TODOROKI, K.; KIMURA, H.; S, H.; ITO, K. (1998). Purification and characterization of extracellular and cell wall bound $\beta$-glucosidases from Aspergillus kawachii. Biosci. Biotechnol. Biochem. 62(10): 1938-1946.

IWASHITA, K. (2002). Recent Studies of protein secretion by filamentous fungi. J. Biosc. Bioeng. 94 (6): 530-535.

JAMES J.A. \& LEE, B.H. (1997). Glucoamylases: microbial sources, industrial applications and molecular biology - a review. J. Biochem. 21: 1-52.

J ORGENSEN, H.; MORKEBERG, A.; KROGH, K. B. R.; OLSSON, L. (2004).. Grown and enzyme production by three Penicillium species on monosaccharides. J. Biotecnol. 109: 295-299.

KADOWAKI, M. K.; POLIZELI, M. L. T. M.; TERENZI, H. F. ; JORGE, J. A. (1996). Characterization of trehalase activities from the thermophilic fungus Scytalidium thermophilum. Biochim. Biophys. Acta. 1291: 199-205. 
KIMURA, I.; YOSHIOKA, N.; TAJIMA, S. (1999). Purification and characterization of a $\beta$ glucosidase with $\beta$-xylosidase activity from Aspergillus sojae. J. Bioscience Bioeng. Vol. 4: (4): 538-541.

KOFFER, H. (1957). Protoplasmatic differences between mesophilic and thermophilles. Bacteriol. Rev. 21: 227:240.

KUBICEK, C. P. (1983). $\beta$-glucosidase excretion in Trichoderma strains with different cell wall bound $\beta$-1,3-glucanase activities. Can. J. Microbiol. 29: 163-169.

LA MARCO, K. L. \& GLEW, R. H.(1986). Hydrolysis of a naturally occurring $\beta$-glucoside by a broad-specificity $\beta$-glucosydase from liver. Biochem. J. 237: 469-476.

LAEMMLI, U. K. (1970). Cleavage of structural proteins during the assembly of the head of bacteriophage T7. Nature. 222: 680-685.

LASA, I. \& BERENGUER, J. (1993). Thermophilic enzymes and their biotechnological potential. Microbiol. 9: 77-89.

LEONE, F. A.; DEGREVE, L. ; BARANAUSKAS, J. A. (1992). Sigraf- A Versatile computer program for fitting enzyme kinectic data. Biochem. educ. 20: 94-96.

LEPAROUX, S., PADRINES, M., PLACIER, G., COLAS, B. (1997). Characterization of a strictly specific acid $\beta$-galactosidase from Achatina achatina. Biochim. Biophys. Acta. 1336: 522-532. 
LENNINGER, A. C.; NILSON, D. L.; COX, M. M. (1993). Principle of Biochemistry. $2^{a}$ Edição. Worth Publishers. New York. N. Y.

LLANILlO, M.; PEREZ, N.; CABEZAS, J. A. (1987). $\beta$-galactosidase and $\beta$-glucosidase activities of the same enzyme from rabbit liver. Int. J. Biochem. 8: 557-564.

LINEWEAVER, H. \& BURK, D. (1934). The determination of the enzyme dissociation. J . Am. Chem. Soc. 56: 658-666.

LOEWENBERG, J. R. (1984). Sophorose induction of na intracellular $\beta$-glucosidase in Trichoderma. Arch. Microbiol. 137: 53-57.

LOWRY, O. H.; ROSEBROUGH, N. J.; FARR, A. L.; RANDALL, R. J. (1951). Protein measurement with folin phenol reagent. J. Biol. Chem. 193: 265-275.

LUSIS, A. J. \& BEKER, R.R. (1973). The $\beta$-glucosidase system of the thermophilic fungus Chaetomium thermophile var. coprophile. Biochim. Biophys. Acta. 329: 5-16.

MAMMA, D.; HATZINIKOLAOU, D. G.; CHRISTAKOPOULOS, P. (2004). Biochemical and catalytic properties of two intracellular $\beta$-glucosidases from the fungus Penicillium decumbens active on flavonoid glucosides. J. Mol. Cat. B: Enzy. 27: 1836-190.

MADIGAN, M.T.\& MARRS, B.L. (1997). Extremophiles. Sci. Am. 66-71.

MAHESHWARI, R.; BHARADWAJ, G.; BHAT, M. K. (2000). Thermophilic Fungi: Their physiology and Enzymes. Microbiol. and Mol. Bio. Rev. 461-488. 
MAWADZA. C.; HATTI-KAUL, R.; ZVAUYA, R.; MATTIASSON. (2000). Purification and characterization of cellulases produced by two Bacillus strains. J. Biotech. 83: 177187.

Mcl Lvaine, T. C. (1921). A buffer solution for colorimetric comparison. J. Biol. Chem. 49: $183-183$.

MEYER, H. P. \& CANEVASCINI, G. (1981). Separation and some properties of two intracellular $\beta$-glucosidase of Sporotrichum (Chrysosporium) thermophile. Appl.and Environ. Microb. 41 (4): 924-931.

MILLER, G. H. (1959). Use of Dinitrosalicylic acid reagent for determination of reducing sugar. Anal. Chem. 31: 426-429.

MORGAN, M. R. J. (1975). Characterization of the lactase of the african migratory locust, Locusta migratoria migratorioides. Ins. Biochem. 5: 479-487.

O' DONELL, K. \& PETERSON, S. W. (1992). Isolation, preservation and taxonomy. In: Finkeelstein, D. B.; Ball, C. (Eds). Biotechnology of filamentous fungi: technology and products. Stoneham-Heinemann, 1992. Cap. 2, p.7-40.

O' FARREL, P. Z.; GOODMAN, H. M.; O' FARREL. (1977). High resolution twodimensional electrophoresis of basic as well as acidic proteins. Cell. 12: 1133-1142.

PANDEY, A.; SOCCOL, C. R.; NIGAM. P.; SOCOOL, V. T. (2000). Biotechnological potential of agro-industrial residues: I sugarcane bagasse. Bio. Technol. 74: 69-80. 
PAEZ DE LA CADENA, M.; RODRIGUEZ-BERROCAL, J,; CABEZAS, J. A.; PEREZGONZALES, M. N. (1987). Heterogeneity of acid $\beta$-galactosidase from rabbit kidney. Int. J. Biochem. 19(8): 685-691.

PERALTA, R. M.; TERENZI, H. F.; JORGE, J. A. (1990). $\beta$-D-Glycosidase activities of Humicola grisea: biochemical and kinetic characterization of a multifunctional enzyme. Biochem. Biophys. Acta. 1033: 243-249.

PERAlTA, R. M.; KADOWAKI, M. K.; TERENZI, H. F.; JORGE, J. A. (1997). A highly thermostable $\beta$-glucosidase activity from the thermophilic fungus Humicola grisea var. thermoidea: purification and biochemical characterization. FEMS Microbiol. Lett. 146: 291-295.

PEREZ-PONS, J. A.; REBORDOSA, X.; QUEROL, E. (1995). Properties of a novel glucose-enhanced $\beta$-glucosidase purified from Streptomyces sp (ATCC 11238). Biochim. Biophys. Acta 1251: 145-153.

PRASAD, A. R. S. \& MAHESWARI, R. (1978). Purification and properties of a trhalase from the thermophilic fungus Humicola lanuginosa. Biochem. Biophys. Acta. 525: $162-170$.

POCSI, I. \& KISS, L. (1988). Kinetic studies on the broad-specificty $\beta$-D-galactosidase from pig kidney. Biochem. J. 256: 139-146.

REESE, E. T.; SIV, R. G. H.; LEVINSON, H. S. (1950). The biological degradation of soluble cellulase derivates ship to the mechanism of cellulase hydrolysis. J. Bacteriol. 59: 485-497. 
REISFELD, R. A.; LEWIS, U. J.; WILLIANS, D. E. (1962). Disk electroforesis of basic proteins and peptides on polyacrylamide gels. Nature (Londom). 195: 281-283.

RIOU, C.; SALMOM, J. M.; VALLIER, M. J.; GUANATA, Z.; BARRE, P. (1998). Purification, characterization, and substrate specificity of a novel highly glucosetolerant $\beta$-glucosidase from Aspergillus orzae. Appl. Microbiol. Environ. 64: 36073614.

RODINOVA, N.A.; RUMYANTSEVA, N. G.; TINNOVA, N. A.; MARTINOWICK, L. T. AND BAKTHADZE, L. N. (1997). $\beta$-glucosidase from the fungus Geotrichum candidum. Biokhimiya. 42: 43-50.

RUSSEL, P. J. \& PERRY, C. B. (1980). Cellobiose induced $\beta$-galactosidase and $\beta$ glucosidase activities of Neurospora crassa. Neurospora Newlsletter. 27: 22-23.

SAHA, B. C. \& BOTHAST, R. J. (1996).Production, purification and characterization of a highly glucose-tolerant novel $\beta$-glucosidase from Candida peltata. Appl. Environ. Microb. 62: 3165-3170.

SAHA, B. (2003). Production, purification and properties of endoglucanase from a newly isolated strain of Mucor circinelloides. Process. Bioch. $\mathrm{Xxx}: \mathrm{xxx}-\mathrm{xxx}$.

SAID, S.\& PIETRO, R. (2002). Enzimas de interesse industrial e biotecnológico. Primeira edição. Editora Eventos. 
SALOHEIMO, M.; KUJA-PANULA, J.; YLOSMAKI, E.; WARD, M.; PENTTILA, M. (2002). Enzymatic Properties and intracellular localization of the novel Trichoderma reesei $\beta$ glucosidase BGLII (Cel 1A). App. And Env. Microbiol. 4546-4553.

SHEWALE, J. G. \& SADANA, J. (1981). Cellulase and $\beta$-glucosidase production by a basidiomycete species. Can. J. Microbiol. 24: 1204-1216.

STERNBERG, D.; VIJAYAKUMAR, P.; REESE, E. T. (1977). $\beta$-glucosidase: Microbiol Production and effect on enzymatic hydrolysis of cellulose. Can. J. Microbiol. 23: 139-147.

STERNBERG, D. \& MANDELS (1982). $\beta$-glucosidase induction and repression in the cellulolytic fungus, Trichoderma reesei. Exper. Mycol. 6: 115-124.

STRAASTMA, G. \& SAMSOM, R. (1993). Taxonomy of Scytalidium thermophilum, an important thermophilic fungus in mushroom compost. Mycol. Res. 97(3): 321-328.

SUE, M.; ISHIHARA, A. \& IWAMURA, H. (2000). Purification and characterization of a $\beta$ glucosidase from rye ( Secale secale) seedlings. Plant Sc. 155: 67-74.

TAKASHIMA ET AL, 1999

THORN,

TSI KLINSKAYA, P. (1899). Sur les mucédinées thermophiles. Ann. Inst. Pasteur. 13: $500-515$.

UZILE, M.; MATSUO, M.; YASUI, T. (1985). Possible identity of $\beta$-xylosidase and $\beta$ glucosidase of Chaetomium trilaterale. Agric. Biol. Chem. 49(4): 1167-1173. 
VENTURI, L. L.; POLIZELI, M.L.; TERENZI, H.F.; FURRIEL, R.P.M.; JORGE, J.A. (2002). Extracellular $\beta$-glucosidase from Chaetomium thermophilum var. coprophilum.: production, purification and some biochemical. J. Basic Microbiol. 42(1): 55-66.

WALLENFELS, K. \& MALHOTRA, O. P. (1961). Galactosidases. Adv. Carbohydrate Chem. 16: 239-298.

WALLENFELS, K. AND WEI L, R. (1972) . $\beta$-galactosidases. In: The Enzymes. Boyer, P. D. Ed. $3^{\text {rd }}$ edn., vol. 7., p.617-663, Academic Press, New York.

WOODWARD, J. \& WISEMAN, A. (1982). Fungal and other $\beta$-glucosidases: their properties and applications. Enzyme. Microbiol. Technol. 4: 73-79.

YAMADA, M.; IKEDA, K.; EGAMI, F. (1973). Further studies on glycosidases from the liver of Turbo cornutus with special reference to $\beta$-galactosidase , $\alpha$-L-arabinosidase and $\beta$-D-fucosidase activities. J. Biochem. 175: 627-632.

ZANOELO, F. F. (2001). Caracterização bioquímica das enzimas do complexo xilanolítico de Scytalidium thermophilum. Dissertação de Mestrado apresentado Faculdade de Filosofia, Ciências e Letras de Ribeirão Preto da Universidade de São Paulo.

ZANOELO, F. F.; POLIZELI, M. L. T. M.; TERENZI, H. F.; JORGE, J. A. (2004). Purification and biochemical properties of a thermostable xylose-tolerant $\beta$-Dxylosidase Scytalidium thermophilum. J. ind. Microbiol. Biotechnol. 31: 170-176. 
